A SOCIAL NETWORK PERSPECTIVE ON ICT AND URBAN TRAVEL 
Examining committee:

Prof.dr. A. van der Veen Prof.dr.ir. E.C. van Berkum Prof.dr. I.S.A. Baud

Prof.dr. G. Tiwari
University of Twente University of Twente University of Amsterdam Indian Institute of Technology Delhi

ITC dissertation number 262

ITC, P.O. Box 217, 7500 AE Enschede, The Netherlands

ISBN 978-90-365-3808-4

DOI $10.3990 / 1.9789036538084$

Cover designed by Job Duim

Printed by ITC Printing Department

Copyright (c) 2014 by Priyasmita Roy

\section{UNIVERSITY OF TWENTE.}

प1C Faculty of gEO-INFORMATION SCIENCE AND EARTH OBSERVATION 


\title{
A SOCIAL NETWORK PERSPECTIVE ON ICT AND URBAN TRAVEL
}

\author{
DISSERTATION
}

to obtain

the degree of doctor at the University of Twente, on the authority of the rector magnificus, prof.dr. H. Brinksma,

on account of the decision of the graduation committee,

to be publicly defended

on Tuesday 2 December 2014 at 14.45 hrs

by

Priyasmita Roy

born on $7^{\text {th }}$ of April 1984

in Kolkata, India 
This thesis is approved by

Prof.dr.ir. M.F.A.M. van Maarseveen, promoter

Dr.ir. M.H.P. Zuidgeest, co-promoter

Dr. J.A. Martinez Martin, co-promoter 


\section{Acknowledgements}

Writing this thesis has truly been a learning experience in my life. It has been a lot of fun and very stressful all in the same time. I have had the privilege to work with dedicated and skilled researchers in a very friendly atmosphere. Thanks to them I have learned a lot about travel and ICT, and more importantly, doing good research. I believe I emerge from this experience not only a better researcher but a much better person.

First and foremost I thank Prof. Dr. Martin van Maarseveen my promoter, for his encouragement, advice and training. It has been an honour to work with him. I really appreciate his intellectual help throughout the course of this research.

I am thankful to my supervisors. I express my sincere and heartfelt appreciations for Dr. Mark Zuidgeest. Without his advice and confidence in me, I would not have been able to acquire the scholarship for this PhD. Thank you for your remarkable support, continuous encouragement and untiring patience. I am extremely grateful to Dr. Javier Martinez for his guidance and constructive inputs throughout this thesis. Thank you for letting me discuss issues big or small, technical or non-technical, and always inspiring me to look for new ways to solve problems. I am enormously thankful to Dr. Gianluca Miscione for keeping me grounded in facts. Thank you for patiently reading the numerous versions of every manuscript and providing critical feedbacks. The endless discussions with my supervisors kept me motivated and striving. My supervisors were my pillars of support and without their assistance this thesis would not have been possible. I cannot thank them enough.

I am thankful to so many people at ITC who helped me at various points of time. Dr. Jaap Zevenbergen and Dr. Richard Sliuzas gave me helpful comments and took the time to discuss my work. Loes Colenbrander helped me with so many logistic matters. John Horn and Paul van Dijk for providing support from the first day I joined ITC. Marie Chantal Bekkers, Thereza van den Boogaard and Bettine Geerdink - Schukking for being kind and always ready to help with all the matters related to the municipality of Enschede. Carla Gerritsen, Desiree Snoek, and Marga Koelen for introducing me to the wondrous world of ITC library and arranging papers and books at very short notice. Very special thanks to the IT department, and particularly Gerrit Schuurman and Aiko Mulder for handling the countless computer related issues which made my life easy. I owe a big thanks to Petra for helping with so many things, not only department related but also personal. Thank you for working tirelessly to get everybody together for my trans-continental meetings with admirable promptness and a genuine smile. 
I am ever so thankful to the many people I met during the surveys at Ahmedabad. They let me ask numerous questions and patiently explained facts and events which no text book could have done. A special thanks to all the people at CEPT University for supporting and helping me during the long data collection months. I am genuinely indebted to you all.

Few PhD students start on the same day in the same research institute. I was lucky to exchange thoughts about my work with Divyani and Maitreyi from the first day of my research. They have helped me a lot, especially in the first years, when everything was so confusing and uncertain; I knew I could count on you. Throughout these years it was a blessing to have both of you as colleague and friends. Sincere thanks to all my other friends: Christine, Sejal, Sukhad, Nandika, Tanmoy, Gaurav, Yamini, Anindita, Paresh, Remi, Ajay, Debanjan, Rishi, Sandeep, Parveen, Pankaj, Talat, Saibal, Pankaj, Tapas, Alfonse, Ha, Razieh, Fang fang, Puhao, Michal, Salma, Sharmin and Carolina. Thank you for providing the much needed moral support and for being a part of my graduate life. Special thanks go to Quang, Stefan, Rik, Guido, Udith, Henk, Peter and Joey, for not only being my office mates but also for your patience, advice and for being there. The time I spent with you all is well cherished.

Finally, my strongest support came from my family. My parents have given me unconditional support and love over the years. Without their attention and self-sacrifice, perusing my dreams would not have been possible. They deserve my utmost respect and sincere appreciation. Last, but not least I thank my husband who was always by my side all these years. His most critical comments and generous compliments have shaped my work for better. Thank you for bearing with me; it has been an honour to share this journey with you.

To them I dedicate this thesis. 


\section{Table of Contents}

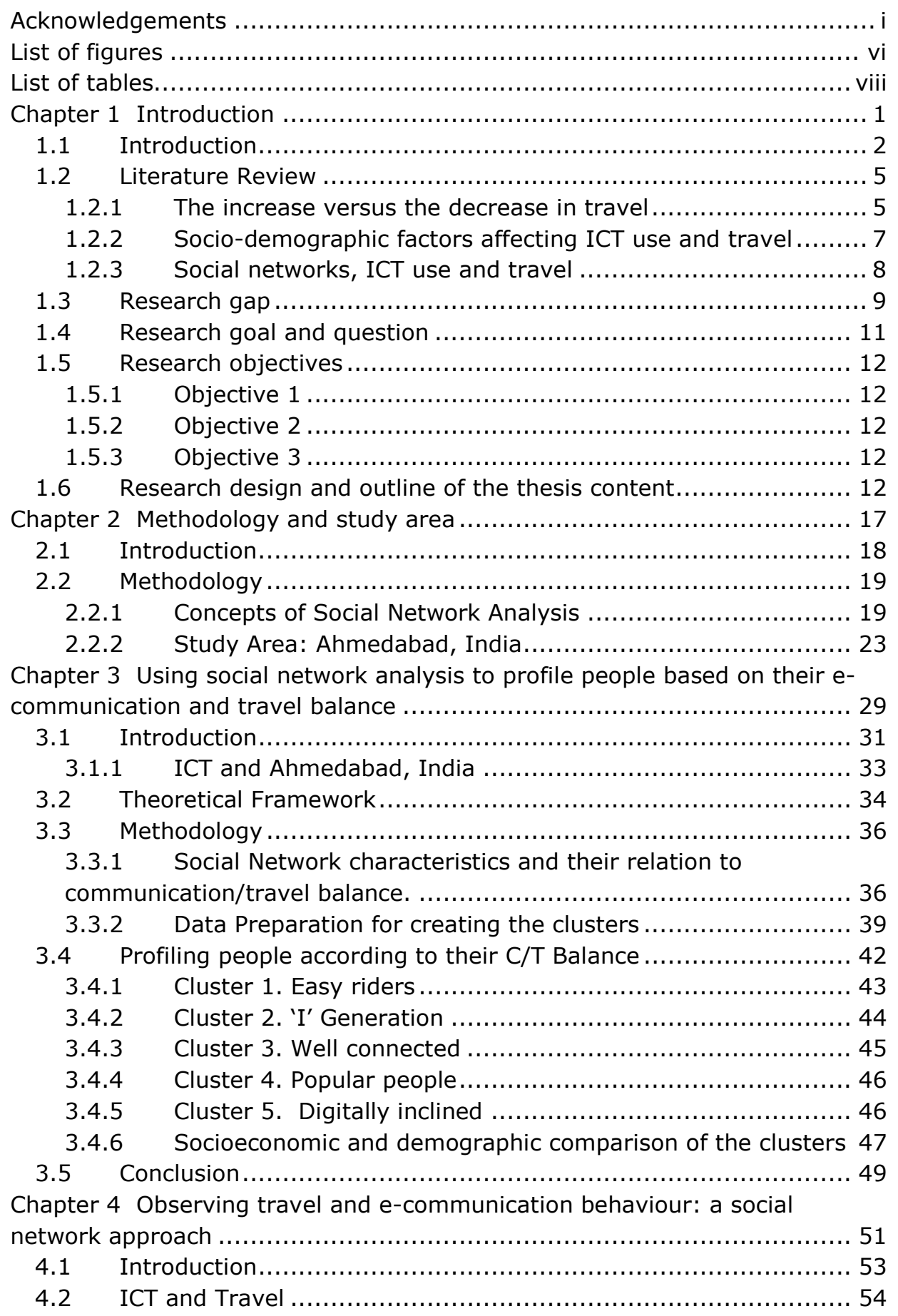




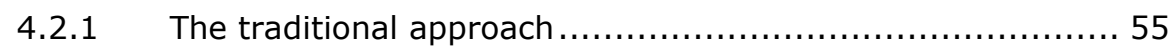

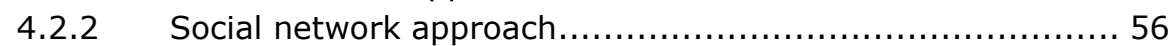

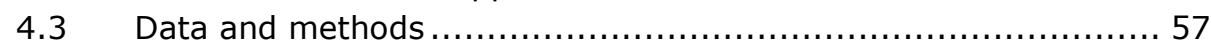

4.3.1 Social Network Profiles ....................................... 57

4.3.2 E-communication and travel............................. 58

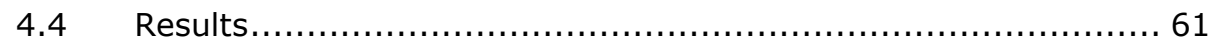

4.4.1 Dissimilar travel behaviour of individuals ....................6 62

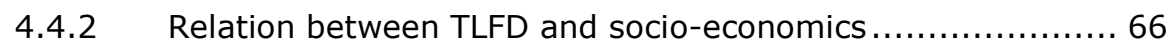

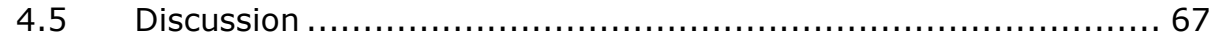

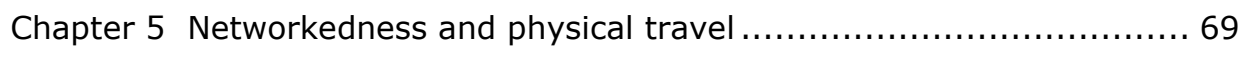

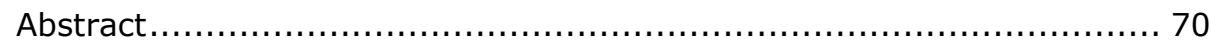

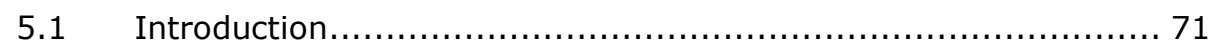

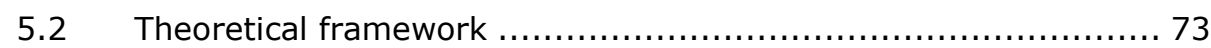

5.2.1 Geographical distance, mode of communication and

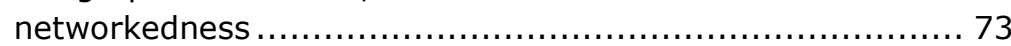

5.2.2 Travel/e-communication balance and networkedness ........ 73

5.2 .3 Socio-demographics and networkedness ........................ 74

5.2.4 Case study: Ahmedabad, India............................. 75

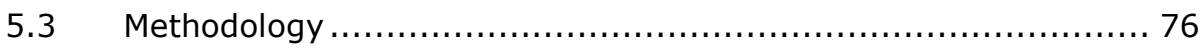

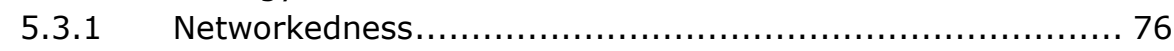

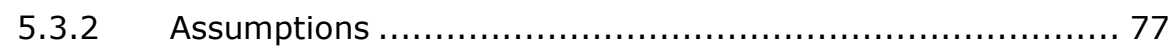

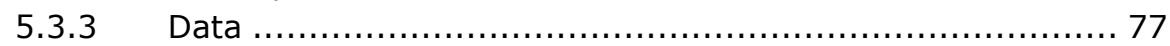

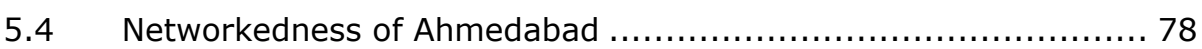

5.4.1 Networkedness and travel/e-communication balance .......... 79

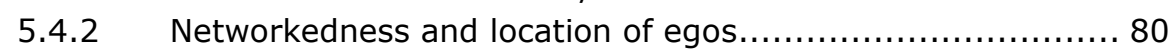

5.4.3 Networkedness and tie-strength of profiles. ................... 84

5.4.4 Networkedness and socio-demographic characteristics ....... 85

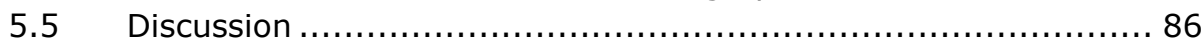

5.5.1 Networkedness is not affected by location at city level ....... 86

5.5.2 Networkedness is ego's location and tie-strength dependent 87

5.5.3 Networkedness is $\mathrm{C} / \mathrm{T}$ profile dependent .................... 87

5.5.4 Networkedness is homogeneous in terms of sociodemographic variables $\ldots \ldots \ldots \ldots \ldots \ldots \ldots \ldots \ldots \ldots \ldots \ldots \ldots \ldots \ldots . \ldots \ldots$

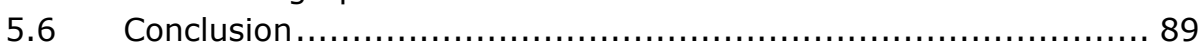

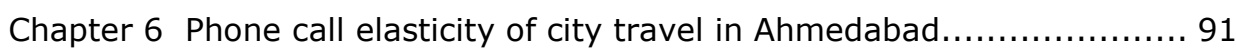

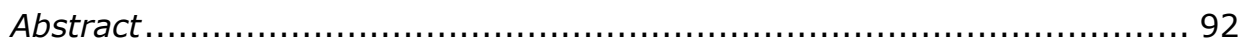

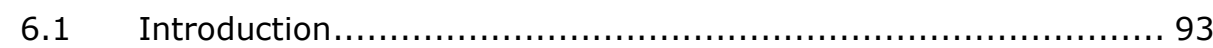

6.1.1 ICT, travel and Ahmedabad ................................ 95

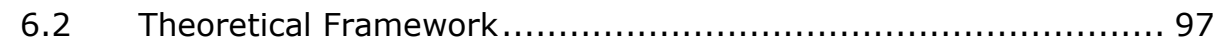

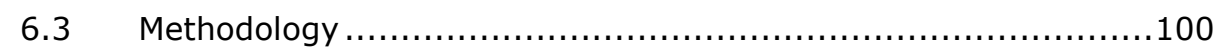

6.3.1 Data preparation for exploring elasticity of travel.............101

6.3.2 Distance calculation ....................................... 103

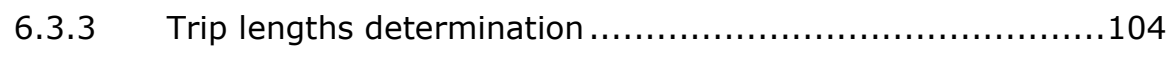


6.3.4 Deriving what trips are substituted by phone calls and

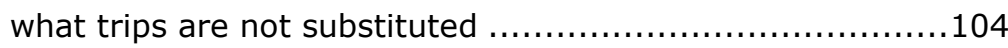

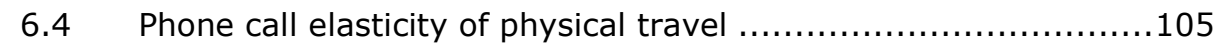

${ }^{*}$ Significant at the 0.05 level................................................. 106

6.4.1 Elasticity of physical travel among different profiles. .........106

6.4.2 Effect of distance travelled on tie-strength ....................108

6.4.3 Association between socioeconomic, demographic, profiles and distance substituted.............................. 110

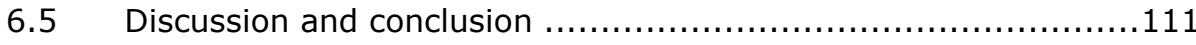

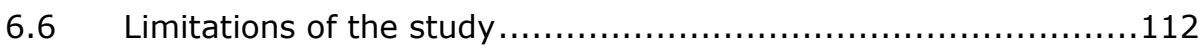

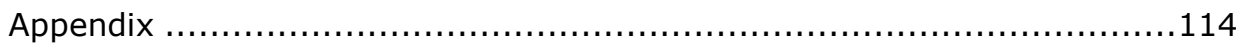

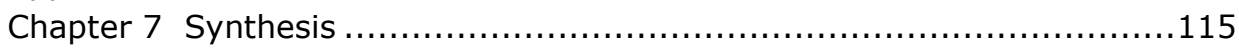

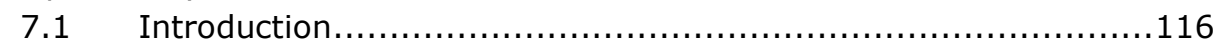

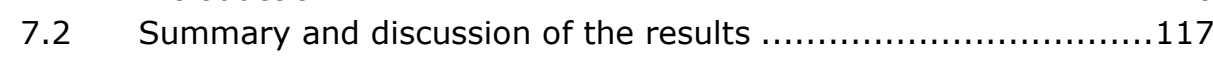

7.2.1 Objective 1: To examine how social network analysis can be included in travel research...........................117

7.2.2 Objective 2: To examine how the inclusion of social networks in travel studies provides new ways of defining space and accessibility.

7.2.3 Objective 3: To analyse and understand the trade-off between ICT and physical travel among social network

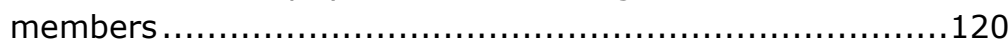

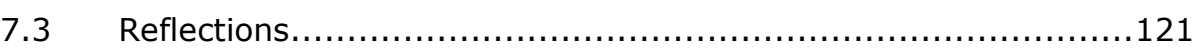

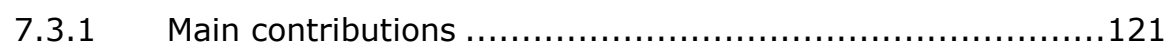

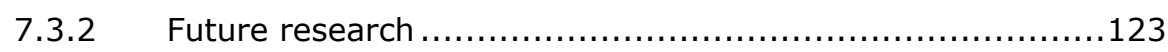

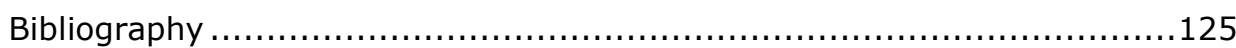

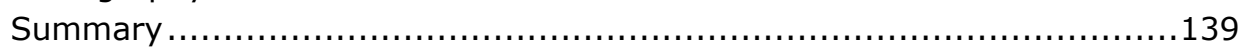

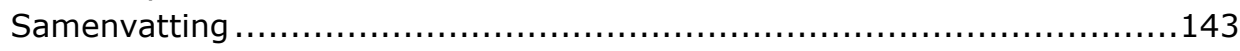

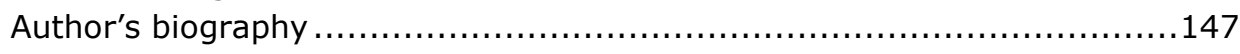

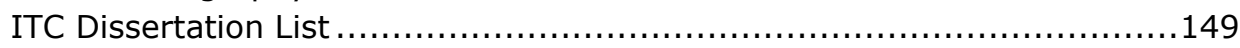




\section{List of figures}

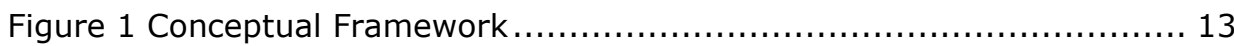

Figure 2 Thesis chapters and their relationship ................................ 15

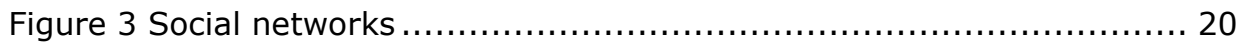

Figure 4 Ego network with "ego" and "alters" (a to g) ........................... 20

Figure 5 Ahmedabad population and economics, 1891-1940s................. 24

Figure 6 Growth of Ahmedabad from 1411 to 1800 ............................. 25

Figure 7 Present map of Ahmedabad .............................................. 26

Figure 8 Plan view \& Aerial view of a 'pol'............................................. 27

Figure 9 Spatial distribution of the sample....................................... 40

Figure 10 Physical travel (left) and E-communication (right) of a typical

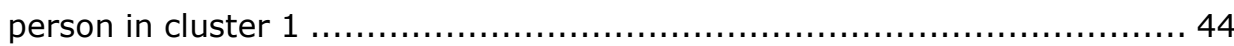

Figure 11 Physical travel (left) and E-communication (right) of a typical

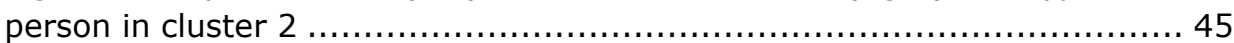

Figure 12 Physical travel (left) and E-communication (right) of a typical

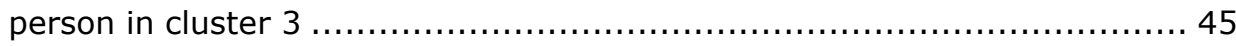

Figure 13 Physical travel (left) and E-communication (right) of a typical

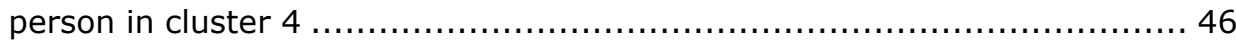

Figure 14 Physical travel (left) and E-communication (right) of a typical

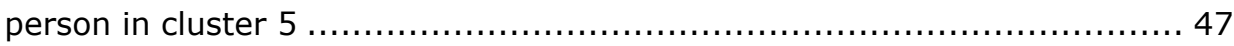

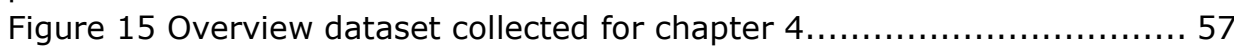

Figure 16 Origin and destination of e-communication trips during traveling 59 Figure 17 Ahmedabad, India: Outer wards containing relatively less land use facilities than inner wards ............................................................. 60

Figure 18 Number/percentage of daily, potential substitutive and substitutive

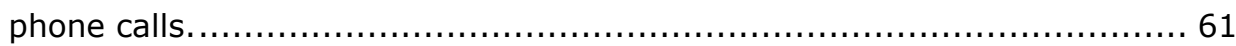

Figure 19 TLFD of physical trips (left) and potential substitutive e-

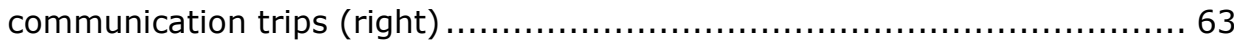

Figure 20 TLFD of physical trips by profile ........................................ 64

Figure 21 Networkedness map of Ahmedabad................................... 79

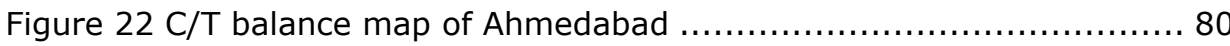

Figure 23 Comparison between location and networkedness of easy riders. 81

Figure 24 Comparison between location and networkedness of well-connected

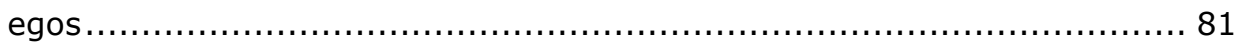

Figure 25 Location and tie strength of popular people ........................... 82

Figure 26 Location and tie strength of digitally inclined ......................... 83

Figure 27 Location and tie strength of ' $\mathrm{I}$ ' generation ............................ 83

Figure 28 Social network relation with whom egos communicate physically 84

Figure 29 Land use and transport lines of Ahmedabad .......................... 96

Figure 30 Theoretical Framework ................................................ 99

Figure 31 Land use map of Ahmedabad (Munshi 2013) ......................104

Figure 32 Example of a phone diary ............................................105

Figure 33 Possible explanations for the behaviour of profile $5 \ldots \ldots \ldots \ldots \ldots \ldots . .108$ 
Figure 34 Willingness to travel any physical distance for strong and weak ties

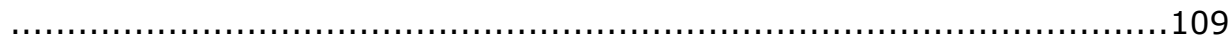

Figure 35 Relations between tie strength and travel distance.................110 


\section{List of tables}

Table 1 Relation between social network concepts and e-communication and

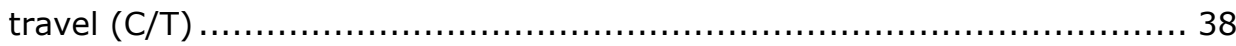

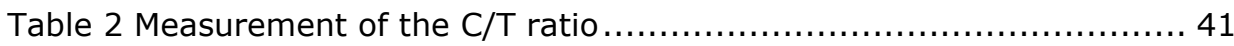

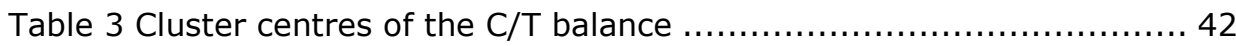

Table 4 Euclidean distances between clusters .............................. 43

Table $6 \mathrm{C} / \mathrm{T}$ balance score of a typical person in cluster $1 \ldots \ldots \ldots \ldots \ldots \ldots \ldots . \ldots 44$

Table $7 \mathrm{C} / \mathrm{T}$ balance score of a typical person in cluster $2 \ldots \ldots \ldots \ldots \ldots \ldots \ldots \ldots \ldots$

Table $8 \mathrm{C} / \mathrm{T}$ balance score of a typical person in cluster $3 \ldots \ldots \ldots \ldots \ldots \ldots \ldots . \ldots \ldots$

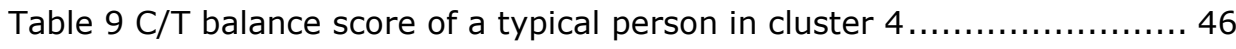

Table $10 \mathrm{C} / \mathrm{T}$ balance score of a typical person in cluster $5 \ldots \ldots \ldots \ldots \ldots \ldots \ldots . \ldots 7$

Table 11 Comparison of socioeconomic and demographic characteristics of Ahmedabad, the census 2001 versus the sample and clusters $\ldots \ldots \ldots \ldots \ldots \ldots . \ldots 48$ Table 13 Statistics of TLFD trend lines by profile (corrected for employment

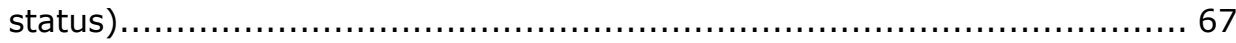

Table 14 C/T balance profiles (Source: Roy et al. (2012)) .................... 74

Table 15 Profile and Networkedness Cross tabulation.......................... 84

Table 16 Correlation between networkedness and socio-demographic

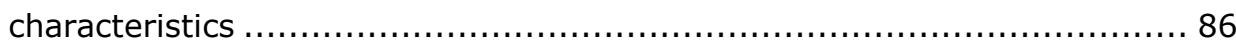

Table 17 C/T Balance profiles (Source: Roy et al. (2012)) ................... 101

Table 18 Socio-economic characteristics of respondents....................102

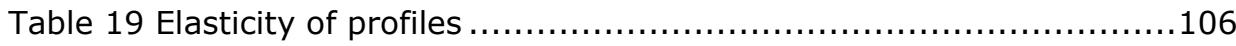

Table 20 The percentage of substituted trips per profile $\ldots \ldots \ldots \ldots \ldots \ldots \ldots \ldots . \ldots 108$

Table 21 Association between socioeconomic, demographic, profiles and distance substituted 
Chapter 1

Introduction 


\subsection{Introduction}

The advent of Information Communication Technologies (ICT) could become as important as the invention of the automobile in shaping people's daily activities. The world has embraced the several functions that ICT enables, such as tele-conferencing, e-commuting; the embrace took rapidly. The need to be at a certain place at a certain time to meet other people, and the need to perform activities before closing time are being challenged by the rise of ICT. The ever increasing need to be spatially mobile challenges people to find new ways of developing social ties and exchange information over distance. This need has major implications for individual travel behaviour, though these effects are very complex and not yet well understood. Consequently, this thesis deals with the relation between ICT and its effects on individual travel from a social networks perspective.

ICT affect our lives in countless ways. They are the hallmark of the information age, and their societal repercussions run the gamut from marked modifications in individual behaviours and lives to regional economic development to global divides and inequalities. One of the main effects of ICT is on individual mobility. In some cases ICT substitutes for physical trips, leading to a reduction of travel, but travel amplification and synergistic effects between travel and ICT are also frequently observed (Mokhtarian, 2003). As the popularity of ICT increases, people's travel behaviour and ultimately the use of transport systems and the spatial configuration of built form could change fundamentally. There is considerable uncertainty about potential outcomes of ICT in the policy areas of transportation and spatial planning. This study therefore contributes further to the understanding of the effects of ICT on travel and policy formulations in urban transport systems.

Transportation can be defined as the movement of people, goods, services, and information. Thus, a lot of travel is undertaken for the purpose of exchanging information. Similarly, ICT allow a large amount of information to be transmitted over a telecommunications network. Such technologies have moved our society from the "Industrial Era" to the "Information Age" and changed people's daily lifestyles as well as travel behaviour. As such, transportation and telecommunications have in common the characteristic that both are means of sharing information among people, and for that reason they are also closely interrelated with each other as substitutes and/or complements (Choo and Mokhtarian, 2007).

It is well established that the Internet and other related ICTs are fundamentally altering the spatial and temporal organization of the activities of households, firms, and other actors in cities. Views on the nature of ICTinduced changes have, however, become more qualified. The reciprocity of 
the links between telecommunications, offline activity, and urban spaces as well as their temporal and spatial complexity is being emphasized (Schwanen et al., 2006).

A number of studies have identified the potential relationships between ICT and travel:

- $\quad$ Firstly, the use of mobile communications affects people's use of time and increase the spatial and temporal flexibility of their daily activities and travel (Kwan, 2002). For instance, mobile phones increase flexibility not only in terms of the place where work can be performed, but also in terms of working hours.

- Secondly, people's increased geographical mobility associated with the use of mobile communications has an impact on their travel and trip making behaviour. With the use of mobile phones, people can spend less time at home because they can now perform certain activities or make arrangements that could only be done at home before (Black, 2001). The widespread uses of communication technologies therefore lead to increases in personal travel instead of decreases.

- Thirdly, the mobile phone may encourage users to spend their free time outside of the home. It may promote and facilitate certain urban practices such as sitting in cafes or dining in restaurants, making it easier to spend leisure in an increasingly urban manner, thus changing the functionality of urban spaces.

- $\quad$ Finally, the flexible use of mobile communications in transit is linked to the flexible use of public urban space (Kenyon, 2002), and mobile communications may alter the traditional spatial division of urban spaces into centres and peripheries. This means that the use of mobile communications may lead to important changes in the function and role of existing nodes in the urban and transportation systems, e.g. people who would otherwise have had to commute every day to the CBD for work now with telecommuting might choose to work from their homes, blurring the core (CBD) periphery (residential areas) concept.

A popular image is that ICT causes a city to expand or even to vanish at the extreme (Muhammad, 2007). As the invention of cars enabled people to break the traditional size of cities, the networked society would liberate people from the traditional workplaces of the industrial age. As workers can now work on fancy telecommunication networks, they do not have to commute to the workplaces. Instead, they can work in an "electronic cottage", in the "extended urban regions" or around the intelligent telecommunication network anywhere, anytime in the digital economy of the information age (Graham, 1997), while making commuting a phenomenon of the pre-information age. Telework is regarded as a pillar of the new economy, and "new work paradigms" and "economic restructuring" claim to 
necessitate the increased adoption. One extension of this line of reasoning is that people will live on bigger housing lots causing further expansion of cities. Although some reservations are expressed, planners tend to take it that more telecommuting, or increased reliance on ICT, will spur the expansion of urban areas and invite leapfrog developments (Mokhtarian and Varma, 1998).

The transition from preindustrial, rural society to modern, industrial society to contemporary digitally networked societies (though this order is not necessarily maintained in some emerging economies) led to new forms of personal social relationships. In preindustrial societies, social networks were determined almost exclusively by primary groups of kin and village community (Hollinger and Haller, 1990). In the course of industrialization and urbanization (which have not always gone together, however) the traditional production and living unit of the 'houseful' (Brunner, 1968) has been dissolved. Economic demands for increased geographic mobility led people to live at growing distance from their kin. Contacts with extended kin were reduced, while emotional bonds within the nuclear family became closer (Shorter, 1977). In contemporary networked society, which typically is also a much more urbanized society, the individual can shape an increasing part of their personal networks by choosing either to maintain it digitally or physically; and change it during his/her lifetime. The average network becomes small, dense and is centred around spouses (Marsden, 1988; McPherson et al., 2006). Thus, in the contemporary networked societies, social networks can be easily maintained over long geographical distances digitally.

In this age of information technologies, the spatial effects of ICTs on future urban and regional growth are major concerns for planners and policy makers. Many scholars (Nobis and Lenz, 2009; Rhee, 2009) assume that the information communication revolution (or rapid evolution) will have profound structural impact on urban development. Urban locational theories will have to be changed or adjusted and policies revised. There is a need to contribute to this scientific debate by analysing the three perspective effects of ICT on:

- The implication of the existing difference of ICT use and the trade-off between ICT and physical travel by people's difference in ICT consumption,

- The spatial and geographical distribution of peoples networks, and

- $\quad$ The actual increase or decrease in physical travel due to ICT uses.

Hence there is a need to explore, what will be the new meaning of travel in hybrid space (hybrid space is that space which is caused by both opportunities available in the virtual space and people's preference for and need for face-to-face interaction). For example, many people who telecommute will additionally commute physically for a certain number of 
days per week or month. Thus, a hybrid space emerges, where distances still matter, but for an increasing number of people to a lesser extent (Shen, 2000) and how will it affect the accessibility of people to their economic and social activities.

\subsection{Literature Review}

Information and Communication (ICT) dates back to the 19th century when Samuel F.B. Morse in 1835 developed the Morse code. Since then ICT has travelled a long way and these vast communication networks have in fact become so ubiquitous that they are almost invisible. Perhaps nowhere is the relationship between society and technology more evident than in the history of communication, for it is the ability to communicate effectively that enables many of the other developments: economic, social, political and cultural, all of which are recognized as being historically significant.

The interaction between ICT and human activity-travel behaviour has been an important theme in transportation research in recent years (Kwan, 2006; Lenz and Nobis, 2007; Lyons, 2009). Researchers have recognized that an increase in the use of ICT may lead to changes in the location, timing and duration of people's activities, and the widespread use of ICT will likely be associated with new patterns of activity and travel in the space-time domain (Kwan, 2002). Analyses of these patterns could provide part of the empirical basis and/or behavioural foundation for enhancing our understanding of the interaction between ICT, activity-travel behaviour and urban form.

Individual mobility has undergone significant changes in the recent decade for a number of reasons, one of which is the increasing availability, power and use of ICT. In some cases ICT substitutes for physical trips, leading to a reduction of travel, but travel amplification and synergistic effects between travel and ICT, (Rheingold, 2002) are also frequently observed.

The term "spatial technologies" adopted from Couclelis (1994) is a collective name for the transportation, communication, and information technologies that modify spatial relations. Advanced telecommunication networks and digital information systems are dramatically redefining urban space (Shen, 1998). They are challenging many basic concepts and analytical frameworks of planning, and raising numerous fundamental questions. To answer some of the questions scholars have put forward their opinions in the form of the following debates.

\subsubsection{The increase versus the decrease in travel}

The earliest studies by transportation researchers focus largely on the effect of telecommuting on travel behaviour. Several of them used the geo coded activity-travel data to assess the impact of home-based telecommuting on 
travel. They observed a significant reduction in work-related travel and a contraction of activity space as a result of telecommuting. For instance, Pendyala et al. (1991) found that telecommuters not only substantially reduced their trip making and the total distance travelled, but also chose non-work destinations that are closer to home. Koenig et al. (1996) observed a significant reduction in the number of trips and vehicle-miles travelled (VMT) for telecommuters. Another study by Mokhtarian (1990) has similar findings: the share of activities performed close to home increased considerably for telecommuters on telecommuting days, and there was a contraction in the size of the activity space for telecommuters on commuting days.

However, other studies suggest that ICT use at home may lead to an increase in non-work trips and activities. Hodge and Koski (1997) observed a considerable reduction in commute-related travel and a slight increase in non-work travel as a result of centre-based telecommuting. Kwan (2002) found that telecommuters undertook a significantly higher number of return home, eat meal, shopping, and social/recreation trips on telecommuting days when compared to non-telecommuting days. The results of other studies (Sasaki and Nishii, 2003) also support the tendency for non-work activities and trips to increase as a result of higher level of ICT use. For instance, Shen (2000) found that people working exclusively at home on a given day spent significantly more time shopping on the work day than did persons working away from home. Schwanen et al. (2006) observed a predominant effect of generation - which occurs when the use of one mode increases the use of another (e.g., the greater the availability of information about activities and people of interest, the greater the travel to participate in those activities or meet those people). They found that increasing use of ICT is unlikely to reduce travel significantly.

One of the main difficulties in assessing the impacts of ICT on travel is identifying the likely activities in which individuals will choose to engage. For example, it is easy to roughly assess how someone who begins to telecommute may reduce his or her commuting. But what other types of travel may that person still engage in, or perhaps even increase given the newly saved time, is not easily calculable. However, when ICT is used for the purpose of economic gain, and the economic activity in question involves travel, it is possible to identify means and ends relations more clearly. This is because empirical data can be collected and analysed over a period of time for a panel of people (Nobis and Lenz, 2009). Also it is easier to gather data related to changes in travel behaviour for economic activity because the concept of "fragmentation" can be applied to such travel changes. 


\subsubsection{Socio-demographic factors affecting ICT use and travel}

All the earlier studies suggest ICT use, as well as any associated travel impacts, is highly dependent on a variety of demographic, incidental, accessibility, and activity-related factors (Lu and Pas, 1999). Fox (1995) found that some factors that have influenced travel were environmental consciousness, costs, budget restrictions and the changing sociodemographic aspects of society. Zhang (2008) found that in the same age groups there was a significant difference in travel behaviour between males and females of Beijing. Haustein et al. (2009) observed that travel of young Germans were influenced by peer pressure, level of socializing and communication with parents.

Van Wee et al. (2006) suggest that the average travel by the Dutch population has increased over the past decades. However, different data sources show different levels of increase. Possible causes for this increase are a rise in incomes, that has probably resulted in a change in both travel costs and benefits, where the benefits of additional travel having increased more rapidly than costs, and possibly the increased comfort level of cars. Another reason for the increase might be the new opportunities offered to travellers to make better use of their travelling time, such as working in the train.

Another important factor affecting ICT use and travel is land-use and urban form. According to Cervero and Kockelman (1997) there are three dimensions of the spatial environment that influence travel: density, diversity and design. The urban form indicator that has received the most attention is urban density. Different kinds of densities have been used to measure the effects of exogenous variables affecting travel. Chatman (2008) found that housing density has a fairly consistent relationship with travel especially with activity frequency and Vehicular Miles Travelled (VMT). Su (2010) showed that population density and urban congestion have a negative impact on travel. Peng and Lu (2007) found that the number of trips produced increased with the increase in employment density.

Thus, it is established that urban spatial density is very important in relation to travel. However, one main difficulty in explaining the impacts of ICT on travel through spatial density is identifying the likely activities in which individuals will choose to engage. For example, it is easy to roughly assess how someone who begins to e-commute due to congestion may reduce his or her commuting. But what additional travel that person still engages in, given the newly saved time is challenging to assess (Choo and Mokhtarian, 2007). To be able to understand the complexity in all these relationships it is important to take a close look at Social Network Analysis. In Social Network Analysis, profiles of individuals are used, that contain all the variables like 
age, income, profession etc. Moreover, the Social Area Network can be used to analyse the network of the individuals that are represented as "nodes" which are connected to other nodes by one or more specific types of interdependency. When analysed, it is possible to empirically generate data that can then be used to assess which relation and travel is being substituted or complemented by ICT (Axhausen, 2008).

\subsubsection{Social networks, ICT use and travel}

Individuals in their conduct of activities come in contact with other people and start participating in social networks. Once involved, these networks need maintenance and induce travel, thereby impacting the scheduling of activities, in time and in space. Participation in these networks then leads to adaptation of preferences and diffusion of knowledge, triggering new activitytravel bundles and changes in travel repertoires. Depending on their binding element, social networks are also dismantled, leading to changing travel patterns (Arentze and Timmermans, 2008). ICT use and travel emerge from the individual's social networks, or, in other words, they can be inferred in part from knowing individuals' social network characteristics. Maintenance and longevity of these networks in turn increase or decrease physical travel. Also, a change in the travel pattern affects the urban space both in its structure and function.

The generation of (or decision to perform) travel can be explained by the individual's propensity and opportunity to engage in a social activity (Chapin, 1974). Propensity not only depends on the individual's socioeconomic and lifestyle attributes (profiles of people) (Lu and Pas, 1999), but also on with whom individuals perform social activities (e.g., family, friends or colleagues), who constitute the individual's social network characteristics, and also on their related communication patterns (e.g. frequency and type of ICT used). As a consequence, ties or links between the individual and other people in the network represent a flow of potential activity travel generated by the interaction between those 'nodes' of individuals. Opportunities to engage in social activities are represented by individuals' time and space prisms (Soo, 2009) which, in part, depend on the spatial distribution of individuals' social networks, and are fixed in the short time horizon (Hagerstrand, 1970).

The social network paradigms try to understand how social structures facilitate and constrain opportunities, behaviours, and cognitions. Social network analysis conceives that overall behaviour is the sum of individual behaviours, and contrasts with explanations that treat individuals as independent units of analysis, as traditionally used in travel behaviour research. Thus, behaviour is explained not only through personal attributes 
but also through social structural attributes that incorporate the interaction among the different social network members. This approach assumes that the whole is the sum of its parts: social phenomena cannot be understood solely by individual characteristics (such as socioeconomic attributes) but must also consider the social structure emerging from the interaction among individuals (Carrasco et al., 2008).

\subsection{Research gap}

Despite increasing attention to ICT and its effect on physical travel and its explanation, a few research gaps can be identified.

\section{Focus on internet rather than electronic communication.}

What becomes apparent when looking at empirical studies of ICT and travel is that many studies focus on the effects of internet use on travel rather than taking all electronic communication per se (Julsrud et al., 2012), even though there are results showing that talking over the phone, SMS and chat are important in maintaining social networks. The interactive nature of mobile phones and hence travel is clearly distinct from other types of electronic communication. By choosing to communicate with others over the mobile phone, people can exercise control over their physical travel, and can make logical decisions affecting their route choices, trip chaining etc. Mobile phones should therefore be considered as a very important part of ICT when its relationship with physical travel is being assessed. Only a few studies pay attention to this. It is important to distinguish between the different modes of e-communication, because the mode determines not only the kind of information exchange, but also the importance of the information. The importance of the information in turn directs the decision to physically travel (or not), and the destination and travel mode to choose. At least a basic distinction between the modes of e-communication must be drawn, because the likelihood of these acutely affects physical travel (Julsrud et al., 2012).

\section{No attention to social networks as an important factor affecting ICT and travel}

Most studies concentrating on ICT and travel pay very little attention to social networks. The focus is mainly on socio-demographic and economic variables. The need to communicate or perform physical travel differs between individuals. The bases of such needs are new ways in which social life is apparently 'networked' (Urry, 2003). Carrasco and Miller (2006) and Silvis et al. (2006) suggest that people with a large social network are likely to have more social interactions hence travel, than people with a small social network. In contrast, Boase et al. (2006) found a negative relationship between the size of the social network and the total number of physical trips. These findings seem to indicate that a larger social network doesn't necessarily mean a higher number of physical trips. According to Palackal et 
al. (2011) people seem to be capable of maintaining large social networks by reducing contact frequency.

\section{Only part of the social network used for analysis}

Another limitation in most studies that consider social networks is that they study only a part of the individual's network. Tillema et al. (2010) study five family members or friends the individuals communicated with. This was done to reduce the load of the people being interviewed. Verdery et al. (2012) while studying the relationship between the proximity of individuals' dwelling units and their social network association, use only one kind of tie (e.g. kinship, family ties) to establish the hypothesis. Though partial network studies are used to study personal networks, they are not particularly useful for assessing indirect ties and other structural properties of large networks. It restricts the analysis to one type of tie only, because it excludes, for example, acquaintances - weak ties - who do not communicate frequently with each other, and it does not allow for the analysis of network structure. The emphasis on confiding ties ignores the literature on weak ties (Granovetter, 1973), which have been shown to be important for individual behaviour in a variety of ways.

\section{Very little empirical research at the individual level}

Most empirical studies fail to provide statistical measures of the increase or decrease of physical travel due to ICT at an individual level. Pendyala et al. (1991) found that telecommuters not only substantially reduced their trip making and the total distance travelled, but also chose non-work destinations that are closer to home. However, which person reduced the total distance travelled and by how much was not studied. Studies that suggested an increase of travel due to ICT (Kwan, 2002; Sasaki and Nishii, 2003; Schwanen et al., 2006) analysed the phenomenon at an aggregate level. Researchers have recognized that an increased use of ICTs may lead to changes in the location, timing and duration of people's activities. This will most probably lead to new patterns of activity and travel in the time-space domain (Kwan et al., 2007). Hence, in order to assess the effect of ICTs on travel behaviour (like the effect of telecommuting on physical commuting), individual-level analyses would be able to identify relationships that are more difficult to assess at the aggregate level. However, current literature lacks individual-level detail at fine spatial and temporal scales (Kwan, 2002) and therefore, does not allow for such a micro-level approach.

\section{Studies from developing economies are not readily available}

Finally most studies have been conducted in USA or Europe. Empirical evidence from developing economies is missing. Not only do the sociocultural and planning context differ from those in the US and Europe; so do the urbanization pace and pattern. Developing economies, unlike the west has traditionally been a well-knit society with strong kinship bonds. While the 
west tries to homogenize differences and globalize markets, many communities are ever more forcefully acknowledging their distinctive characteristics and celebrating their cultural differences (Mebrahtu et al., 2000). Societies that have undergone particularly rapid political, economic and social change have a great deal in common. However, they are different from developed societies on a lot of grounds, the most important being their social network ties and mode of communication. Thus, the specific characteristics of the developing society and travel behaviour have been kept in mind when studying the potential effects of ICT on physical travel.

\subsection{Research goal and question}

As has been shown in previous sections, effects of ICT on physical travel has grown rapidly in recent years (Aguiléra et al., 2012; Yuan et al., 2012). As yet it is unknown how social networks might affect the decisions to ecommunicate or travel physically. If individual's e-communication patterns change due to their social networks, it will affect their physical travel. The studies that relate e-communication and physical travel pay very little attention to social networks. The few that do in fact study social networks use only partial networks. Moreover, most studies are western country based, which faces different socio-cultural, urbanization pace and planning contexts than developing countries and these factors can be expected to influence the decision to e-communicate or meet face-to-face.

Consequently, the main goal of this research is to provide insight into individuals' ICT adoption and the implications this might have on their physical travel. To achieve this goal the following research question is formulated.

How can social network analysis be used to measure the effects of ICT on physical travel for rapidly growing developing economies like Ahmedabad.

This main research question comprises of a set of interrelated hypotheses which if successfully tested will to a large extent answer the main question, which are:

- Individuals belonging to different social network profiles use and are affected by ICT differently.

- Individuals will trade-off e-communication and physical transport to maintain their social networks, which is relevant to provide space and accessibility a new meaning.

- Social networks can explain generation, maintenance and longevity of physical travel which is important for urban travel policy makers. 


\subsection{Research objectives}

The objective of this research is to quantify the relation between ICT uses and physical travel for a fast-developing metropolitan city in India, and to efficiently use social network as a tool for travel research.

\subsubsection{Objective 1}

To examine how social network analysis can be included in travel research.

Questions

- What role do social ties play in the travel and communication of people?

- How to use a social network to create homogeneous profiles?

- What does the social network of people belonging to different profiles look like?

\subsubsection{Objective 2}

To examine how the inclusion of social networks in travel studies provides new ways of defining space and accessibility.

\section{Questions}

- How do individuals adapt their travel behaviour for communicating with different members of their social networks?

- How does the geographical location of social network members affect ICT usage and physical travel?

- To what extent can social network analysis be used to model these travel patterns and ICT usages?

\subsubsection{Objective 3}

To analyse and understand the trade-off between ICT and physical travel among social network members

Questions

- What are the factors affecting the trade-off between ICT and physical travel?

- Does the social network of individuals affect the trade-off?

- How can the trade-off be quantified?

\subsection{Research design and outline of the thesis content}

A conceptual framework guiding this study is presented in Figure 1. It relates individual's travel decision making to technology (ICT) and individual's characteristics, that frequently are suggested to account for individual travel behaviour (Bamberg et al., 2011). From the earlier discussions it is clear that ICT influences individual's travel decisions. Apart from ICT, the individuals social and various external factors which make up the individual's social 
networks, impact the way people use technology (ICT) and change their communication/travel balance. Finally, it highlights the importance of the effect these variables have on the increase or decrease of physical travel, leading to a change in urban travel pattern.

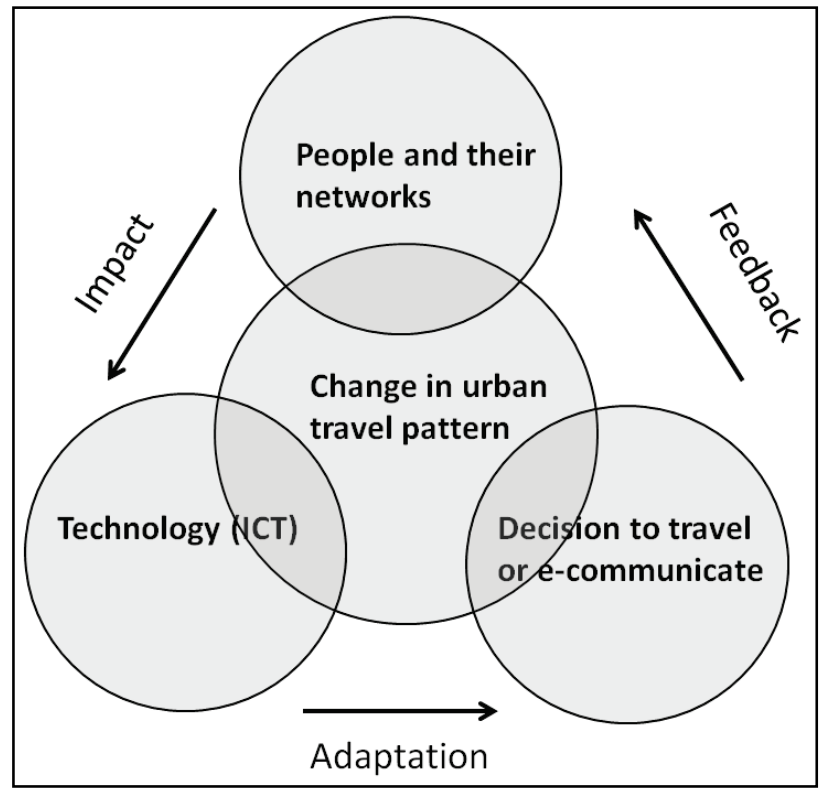

Figure 1 Conceptual Framework

The research is composed of several inter-related stages (Figure 2) where theory, methods and application constitute the three major sections.

Chapter 1 sets the stage for this research by introducing the research arena, with a general background on the various on-going debates concerning the effects of ICT on travel. It also discusses empirical research on the increase versus the decrease of travel due to ICT, travel behaviour and social factors, including aspects of individual characteristics. It provides an introduction to social network analysis which is later used in the thesis. Finally, it raises the issues that need to be addressed, and outlines the research objectives. The conceptual framework discussed earlier in this section is the result of this review.

Chapter 2 offers a methodological discussion, and provides a detailed account of social network analysis. This chapter also describes the context of Ahmedabad and its appropriateness as a case study.

Chapter 3 answers research objective 1. To examine how social network analysis can be included in travel research. The first section of the chapter 
discusses how social network analysis can be used to determine the role of social ties in affecting individual travel. It clearly defines social network characteristics and describes which of those are essential for travel research. The second section of the chapter uses these characteristics to profile individuals based on their e-communication/physical travel balance (C/T balance). Finally, the chapter arrives at five distinct $\mathrm{C} / \mathrm{T}$ balance profiles.

Chapter 4 continues with objective 1 introducing the social network approach to explore the physical versus e-communication debate. It uses the $\mathrm{C} / \mathrm{T}$ balance profiles to study the travel patterns of Ahmedabad. For each profile the travel and e-communication behaviour of people is assessed thoroughly for seven travel demand related aspects. The chapter investigates whether the differences in the various travel behaviour aspects can be attributed to socioeconomics, spatial characteristics and social networks. The analysis shows that the trip-length-frequency distributions show differences which cannot be explained by socioeconomics or spatial characteristics alone but by social network profiles. In addition, the social network profiles reveal distinct travel patterns. This chapter successfully establishes that social network analysis can be used as a complement to trip distribution modelling.

Chapter 5 develops the concept of networkedness. This chapter answers research objective 2 . The chapter focuses on providing new definitions of space and accessibility. It defines networkedness and empirically investigates networkedness, its characteristics and its relation with the $C / T$ balance profiles. Networkedness is defined as the density of the total number of alters an ego communicates with. Analysis of networkedness (calculated for every ward in Ahmedabad) shows that the inner wards have higher networkedness compared to the outer wards; however, no particular pattern can be established. When compared with other variables it is found that networkedness is affected by ego's location, ego's tie strength and the communication and travel balance. However, socio-demographic variables and location within the city level do not affect networkedness.

Chapter 6 deals with research objective 3. In the chapter social network analysis is operationalized for a statistical analysis of the substitution versus additive effects of phone calls on physical distance travelled by individuals. It is done by evaluating the phone call elasticity of physical travel. The phone call elasticity shows a variation among different people which can be connected to the type of trips that are substituted. The substituted trips are related to the social networks of individuals. The analysis also studies the relevance of social ties in Ahmedabad, India, as a source of explanation of social activity. 
Chapter 7 concludes the dissertation by presenting a synthesis of obtained results and conclusions from chapters 2-6. A reflection on the main topics in these chapters is given and recommendations for future research are provided.

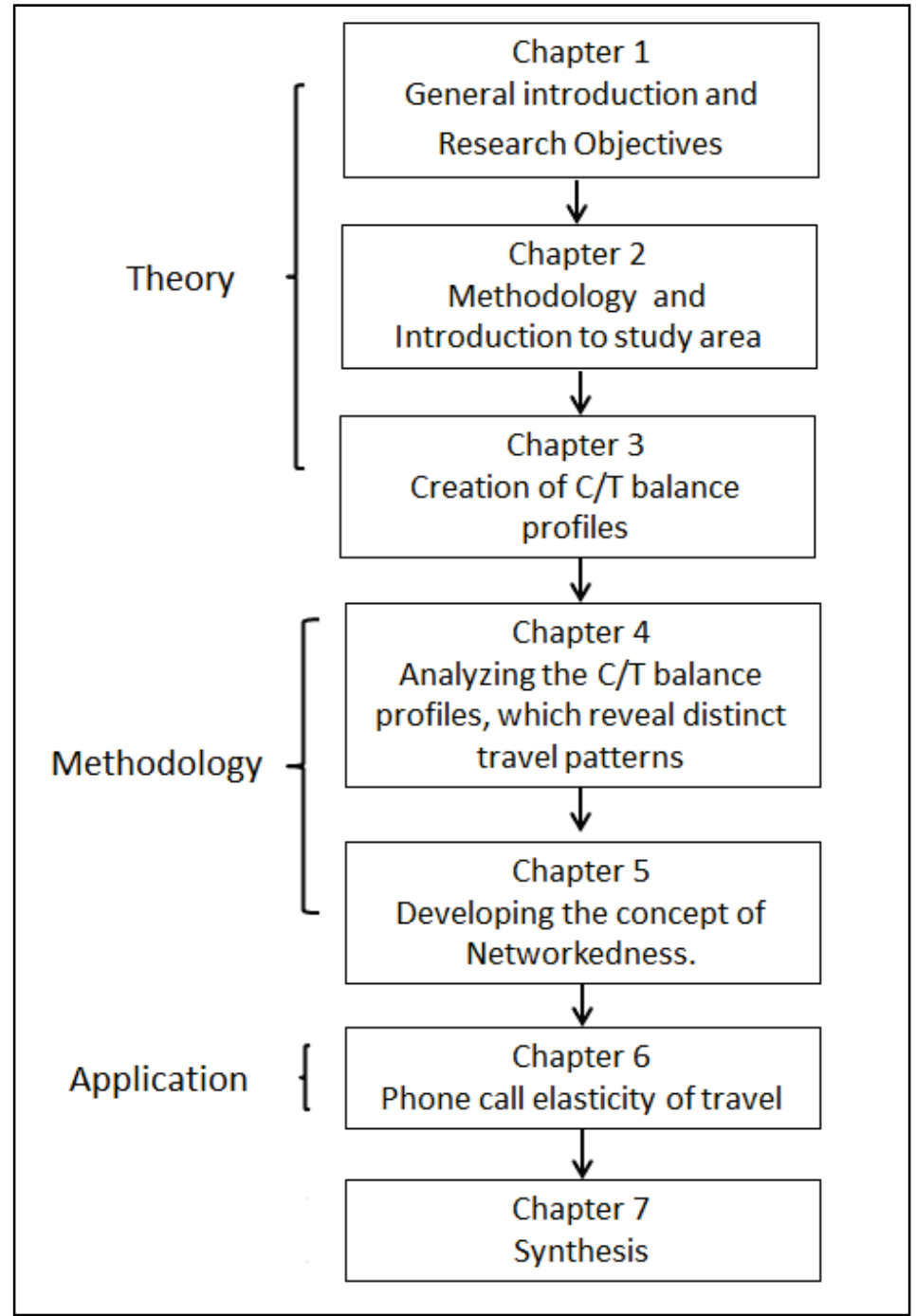

Figure 2 Thesis chapters and their relationship 
Chapter 2

Methodology and study area 


\subsection{Introduction}

The goal of this research is to provide insight into individuals' adoption of ICT use and the implications this might have on their physical travel. A few observations from the review of early scientific research into the relationship between "transport in the age of mobile communication" can be made:

- ICT use for activity of individuals leads to a change in their travel pattern.

- ICT affects the travel of people belonging to different profiles differently which leads to a change in the travel pattern.

- People's travel is to a large extent affected by their social networks.

- There is substantial difference between countries and cultures in this relationship

Salomon has developed a scheme that categorized the potential effects into two basic types, namely 'substitution' and 'complementarity' (Salomon, 1986). He subdivided complementarity into "enhancement" which was generation of additional travel due to availability of additional ICT usage, and "increasing efficiency" suggesting that the efficiency of travel increased by the application of e-communications. "Increasing efficiency", however, was basically ascribed to the supply side. So complementarity in Salomon's understanding was the "increase in demand for transport resulting from the enhanced use of telecommunications" (Salomon, 1986).

Over the years, based on the seminal works of Salomon, many researchers have tried to better understand how transport and electronic communication inter-relate. Major understandings of this cause-effect are the two different kinds of relationship that have been provided by Graham and Marvin (2002) and Mokhtarian (1990):

Modification: change in travel due to ICT usage (not necessarily increase or decrease);

Neutrality: no effect of ICT on travel.

However, communication between people by ICT does not take place independently of face-to-face contacts (Dijst, 2009). Cyberspace can function as an annex to social space, consolidating and reinforcing social practices and cultural norms tied to specific locales, regions, or nation-states (Aoyama, 2003). There is increasing evidence (Farag et al., 2007; Lundevaller, 2009) that the adoption and use of the Internet by individuals is situated in sociophysical contexts and that technology trajectory depend on and reinforce nation-specific institutional regimes, urban forms, and cultures. Work along these lines thus shows that the Internet cannot be separated from its geographical or social context. 
Undoubtedly, these efforts enhanced our understanding of the connection between ICT usage and travel behaviour. However, due to the complex nature of the interaction between ICT use and human travel behaviour, many scholars have been sceptical of simple and universal conclusions of how ICTs affect daily travel (Yuan et al., 2012). Mokhtarian and Salomon (2002) recognized the differences between long-term studies and short-term studies. They stated that short-term empirical studies usually observed substitution effects of ICT. However, long-term studies often found significant amplification between ICT and activity behaviour. In more recent studies, researchers focused on the development of transportation problems in the age of instant access (Hjorthol et al., 2010). Mokhtarian (2009) explained the paradox that transportation problems are becoming worse in spite of the substitution of telecommunication. So while the effects of ICT-use on working or travel has received attention, relatively little is known on the effects of social relations on travel. In this research, we will examine closely the relation between social ties and travel and the effects of ICT on them. In the following section an introduction to social network analysis is provided.

\subsection{Methodology}

\subsubsection{Concepts of Social Network Analysis}

A social network is a social structure made of individuals (or organizations) called "nodes" which are tied (connected) by one or more specific types of interdependency, such as friendship, kinship, financial exchange, dislike, sexual relationships, or relationships of beliefs, knowledge or prestige (Figure $3)$.

Social network analysis views social relationships in terms of network theory about nodes and ties. Nodes are the individual actors within the networks, and ties are the relationships between the actors. The resulting graph-based structures are often very complex. There can be many kinds of ties between the nodes.

In its simplest form, a social network is a map of all of the relevant nodes between all the nodes being studied. The network can also be used to measure social capital -- the value that an individual gets from the social network. These concepts are often displayed in a social network diagram, where nodes are the points and ties are the lines. 

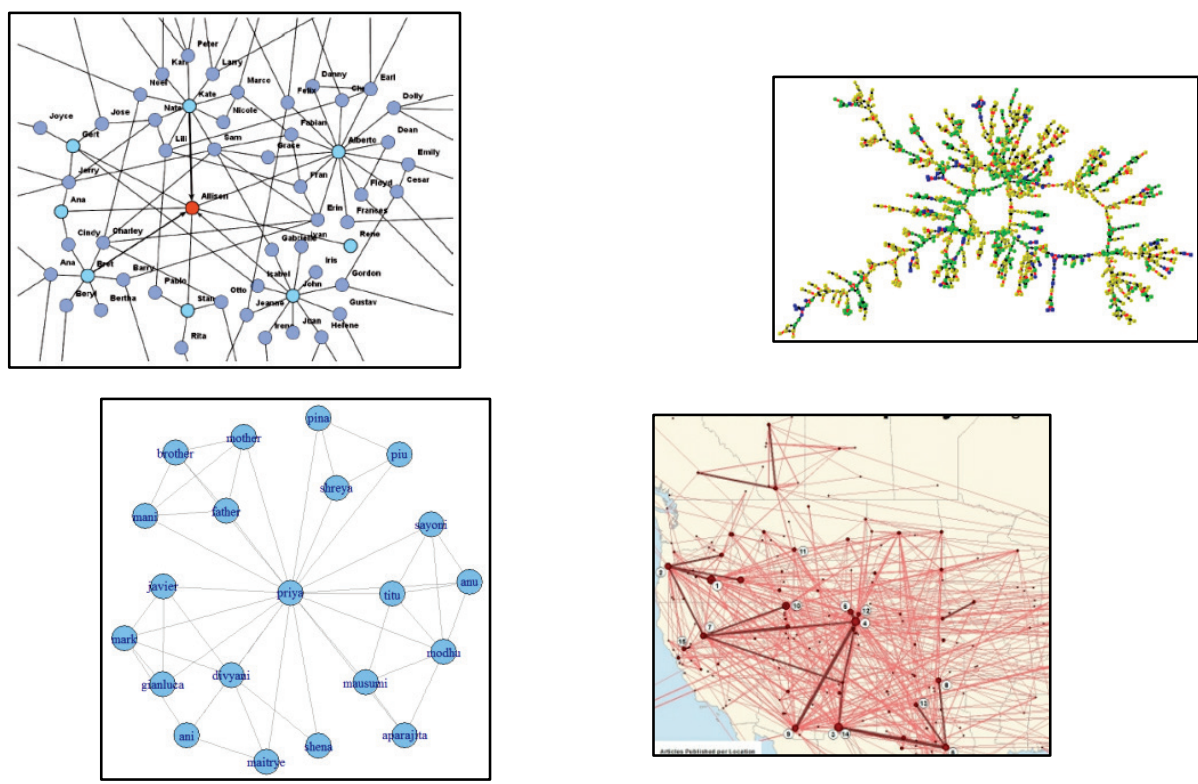

Figure 3 Social networks

Each individual (called ego) has a social network, defined as a set of actors or alters who have relationships or ties with the ego, and who may or may not have ties with each other (Figure 4).

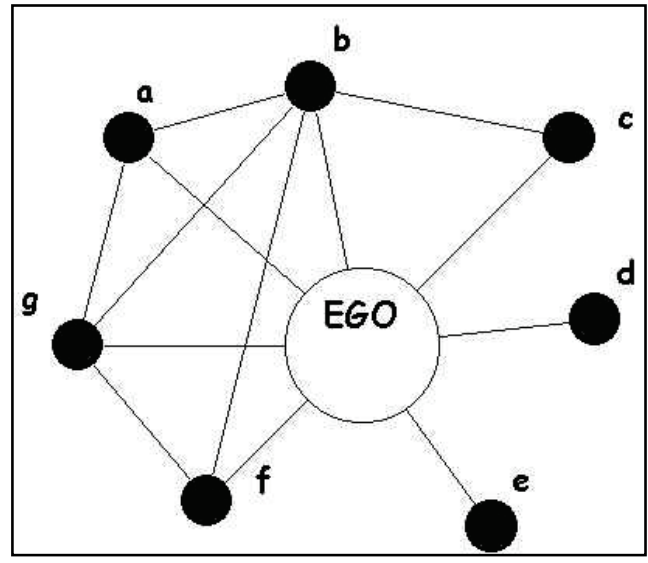

Figure 4 Ego network with "ego" and "alters" (a to g) 


\section{Name generators}

In any network study defining the network's boundary is very important. In egocentric methods, the most used technique to define the boundary is the name generator, which consists of free recall questions that elicit alters from an ego's network (Marsden, 2005).

Many times the name generator elicits only a part of the respondent's social contacts. The key task then is to ask the appropriate specific questions that will elicit the network members relevant for the specific phenomenon of interest. The number of alters elicited can be limited (Tillema et al., 2010) or unlimited (like in this study). There is an extensive literature that compares different name generators (Marsden, 2003; Marin and Hampton, 2007; Pustejovsky and Spillane, 2009). They discuss aspects like the effect of name generators in influencing the network size, the number of "core" and extended network members that each elicits the relevance of the order and wording of questions, and the forgetting phenomena. Finally, name generators are also important to measure tie strength between egos and each alter. The chosen indicator will impact on the reliability of tie strength measures, emotional closeness being the most usual and accepted one (Marsden and Campbell, 1984). From a practical point of view, a key challenge here is to gather an adequate amount of information in an efficient and reliable way. In general, a sampling strategy is usually performed (Marsden, 2005), although no firm guidelines can be found from the literature about this issue.

\section{Ties and Tie-strength}

The basis of any social network analysis are the 'relationships'. Relationships indicate a connection between two or more people or things. Individuals/ things who maintain a relationship are said to be linked by that relationship. Pairs can be linked by one or more relationships, e.g. pairs may be colleague and friends at the same time (Haythornthwaite, 1996). Social network analysis identifies the ties, and examines the relationship that forms and maintains the ties. Then it is possible to ask questions such as: "What types of information are exchanged by these different pairs?" "what is the mode of the information exchange?" "How does their kinship or friendships affect the way in which they exchange information?" "Who does not receive certain information?" and "How do actions differ based on who the sender of information is?"

To explore these questions it is important to know from whom the information was received or to whom the information was passed on. This question identifies an important characteristic of ties: strength.

Strength refers to the intensity of a relationship (Graham, 1997), for example, a relationship in which a large number of goods are exchanged or in 
which actors meet and exchange information frequently is known as a strong tie. A relationship in which few goods are exchanged or in which information is exchanged infrequently is known as a weak tie (Haythornthwaite, 1996).

Emerging from the attribute of strength is the concept of tie strength. The strength of a tie may depend on the number and types of relationships which a pair maintains, and on the strength of each individual relationship. The measurement of tie strength is problematic because it is very context dependent. Measurement of strength needs to vary according to the subject of the research and the research goals (Haythornthwaite, 1996). Granovetter (1973) defined tie strength as the combination of the amount of time, the emotional intensity, the intimacy (mutual confiding), and the reciprocal services which characterize the tie. Marsden and Campbell (1984) have used a combination of contact, duration of the association, intimacy of the tie, provision of reciprocal services and kinship to measure tie strength. Carrasco et al. (2008) uses emotional closeness for measuring the tie strength for egocentric networks. Sometimes, tie strength does not only depend on time spent, emotional intensity or intimacy but on the relationship itself. i.e. family is assumed to be a strong tie (Palackal et al., 2011) while acquaintance is considered as a weak tie. In case of egocentric networks tie strength is measured only from the ego perspective, for both ego-alter pairs and alter-alter pairs. The main reason is that it would be very expensive to interview both the ego and the alter in a large sample survey.

\section{Decision to perform an activity - physically or electronically}

The decision to perform a social activity can be characterized by the individual's propensity and opportunity to engage in a social project, inspired by Chapin's general activity patterns model (Chapin, 1974). The maintenance of social networks is realized through social activity (van den Berg et al., 2012). To communicate with geographically separated network members, people can either meet face-to-face or use ICT (Ortúzar and Willumsen, 2006; van Wee, 2009). While face-to-face meetings require physical travel, ecommunication requires 'virtual' travel which allows individuals (ego and alter) to maintain their current geographical location. (Kenyon and Lyons, 2007). Physical travel and e-communication are therefore, with respect to communication, a means to the same end. The mode (physically/electronically) of communication often depends on "with whom" the interaction is taking place (Tillema et al., 2010).

The relation between tie-strength and mode of communication (face- to-face or e-communication) has been studied in different contexts (Haythornthwaite, 2001; Axhausen, 2008; Carrasco et al., 2008; Dugundji et al., 2008; Tillema et al., 2010). Some argue that strong ties are more prone to electronic means of communication while others are of the opinion that 
weak ties are maintained electronically. Firstly, it is usually found that communication along strong ties takes multiple forms, and people will easily adapt their mode of communication to get the information across (DeSanctis and Poole, 1982). Secondly, where weak ties are concerned, people will rely on socially sanctioned means of communication that have an impersonal contact. Weak ties are more prone to be ICT based while strong ties will have more physical communications. One of the reasons for such a behaviour was that e-communication is less appropriate or useful for emotionally laden exchanges, or for the delivery of complex information (Fish et al., 1993; Mok et al., 2010). Thirdly, the argument for this was that strongly related ties with their higher eagerness and motivation to communicate will manage to modify the 'lean' electronic environment to support their needs. E.g. ecommunication users modify text-based e-communication by incorporating variety and emotion into their exchange, e.g., using emoticons and acronyms (McLaughlin et al., 1995; Paolillo, 2001) Studies in Japan have suggested a substitution effect of Internet use on time spent physically with family and friends (Boase and Kobayashi, 2008). It is conceivable, however, that this relation reflects the fact that the researchers did not take socio-demographics into account. Kestnbaum et al. (2002) used time use diary data for the USA to show that Internet use diminishes the time spent on socializing and visiting non-family members; however, after controlling for sociodemographics, this result was no longer statistically significant. Thus, there is no unanimity among researchers on the mode of communication and tiestrength.

\subsubsection{Study Area: Ahmedabad, India}

This thesis has been operationalized taking Ahmedabad city in India as a case. Ahmedabad is the largest city in Gujarat, India. It is the seventh largest city and seventh largest metropolitan area of India, with a metropolitan population of 4.2 million. In 2010, the Forbes magazine rated Ahmedabad as the fastest growing city in India, and third in the world. The history of Ahmedabad stretches as far back as in the 11th century and links itself with old towns of Ashaval and Karnavati about 1000 years ago. Ahmedabad was founded in 1411 A.D. by Ahmed Shah of Gujarat near the old trading centre of Asaval. The city was initially developed on the eastern bank of the river Sabarmati that covered an area of 2 square miles which is now regarded as the walled city. The city emerged as an important commercial and manufacturing centre with specialization in textiles. Most of the material then produced used to be exported. Mostly people worked and lived at the same place except for marketing which was done at Bhadra Fort, Teen Darwaza, Manek Chowk and market centres near main Gath (Gillion, 1968). In 1456 $A D$, an enclosing wall was constructed defining a periphery to the city-limits. 
The city within this wall got structured into wards, organized by 12 main roads each terminating at a gate in the wall (EuroIndia, 2009).

Famine and development of new centres for manufacturing of textiles resulted in decline of Ahmedabad city since the second quarter of the 17th century. Over and above the revenue taxation and changing political situation of India had led to the further declination of the city until it came under British rule in 1817 . But even after so many ups and downs seen by the city its manufacturing sector thrived through centuries.

The first focus of the British rule was to provide security under the umbrella of a good city government to revive its prosperity. Therefore city taxes were reduced and the connectivity of the city to the northern and central parts of India was improved. As such, the city started to gain its lost prosperity leading to the first setup of a textile mill in 1857 (Bhide, 1976). This had led the city towards a new and modern development that can be understood by the changes in population growth.

\begin{tabular}{|l|c|c|c|}
\hline Year & Population & No. of mills & Workers \\
\hline 1891 & 144,451 & 9 & 7451 \\
\hline 1901 & 181,774 & 29 & 16,887 \\
\hline 1911 & 213,727 & 50 & 31,319 \\
\hline 1921 & 274,007 & 51 & 43,515 \\
\hline 1940 s & & 83 & 125,000 \\
\hline
\end{tabular}

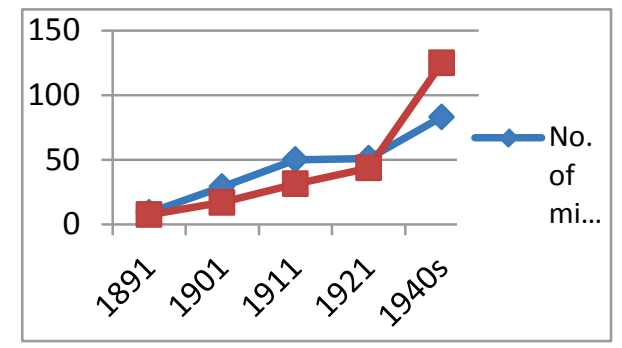

Figure 5 Ahmedabad population and economics, 1891- 1940s Source: adapted from Gillion (1968)

With the further expansion and development of textile mills Ahmedabad became an important centre for textile industry. This had resulted in the growth of population and development in the north, east and south-east with further intensification within the walled city (Figure 2). The western banks of Sabarmati were not yet meant for development because of the poor accessibility.

The major growth of the industrial sector took place in the late 19th and early 20th century which changed the face of the city. Population and development of area grew beyond the administrative boundaries. With the construction of the first bridge, the western banks of Sabarmati opened up to accommodate the expansion of the city (Bhide, 1976). However, since 1920s the textile mills started to see a decline again due to the competitive foreign industries producing a better quality in low prices. This led to the closing of local mills and development of new modern mills. The period from 1950s to 1960 saw a period of decline in the growth of textiles and increased growth in 
the commercial sector. The city was in its full boom and the development extended beyond the limits of the municipal boundaries with development of industries and residences along the major routes in north, east and southeast. The city is governed by Ahmedabad Municipal Corporation (AMC), established in July 1950. In 1960s, the Bombay state was divided and Gujarat state was formed. In its programme of industrialization Ahmedabad was selected as a centre for industrial development at three places- Naroda, Odhav and Vatva i.e. at the northern, eastern and southern fringe of the city. Though still the walled city held the major commercial activities. During the late 1970s the demand for land increased having an impact on the land prices. Though in the late 1990s, a slow and steady change from residential to commercial started to take place along the major roads like Ashram road and sub-arterial roads resulting in new commercial establishments in the west. The industrial development continued to grow in the east part of the city (Figure 6).

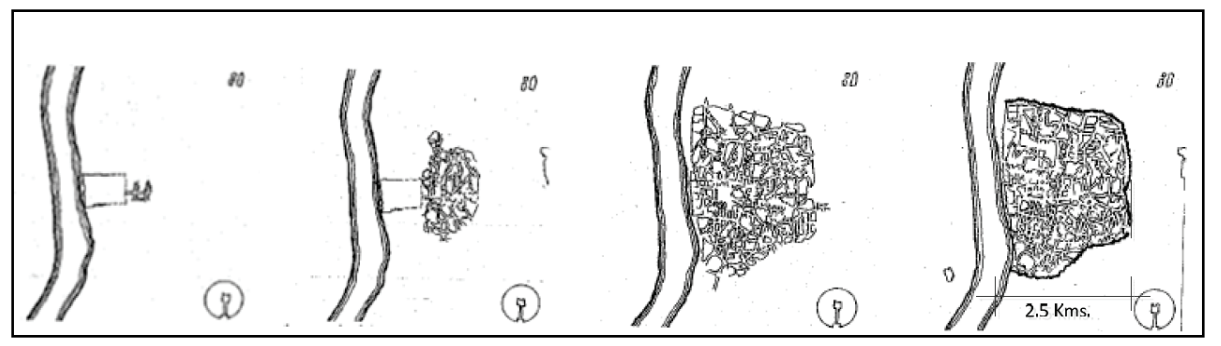

Figure 6 Growth of Ahmedabad from 1411 to 1800

In 2002 a major change in the city's spatial organization took place because of the riots. The riot was spurred by an incident in the nearby city of Godhra. A Hindu-Muslim riot started in Ahmedabad that continued for two and a half months. According to official estimates, members of the Hindu community killed 1180 Muslims, while un-official estimates find that perhaps 5000 Muslims were killed (Chatterjee, 2009). The riot displaced approximately 100,000 Muslims from their homes, often forcing them to resettle in peripheral areas of the city. The economic, cultural, and built landscape was substantively altered (Yagnik and Sheth, 2002). Overnight, Hindu temples and roads were built over destroyed Muslim shrines. This gave a final boost to the already fast developing western part. Emerging features of the western land use after the riots were gated communities. These are residential complexes with commercial areas surrounding them. An interesting feature of this land use is that usually ethnically these gated colonies are homogeneous. 


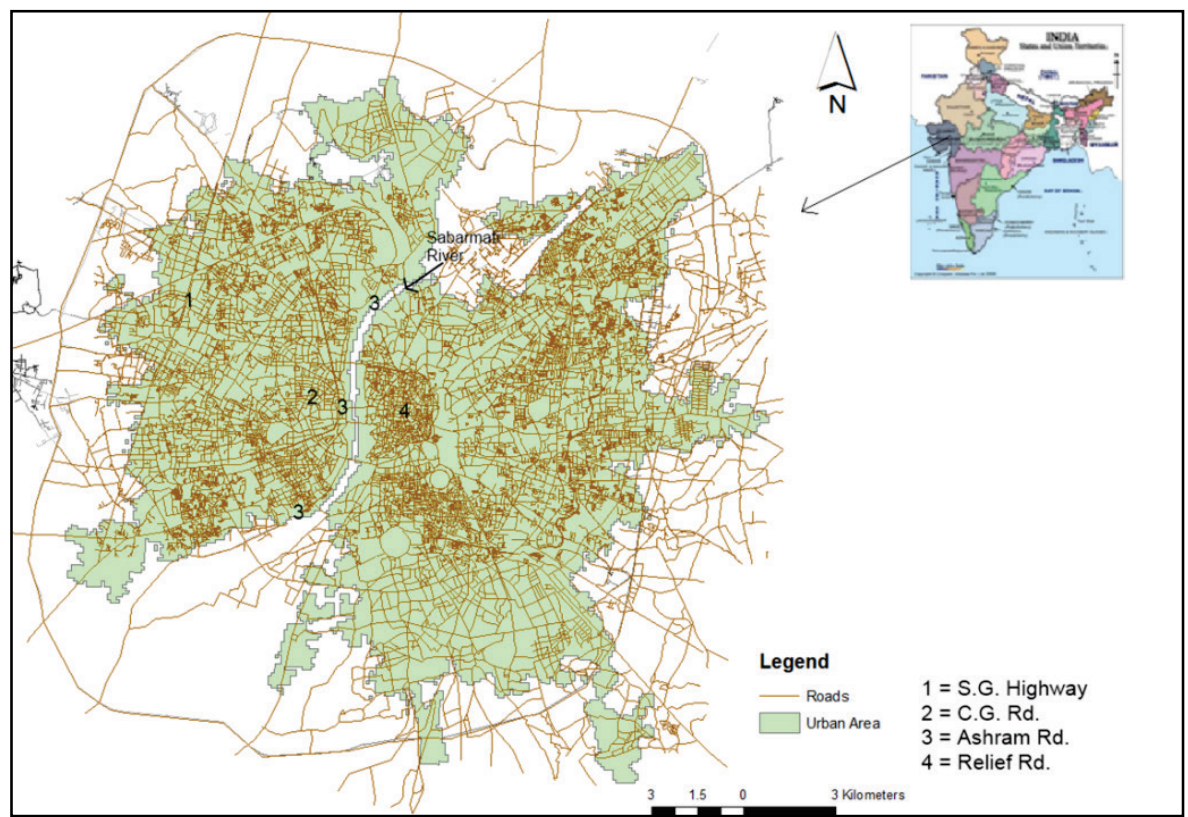

Figure 7 Present map of Ahmedabad

Source: India political urban area (MAPSOFINDIA)

and roads (CARTOSAT-1 December 2007), Google maps

In Gujrat and in Ahmedabad especially, strong kinship ties are very important. Due to these strong kinship ties and the inexpensive way of communicating by phone and internet, people in Ahmedabad are maintaining their social network both physically as by e-communication. Ahmedabad, with a huge hinterland of processing industries reflects the dynamism and challenges of a fast urban growth in the context of a developing economy. This city, with a more or less stable population of industrial workers and traders for many decades have suddenly transformed itself into a city of unprecedented industrial growth. This is due to it being identified as a growth centre for the entire western region of India since independence (Modi, 1991) (Figure 7). Nonetheless, rapid changes brought by economic development coexist with more traditional aspects of social fabric. For instance the society in Ahmedabad is a very well knit society. The kinship bonds are very strong. Sometimes, this closeness is clearly reflected even in the physical layout of the city (Lang, 1994). In the pols of Ahmedabad, there is a close tie between kinship, occupation and a clearly bounded residential territory. A 'pol' (Figure 8 ) is a self-contained neighbourhood, sheltering a large number of people. Some of these pols are virtually small villages, transversed by narrow streets, usually terminating in squares with community wells. These pols were protected by gates, cul-de-sacs and secret passages. The pols are named after the community that inhabited the area. Usually they were named after a 
particular cast or after great men belonging to that specific cast. These poles are inhabited by Gujaratis. Non-gujaratis are rarely seen living in the pols.

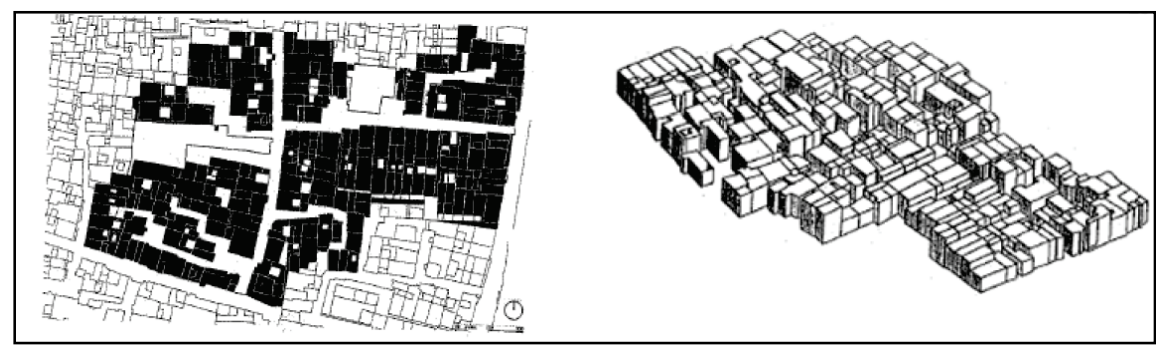

Figure 8 Plan view \& Aerial view of a 'pol'

Source: Munshi (2013)

A large population, low telephony penetration levels, and a rise in consumer spending power have led to Ahmedabad being one of the fastest-growing telecom markets in India. The number of mobile connections grew from a little over 4 hundred in 1997 to over 3 million in 2010. A survey in 2002 on ICT-enabled services ranked Ahmedabad fifth among the top nine most competitive cities in the country (Adhvaryu, 2010). Compared to mobile phones, internet penetration has not been very fast. Ahmedabad has only $8 \%$ internet penetration as compared to $76 \%$ mobile penetration (TRAI, 2010).

In terms of infrastructural networks, Ahmedabad not only has a central position in the heart of Gujarat, but also enjoyed strategic importance. It is well connected to other major cities of India by roadways, railways and airways (Bhatt, 2003). In late 1970's O.N.G.C (Oil and Natural Gas Corporation Limited) started its operations in the 400 wells near Ahmedabad (O.N.G.C., 1956). With the setting up of the national institutions like O.N.G.C. and I.S.R.O (Indian Space Research Organization) the city became of greater importance to the national economy of Western India. At the international level, the city became important due to the diamond trade since the 1960's (Henn, 2010). The diamond trade is a highly clustered trade and is concentrated only in three countries. The Palanpuri gem dealers regards family relationships as an important precondition for carrying out transactions. They also refer to a complex joint family system, meaning that even 'remote' relatives are treated as close family members (Henn, 2012). This makes Ahmedabad a plausible case study because, it has a well-knit social structure (Sapovadia, 2007) and the city is in the process of both rapid economic and social transition. 


\section{Chapter 3}

\section{Using social network analysis to profile people based on their e-communication and travel balance ${ }^{1}$}

\footnotetext{
${ }^{1}$ This chapter is based on Roy, P., A. J. Martínez, G. Miscione, M. H. P. Zuidgeest, and M. F. A. M. van Maarseveen (2012). Using Social Network Analysis to Profile People Based on Their E-Communication and Travel Balance. Journal of Transport Geography, 24, pp.111-22.
} 


\section{Abstract}

The new era of Information and Communication Technologies (ICT) enables people to communicate and interact with each other in new and different manners, changing the way they conduct their daily lives. This change inevitably has significant implications for physical travel in the age of electronic communication (e-communication). This paper aims to provide greater insight into people's travel behavior based on their e-Communication to Travel balance ( $\mathrm{C} / \mathrm{T}$ balance). This balance represents the ratio between an individual's e-communication and physical travel. The analysis studies the relevance of social ties in Ahmedabad, India, as a source of explanation of social activity, thus travel, undertaken by individuals. It is hypothesized that the $\mathrm{C} / \mathrm{T}$ balance emerges from an individual's social network characteristics. The ability of an individual to engage in social activities not only depends on the individual's socioeconomic and lifestyle attributes, but also on the 'modality' of such interactions (e.g. physical travel or e-communication). The different modalities create different social networks. Each network represents a particular flow of potential activity travel generated by interaction between the individuals. These networks have been clustered on the basis of their $\mathrm{C} / \mathrm{T}$ balance to get distinct people's profiles that can be used to target transport and ICT policies better. 


\subsection{Introduction}

This chapter considers the role that social ties play in the travel and communication of people. It is well established that the recent information and communication technologies (ICTs) are fundamentally altering the organization and travel of households, firms and other actors in cities (Mokhtarian, 1990; Rheingold, 2002; Schwanen et al., 2006). The basis of such interactions are new ways in which social life is apparently 'networked' (Urry, 2003). Axhausen (2002) links travel with social networks, arguing that daily life revolves around family, colleagues, friends and shopping. Societies have moved from being based upon strong overlapping membership of social groups to a system of 'networks' today where connections are spatially dispersed and networks do not necessarily overlap with one another.

That there is a relationship between ICT and travel is evident. Various analyses have supported this position (Kenyon, 2006; de Graaff and Rietveld, 2007; Kwan, 2007; Lyons, 2009). The term 'spatial technologies' adopted from Couclelis (1994) is coined as a collective name for transportation, communication and information technologies that modify spatial relationships (Shen, 1998). Salomon (1986) for example has developed a scheme that categorized the potential effects of ICT on travel into two basic types, namely 'substitution' and 'complementarity' (Salomon, 1986). The use of ICT affects people's use of time and increases the spatial and temporal flexibility of their daily activities and travel (Kwan, 2002). People's increased geographical mobility associated with the use of mobile communication has an impact on their travel and trip making behavior (Black, 2001).

The earliest studies into the effect of ICT upon travel by transportation researchers focus largely on the substitution effect of ICT on travel behavior. Several studies used Geo-coded activity-travel data to assess the impact of ICT on travel. They observed a significant reduction in work-related travel and a contraction of activity space as a result of e-communication. Here ecommunication refers to the use of ICT. While in most studies the term ICT refers to the use of mobile phones, wireless personal digital assistants (PDAs), wireless portable computers, wireless messaging devices (e.g. pagers) and combo devices such as Web-enabled PDA cell phones (Kwan, 2006), we limit ICT use in this paper to mobile and landline phones as well as internet. The terms e-communication and e-commuters are used here to indicate the use of these specific types of ICT for the purpose of the study and the case city.

Pendyala et al. (1991) found that e-commuters (people using a certain kind of ICT) not only substantially reduce their trip making and the total distance travelled, but also chose non-work destinations that are closer to home. Koenig et al. (1996) also observed a significant reduction in the number of 
trips and vehicle-miles travelled (VMT) for e-commuters. Another study by Mokhtarian (1990) has similar findings: the share of activities performed close to home increased considerably for e-commuters on e-commuting days (that is days at which one works from home) and there was a contraction in the size of the activity space for e-commuters on e-commuting days. Helminen and Ristimaki (2007) also found that e-commuting reduced total kilometres travelled in Finland, but when the commuting trip exceeds $100 \mathrm{~km}$ a second apartment near the workplace becomes common and has a stronger impact on commuting kilometres travelled.

Other studies suggest that ICT use at home may lead to an increase in nonwork trips and activities. These studies focus largely on the complementarity effect of e-commuting on travel behaviour. For instance, Hodge and Kiosk (1997) observed a considerable reduction in commute-related travel and a slight increase in non-work travel as a result of e-commuting. Kwan (2002) found that e-commuters undertook a significantly higher number of return home, eat meal, shopping, and social/recreation trips on e-commuting days when compared to non-e-commuting days. The results of other studies (Sasaki and Nishii, 2003) also support the tendency for non-work activities and trips to increase as a result of higher level of ICT use. For instance, Shen (2000) found that people working exclusively at home on a given day spent significantly more time shopping on the work day than did persons working away from home. Van de Coevering and Schwanen (2006) observed a predominant effect of generation, which occurs when the use of one mode increases the use of another (e.g., the greater the availability of information about activities and people of interest, the greater the travel to participate in those activities or meet those people). Even the most humble introduction of ICT (the mobile phone) was able to increase the average travel distance of fishermen in Kerala, India (Foss and Couclelis, 2009). Thus, it is found that increasing use of ICT is unlikely to reduce travel significantly.

The above studies establish that ICT is fundamentally changing the way people move around in the city. They conclude travel either increases or decreases. However, individuals do not only use ICT to complement travel they also use ICT to substitute travel. The earlier studies have looked into an 'either or' situation, but they have not studies an 'and' situation, where both substitution and complement can happen simultaneously. In this study we will look into this balancing of substitution and complementarity which individuals undertake in maintaining their social ties i.e. social networks.

All the earlier studies suggest ICT use, as well as any associated travel impacts, is highly dependent on a variety of demographic, incidental, accessibility, and activity-related factors (Lu and Pas, 1999). Fox (1995) found that some factors that have influenced travel were environmental 
consciousness, costs, budget restrictions and the changing socioeconomic aspects of society. Zhang et al. (2008) found that in the same age groups there was a significant difference in travel behaviour between males and females in Beijing. Haustein et al. (2009) observed that travel of young Germans were influenced by peer pressure, level of socializing and communication with parents.

One main difficulty in explaining the impacts of ICT on travel is identifying the likely activities in which individuals will choose to engage. For example, it is easy to roughly assess how someone who begins to e-commute may reduce his or her physical travel. But what other types of travel that person may engage in, with the saved time is difficult to assess (Choo and Mokhtarian, 2007). However, if a closer look is taken into the social networks of the individuals it is possible to empirically generate data which can then be used to calculate whether travel is being substituted or complemented by ICT (Axhausen, 2008). This is because through social network we can explain why travel is generated and how through social ties travel is maintained. Social networks take into account factors that affect travel and then try to explain if travel is substituted or complemented through ICT.

\subsubsection{ICT and Ahmedabad, India}

Ahmedabad is the case study. Ahmedabad is the largest city in Gujarat, India. It is the seventh largest city and seventh largest metropolitan area of India, with a metropolitan population of 4.2 million. In 2010, the Forbes magazine rated Ahmedabad as the fastest growing city in India, and third in the world. With the city's population, the telecom industry of Ahmedabad also has grown over the years. A large population, low telephony penetration levels, and a rise in consumer spending power have led to Ahmedabad being one of the fastest-growing telecom markets in India. The number of mobile connections grew from a little over 4 hundred in 1997 to over 3 million in 2010. A survey in 2002 on IT-enabled services ranked Ahmedabad fifth among the top nine most competitive cities in the country (Adhvaryu, 2010). Compared to mobile phones, internet penetration has not been very fast. Ahmedabad has only $8 \%$ internet penetration as compared to $76 \%$ mobile penetration (TRAI, 2010).

Ahmedabad has a wide range of transport modes ranging from private cars to two wheelers (two wheeled motorized vehicles that are gasoline-powered scooters and motorcycles (ADB, 2009)) to government run public transport. The number of registered vehicles in Ahmedabad grew from 1.1 million in 1999, to 2.8 million in 2010. Among the number of registered vehicles twowheelers account for around $70 \%-72 \%$ of total vehicles registered. This is an indirect indication of derelict state of public transport (bus) services in 
Ahmedabad (GoG, 2010). Only 0.9 million commuters use the public transport everyday which is only $0.8 \%$ of traffic on the roads

Ahmedabad is home to a large cosmopolitan population. Due to the high industrialization rate the city has attracted people from all over the central and western region of India. So, in Ahmedabad people from all regions of India can be found. A distinct feature of Ahmedabad is its peaceful coexistence of the old walled city and the new city. The city is like any other Indian city with distinct characteristics of its own. The Gujratis believe in strong kinship ties, slightly less than half of all real estate (30\%) (Sapovadia, 2007) in Ahmedabad is owned by "community organizations" (i.e. cooperatives), and the spatial growth of the city to a large extent is contributes to the number of these organizations. All these make Ahmedabad a good choice for the study because in Ahmedabad people have strong social networks and they use e-communication and physical travel to maintain their relations.

\subsection{Theoretical Framework}

The earlier empirical studies show that there exists a relationship between ICT and travel (Nie et al., 2002; Muhammad, 2007). Some suggest an increase in travel while others suggest a decrease in travel. Although most models aimed at understanding travel behaviour and ICT are able to explain the "generation" of trips, they still heavily rely on the individual's socioeconomic characteristics. But these studies generally overlook the social setting of the individual which to some extent explains the "maintenance" and "longevity" of such trips. Thus a better approach to understand the generation, maintenance and longevity of individual activity and travel in general, would be to look into the elements that are less measurable in terms of costs and socioeconomics, as already pointed out by Chapin (1974). In such a situation it is important to study the individual's social network characteristics to explain the effects of an individual's social setting on travel/communication decisions, and how these effects can be correctly measured and used to cluster people accordingly.

Individuals in their conduct of activities come into contact with other people and start participating in social networks. Once involved, these networks need maintenance and induce travel, thereby impacting upon the scheduling of activities, in time and in space. Participation in these networks then leads to diffusion of knowledge, triggering new activity-travel bundles and changes in travel. Depending on their binding element, social networks are also dismantled, leading to changing travel patterns. Travel emerges from the individual's social networks, or, in other words, they can be inferred in part from knowing individuals' social network characteristics. Maintenance and 
longevity of these networks in turn increase or decrease physical travel (Carrasco and Miller, 2006).

Usually communication between people via ICT applications does not take place independently of physical contacts; the various communication modes/services can be regarded as communicating vessels. Mokhtarian (1990)and Salomon (1986) suggest that the interaction between the two can take on various forms: substitution (e.g. electronic communication reduces the number of physical contacts); complementarity (e.g. electronic communication stimulates physical contacts); modification or changes in the nature, temporal and spatial locations of physical and electronic communications; or neutrality (no impact of one mode/service on the other). On the basis of literature, we look at the relationships between social contacts and the use of electronic communication modes and services and travel.

The commencement of any travel can be explained by the individual's propensity and opportunity to engage in a social activity (Chapin, 1974). Propensity not only depends on the individual's socioeconomic and lifestyle attributes (profiles of people) (Carrasco and Miller, 2006), but also on with whom individuals perform social activities(e.g., family, friends or colleagues), these people constitute the individual's social network, and also on their related communication patterns (e.g. frequency and type of ICT used). As a consequence, ties or links between the individual and other people in the network represent a flow of potential activity travel generated by the interaction between those 'nodes' of individuals.

There is literature regarding the interaction between communication and travel (Pendyala et al., 1991; Kwan, 2006; Nobis and Lenz, 2009) and to a somewhat lesser extent regarding the influence of relational and geographical distance on communication (Dugundji et al., 2008). We find some gaps in literature in this regard. Firstly, many studies which focus on the effects of ICT on travel focus mainly on internet use rather than taking all electronic communication per se, even though there are results showing that talking over the phone, SMS and chat are important in maintaining the social networks. Secondly, with some recent exceptions e.g. (Axhausen, 2002; Arentze and Timmermans, 2008; Carrasco et al., 2008) there are few investigations at the level of social networks. And even amongst the few studies that have been done, only a sample part of the ego's (individual's) network is used for the study so as to constrain the workload of the respondent (Tillema et al., 2010). Finally, due to a large variation in sociocultural and spatial context, results from empirical studies are not immediately transferable to other countries, like India in this case. 
In this chapter, we will address these gaps by investigating the trade-offs between e-communication use and travel that emerges from the individual's social network in India, on the basis of empirical data. For this purpose we have applied a simplified social network approach by focusing on communications (both virtual and physical) between a specified person (in this case the respondent) and other network members ('egocentric social network approach'). In the study we assume that the whole is sum of its parts and the overall behaviour is the sum of individual behaviour. Thus, behaviour is explained not only through personal attributes but also through social structural attributes that incorporate the interaction among the different social network members.

Thus, to incorporate the social structural attributes in this study, we try to identify clusters or homogeneous profiles based on the trade-offs between ecommunication and physical travel. The homogeneous profiles created will possess within group homogeneity and between group heterogeneity.

Axhausen (2002) remarks "the need to underpin our travel models with a better understanding of the social structures of daily life and, as we implicitly forecast/speculate about them we predict travel behaviour over long time horizons, anyway..". In this chapter we will address the social structure part by trying to understand the social dimension as an attribute of a social activity. For example, we might visit an elderly lady once a week, traveling one hour not because we live at an hour's distance and she is a nice lady but because she is our grandmother (Carrasco and Miller, 2006). Also this once a week travel may become everyday travel if we come to know over the telephone (or any other way) that she is sick and needs help. Hence travel behaviour is cause/changed because of our social links (social networks).

\subsection{Methodology}

\subsubsection{Social Network characteristics and their relation to communication/travel balance.}

A social network is a social structure made of individuals (or organizations) called "nodes," which are tied (connected) by one or more specific types of interdependency, such as friendship, kinship, financial exchange, dislike, sexual relationships, or relationships of beliefs, knowledge or prestige. Social network analysis views social relationships in terms of network theory about nodes and ties. Nodes are the individual actors within the networks, and ties are the relationships between the actors. The resulting graph-based structures are often very complex. There can be many kinds of ties between the nodes (Table 1 ). 
Social Network Analysis is based on the importance of relationships among interacting units. The Social Network perspective encompasses models and applications that are expressed in terms of relations, concepts or processes. That is, relations defined by the linkages among units are a fundamental component of network theories. Of critical importance for the development of methods for Social Network Analysis is the fact that the unit of analysis is not the individual but an entity consisting of a collection of individuals and the linkages among them. So it is easy to locate the changes that take place in a linkage and investigate the reasons for such changes (Wasserman and Faust, 1997).

Each network has certain characteristics pertaining to the ego and the ego's network. The characteristics that are used for the analysis of the networks of the ego and the classification into homogeneous profiles are listed below. 
Table 1 Relation between social network concepts and e-communication and travel (C/T)

\begin{tabular}{|c|c|c|}
\hline Concept & Definition & Relation to e-communication and travel $(\mathrm{C} / \mathrm{T})$ \\
\hline Closeness & $\begin{array}{l}\text { Closeness provides the degree an individual } \\
\text { is near all other individuals in a network } \\
\text { (directly or indirectly). It reflects the ability to } \\
\text { access information through the network } \\
\text { members. Thus, closeness is the inverse of } \\
\text { the sum of the shortest distances between } \\
\text { each individual and every other person in the } \\
\text { network. }\end{array}$ & $\begin{array}{l}\text { Closeness is important for } \mathrm{C} / \mathrm{T} \text { because one has } \\
\text { to either travel physically or communicate } \\
\text { virtually (or do both) to maintain the network. }\end{array}$ \\
\hline $\begin{array}{l}\text { Average } \\
\text { Degree }\end{array}$ & $\begin{array}{l}\text { Average degree provides the count of the } \\
\text { number of ties to other actors in the network } \\
\text { (Bruggeman, 2008). }\end{array}$ & $\begin{array}{l}\text { The higher the degree the more number of } \\
\text { people know each other, the lower number of } \\
\text { degree the lesser number of people know each } \\
\text { other, which might or might not have an effect } \\
\text { on one's communication and travel (virtual and } \\
\text { physical). So in order to enquire if this number } \\
\text { of contacts has an effect on people's C/T this } \\
\text { variable is necessary. }\end{array}$ \\
\hline Density & $\begin{array}{l}\text { Density is the ratio of the actual number of } \\
\text { relationships between people observed in the } \\
\text { network and the total number of relationships } \\
\text { that are possible within the network } \\
\text { (Wasserman and Faust, 1997). It is a } \\
\text { measure of the global clustering of the } \\
\text { network. }\end{array}$ & $\begin{array}{l}\text { Density shows how well everyone is connected } \\
\text { in the network. The relevance of density to } \\
\text { transport and communication is that we assume } \\
\text { higher the density more the interaction via } \\
\text { communication and transport and vice versa. }\end{array}$ \\
\hline Diameter & $\begin{array}{l}\text { The diameter of a network is the length } \\
\text { (edges) of the longest path between any two } \\
\text { nodes. This is same like closeness but gives } \\
\text { the absolute number of vertices. This gives } \\
\text { the maximum number of vertices information } \\
\text { has to travel to reach all the members in the } \\
\text { network. }\end{array}$ & $\begin{array}{l}\text { Diameter is important for the C/T because the } \\
\text { bigger the diameter the more is the chance of } \\
\text { individuals shifting to e-communication for } \\
\text { maintaining the networks (Tillema et al., 2010). }\end{array}$ \\
\hline Path Length & $\begin{array}{l}\text { The distances between pairs of nodes in the } \\
\text { network. Average path-length is the average } \\
\text { of these distances between all pairs of nodes } \\
\text { (Bruggeman, 2008). This is also like } \\
\text { closeness but the difference is that closeness } \\
\text { takes into account the indirect ties also but } \\
\text { path length only takes into consideration the } \\
\text { direct ties. Also it is directly opposite of } \\
\text { diameter. }\end{array}$ & $\begin{array}{l}\text { Path length is important when dealing with one's } \\
\text { C/T because, some information travel virtually } \\
\text { (e.g. information can be posted on face book } \\
\text { and people will get to know) while some others } \\
\text { have to be passed on directly (e.g. buying milk } \\
\text { from the milk man). }\end{array}$ \\
\hline Transitivity & $\begin{array}{l}\text { Transitivity is also a measure of the whole } \\
\text { network. Transitivity is the proportion of } \\
\text { someone's contacts that are mutually } \\
\text { connected with each other. Transitivity is also } \\
\text { a measure of 'local clustering'. If on an } \\
\text { average people are highly interconnected, } \\
\text { local clustering is high; if they are mostly } \\
\text { disconnected, clustering is low. This gives a } \\
\text { comparison with density as it gives a } \\
\text { comparison between local and global } \\
\text { clustering }\end{array}$ & $\begin{array}{l}\text { Transitivity is important for the } \mathrm{C} / \mathrm{T} \text { because } \\
\text { when individuals belong to different profile (e.g. } \\
\text { social clubs) their transitivity becomes high } \\
\text { while the density remains low. This can be used } \\
\text { to explain their particular C/T behavior. }\end{array}$ \\
\hline Vertices & $\begin{array}{l}\text { Networks are made up of nodes or people } \\
\text { (vertices), which could be the junctions or } \\
\text { terminals i.e. the number of people in the } \\
\text { network. This variable shows how big or small } \\
\text { a person's network actually is. }\end{array}$ & $\begin{array}{l}\text { It's important for the C/T because it is usually } \\
\text { found that the more people one knows more is } \\
\text { he/she has to either physically travel or virtually } \\
\text { communicate to maintain the relation (Tillema et } \\
\text { al., 2010). }\end{array}$ \\
\hline
\end{tabular}




\subsubsection{Data Preparation for creating the clusters}

To gain greater insight into people's e-communication for interacting with members within their social network and into the interaction between ecommunications and physical communication we have to first and foremost distribute the individual's network attributes in groups, thereby creating homogeneous subgroups, characterized by within group similarity and between group differences. These distributions create a distinctive social context to which individuals respond. As homogeneity increases, these differences are increasingly likely to acquire meaning to subgroup members thus to influence social behaviour (Lawrence and Zyphur, 2010).

In the chapter we create the social network of the individual based on an extensive questionnaire survey. We choose the 'egocentric' approach because in 'whole-network' studies the number of individuals are usually predefined (Marsden, 2005). Since data was collected in an urban setting with a large population (lists of the population are not known in advance or are too long), it was difficult to predefine the population and the wholenetwork study was impractical, making egocentric data collection a more feasible method. An egocentric approach studies specific actors or 'egos' and those who have relations with them, called 'alters'. That is, from the respondent's perspective, egocentric networks constitute a 'network of me' or a network of actors (ego) with whom the respondent has some relationship (alters).The questionnaire was designed explicitly to collect data about the individual's social network using an egocentric scheme (Kowald et al., 2010), constituted by the social structure of specific individuals (ego), and the interplay between their social activities and social networks. More explicitly the objective of the data collection is to gather a data set that can help to study the effects of travel in the aspects of (i) their generation (ii) their maintenance and longevity through the social networks and (iii) effective clustering of the networks so as to study the different profiles emerging out of such clustering.

We collected data through 436 questionnaires in the city of Ahmedabad, India between August and October 2010. The sampling strategy consisted of a single stage cluster sampling. Within each administrative ward respondents were randomly selected via a systematic sampling approach. It was an interviewer-led survey.

We surveyed the area of Ahmedabad Municipal Corporation (AMC) jurisdiction. AMC has 43 administrative wards and 8 outgrowths (area added to the jurisdiction of AMC after 2007). For our questionnaires we took into consideration the total population of a particular ward. And what percentage of that population resides in that ward compared to the total population. 
Then the same proportion of sampling units was selected in that ward. And the individuals from that ward were selected randomly at an interval of 5 households. If the individual from one household was not available we shifted to the next household. The total number of questionnaires stood at 436 (Figure 9).

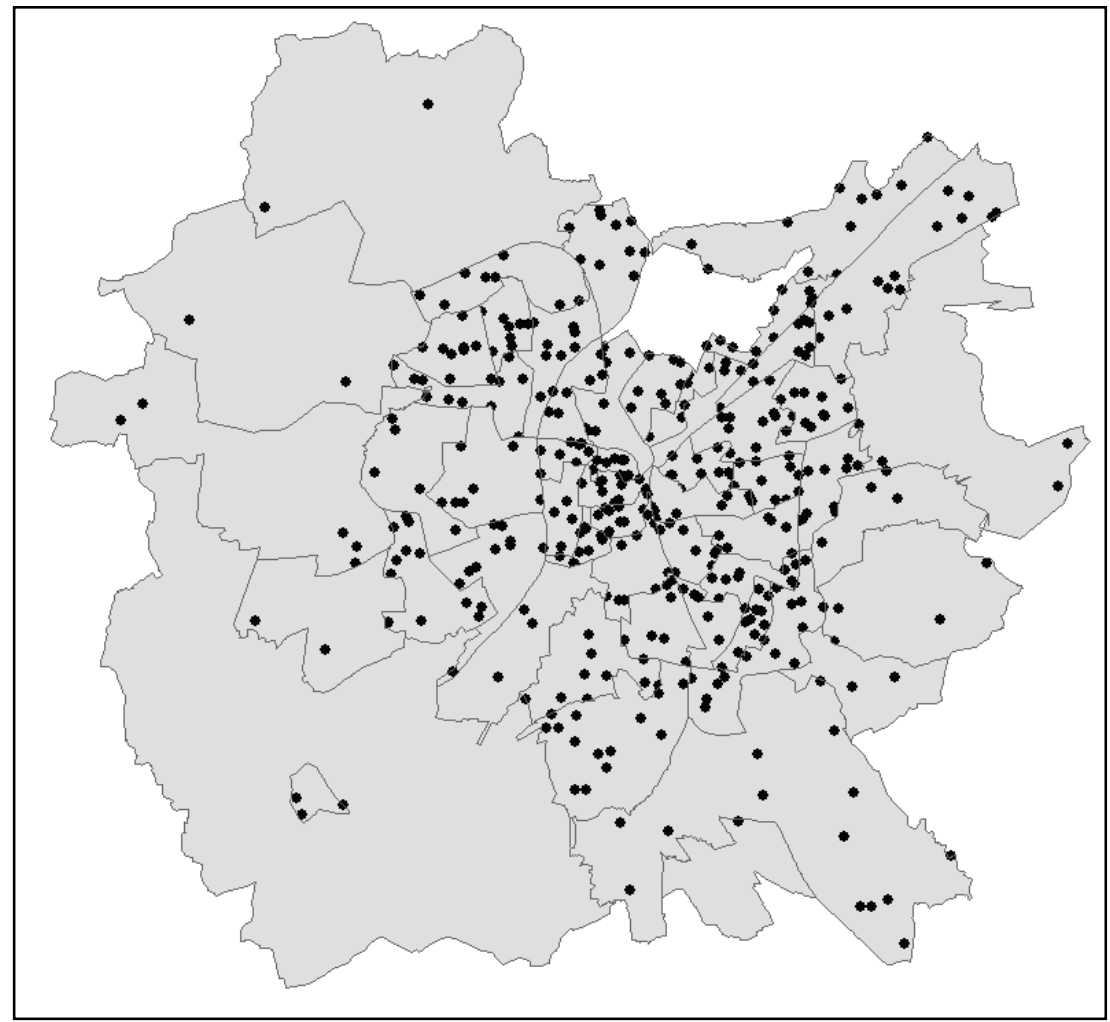

Figure 9 Spatial distribution of the sample

The questionnaire contained questions regarding

- socioeconomic background and lifestyle, (e.g. age, gender, literacy level)

- ICT use in general and with regard to social contacts in particular. With respect to the latter, respondents were asked to state with which colleagues, relatives (excluding household members) friends and acquaintances did they communicate most frequently (at least once a month through either virtual or physical communication). The questionnaire specified one month because it would be difficult for the respondent to remember his/her activities for more than one month.

- We chose to select friends, relatives, colleagues and acquaintances because they represent important parts of people's social networks and because questions regarding characteristics of these network relationships are easy for respondents to answer. The reason for 
choosing family, friends, relatives and colleagues is that they represent the strong ties of a person. The acquaintances represent the weak ties of a person. We specify if the ego communicates (either physically or electronically) with their acquaintances because there could be absent ties; that two people know each other does not qualify them as weak ties, in fact it is an 'absent' tie (Granovetter, 1973) .

- Respondents were asked to indicate how often they were in touch with each alter via electronic means (i.e. phone, email, internet) and face to face on a four-point scale ranging from 'everyday' (1) to 'once a month' (4). We also asked respondents to provide the place of residence of their relatives, friends and acquaintances. For colleagues, we assumed that the respondents communicated with them at the work place. A distinction was made between relatives (excluding household members), friends, acquaintances and colleagues.

From the 436 responses we then derived the physical and virtual social networks of each person based on their modes of communication i.e. face to face and electronic (e-mails, phone, SMS and chat). The social networks were based on the number of times a person communicated his/her alters either physically or electronically. This resulted in two networks for each respondent one for their e-communication and one for their physical travel. Each network had 7 characteristics (Table 1) and each character had a value. So now we had two tables each with the value of 7 characteristics for every ego. Based on the details of these $872(436 \times 2)$ social network tables we created the communication/travel ratios of each of the characteristics by dividing the physical travel values with the e-communication values (table 2 ). Then we created boxplots for the 436 respondents to find out the outliers. Based on an analysis of boxplots we found that 18 respondents were extreme outliers and we decided to exclude them from the final analysis. So from the 436 questionnaires we arrived at 418 valid questionnaires.

Table 2 Measurement of the $\mathrm{C} / \mathrm{T}$ ratio

\begin{tabular}{|l|c|c|c|c|c|c|c|}
\hline & Density & $\begin{array}{l}\text { Transi- } \\
\text { tivity }\end{array}$ & Vertices & Diameter & $\begin{array}{l}\text { Path } \\
\text { Length }\end{array}$ & Degree & $\begin{array}{l}\text { Close- } \\
\text { ness }\end{array}$ \\
\hline $\begin{array}{l}\text { physical } \\
\text { travel }\end{array}$ & 0.4697 & 0.5714 & 12 & 2 & 1.6818 & 5.3103 & 0.08 \\
\hline $\begin{array}{l}\text { e- } \\
\text { commu- } \\
\text { nication }\end{array}$ & 0.6264 & 0.9592 & 14 & 3 & 1.8352 & 4.5 & 0.09 \\
\hline $\begin{array}{l}\text { C/T } \\
\text { Ratio }\end{array}$ & 0.74 & 0.59 & 0.85 & 0.66 & 0.91 & 1.17 & 0.88 \\
\hline
\end{tabular}


Now for the 418 valid questionnaires, we had the $C / T$ ratios of all the 7 characteristics (Table 2). In order to cluster the egos based on their $\mathrm{C} / \mathrm{T}$ ratios, we apply the K-means clustering method on the 7 characteristics of the 418 questionnaires (Table 3). K-means (MacQueen, 1967; Lin et al., 2010 ) is one of the simplest unsupervised learning algorithms that solves the clustering problem. The fundamental idea of $\mathrm{K}$-means classification is to look for $\mathrm{K}$ averages or mean values, about which the data can be clustered around similar observations. The simple task of $\mathrm{K}$-means is to find $\mathrm{K}$ 'cluster centers', and then associate each point $\mathrm{p}$ with the cluster whose center is nearest to the point. K-means clustering is done when the study needs a good set of cluster center values.

Table 3 Cluster centres of the C/T balance

\begin{tabular}{|l|c|c|c|c|c|}
\hline \multirow{2}{*}{ Characteristics } & \multicolumn{5}{l}{} \\
\cline { 2 - 6 } & \multicolumn{7}{|l}{ Cluster Centres } & \multicolumn{1}{l|}{} \\
\hline Density & 1 & 2 & 3 & 4 & 5 \\
\hline Transitivity & .837 & 3.425 & 1.946 & 1.021 & 1.065 \\
\hline Vertices & 2.806 & .395 & .617 & .561 & .971 \\
\hline Diameter & 1.295 & .760 & .941 & 1.622 & .848 \\
\hline Path Length & 1.313 & .715 & .883 & 1.259 & .985 \\
\hline Degree & 1.444 & 1.184 & 1.143 & .914 & .989 \\
\hline Closeness & .791 & 1.474 & 1.156 & .799 & 1.019 \\
\hline
\end{tabular}

\subsection{Profiling people according to their C/T Balance}

The K-means clustering was applied to the $\mathrm{C} / \mathrm{T}$ ratios of the 418 egos. The outcome was the communication/travel balance ( $C / T$ Balance). The $C / T$ balance can be defined as the ratio between an individual's e-communication and physical travel.

There is also difference between the clusters in a 5 cluster analysis. We find a between cluster difference visible (Table 4) suggesting that there is the highest difference between the characteristics of egos in cluster 1 and cluster 2. This table shows the Euclidean distances (the distance between two points that is computed by joining them with a straight line) between the final cluster centers. Greater distances between clusters correspond to greater dissimilarities. 
Table 4 Euclidean distances between clusters

\begin{tabular}{|c|c|c|c|c|c|}
\hline Cluster & 1 & 2 & 3 & 4 & 5 \\
\hline 1 & & 4.013 & 2.754 & 2.030 & 2.071 \\
\hline 2 & & & 1.585 & 2.813 & 2.556 \\
\hline 3 & & & & 1.336 & 1.006 \\
\hline 4 & & & & & .857 \\
\hline 5 & & & & & \\
\hline
\end{tabular}

Table 5 Number of observations in each cluster

\begin{tabular}{|l|c|c|}
\hline Clusters & $\begin{array}{l}\text { Number of } \\
\text { observations }\end{array}$ & $\begin{array}{l}\text { Percentage of } \\
\text { observations }\end{array}$ \\
\hline 1 & 23 & $6 \%$ \\
\hline 2 & 36 & $9 \%$ \\
\hline 3 & 109 & $26 \%$ \\
\hline 4 & 90 & $21 \%$ \\
\hline 5 & 160 & $38 \%$ \\
\hline Total & 418 & $100 \%$ \\
\hline
\end{tabular}

The highest numbers of cases were in cluster 5 with about $38 \%$ of the egos in the cluster, followed by cluster 3 with $26 \%$. Cluster 4 has $21 \%$ of the egos while cluster 2 has $9 \%$ of the egos. Lowest was cluster 1 with only $6 \%$ of the total number of egos (Table 5). We preferred to carry on the analysis with 5 clusters because; in a 4 or 3 cluster analysis one cluster was assigned a large number of observations which made the clustering skewed. That in turn made the analysis and explanation difficult.

\subsubsection{Cluster 1. Easy riders}

Cluster 1 represents egos with low e-communication and high physical communication (Table 3). They prefer to maintain their social networks through physical travel; hence they are termed easy riders (Figure 10). The vertices ratio is 2.8 , which is the highest among all the clusters, meaning egos in this category prefer to maintain their social networks with very few alters virtually and more alters physically. Also the path length is 1.3 suggesting the egos belonging to this profile communicate with their alters physically 1.3 times higher than they do virtually (Table 6). This cluster scores lower on physical density, transitivity and degree, one possible 
explanation could be due to the higher amount of effort involved in communicating physically especially in terms of cost and time.
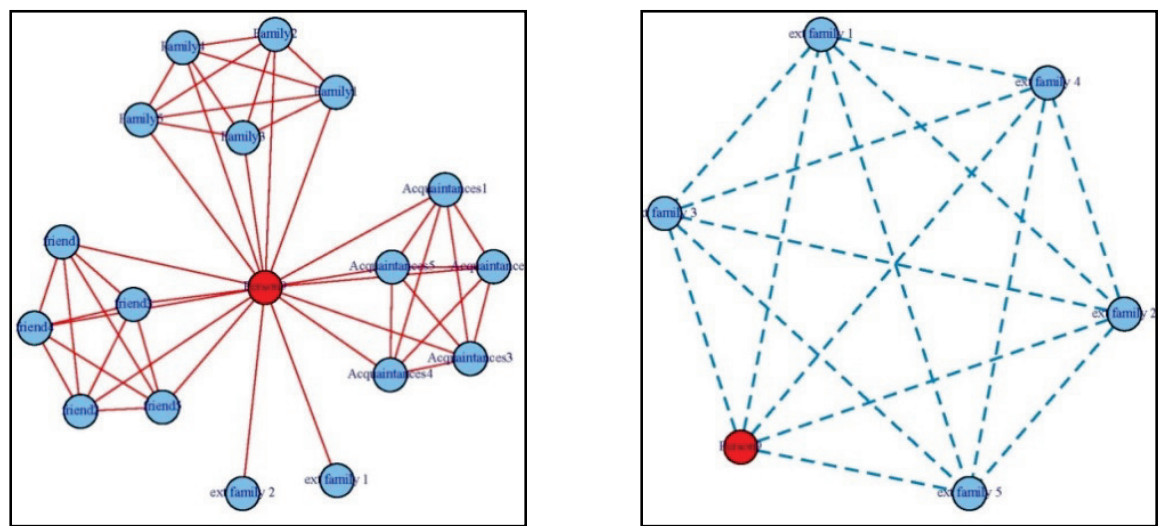

Figure 10 Physical travel (left) and E-communication (right) of a typical person in cluster 1

Table $5 \mathrm{C} / \mathrm{T}$ balance score of a typical person in cluster 1

\begin{tabular}{|l|c|l|c|c|c|c|c|}
\hline $\begin{array}{l}\text { Charac- } \\
\text { teristics }\end{array}$ & Density & $\begin{array}{l}\text { Transi- } \\
\text { tivity }\end{array}$ & Vertices & Diameter & $\begin{array}{l}\text { Path } \\
\text { Length }\end{array}$ & Degree & $\begin{array}{l}\text { Close- } \\
\text { ness }\end{array}$ \\
\hline C/T ratios & 0.366 & 0.785 & 2.833 & 1.000 & 1.391 & 1.171 & 1.143 \\
\hline
\end{tabular}

\subsubsection{Cluster 2. 'I' Generation}

Cluster 2 represents a very virtual profile of egos (Table 3). This Cluster scores low on vertices suggesting egos belonging to this cluster communicate with a very small number of alters physically. But an important feature of this cluster is that the global density (density) is very high (highest among all the clusters) but local density (transitivity) is not as high in comparison meaning egos in this cluster might be members of different profile with inter group connections but no intra profile connections (Figure 11) and (Table 7). The reason for the highest closeness could be since egos are highly virtual in this profile spreading information is easier with practically no effort thereby establishing high communication with very little effort and cost. 

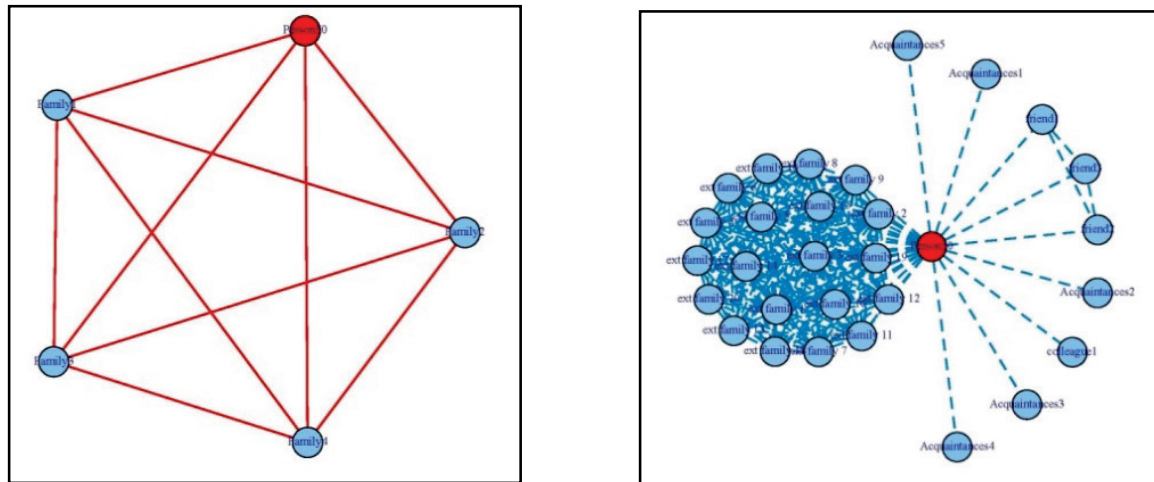

Figure 11 Physical travel (left) and E-communication (right) of a typical person in cluster 2

Table $6 \mathrm{C} / \mathrm{T}$ balance score of a typical person in cluster 2

\begin{tabular}{|l|c|c|c|c|c|c|c|}
\hline $\begin{array}{l}\text { Charac- } \\
\text { teristics }\end{array}$ & Density & $\begin{array}{l}\text { Transi- } \\
\text { tivity }\end{array}$ & Vertices & Diameter & $\begin{array}{l}\text { Path } \\
\text { Length }\end{array}$ & Degree & $\begin{array}{l}\text { Close- } \\
\text { ness }\end{array}$ \\
\hline $\mathrm{C} / \mathrm{T}$ ratios & 3.093 & 1.053 & 0.167 & 0.500 & 0.671 & 0.427 & 0.718 \\
\hline
\end{tabular}

\subsubsection{Cluster 3. Well connected}

Cluster 3 represents a profile of egos that have nearly equal numbers of virtual and physical connections but slightly inclined towards ecommunication (Table 3). Most of the ratios in this category tend to be near 1 or just a little bit over 1 suggesting equal weights in both physical and ecommunication. However, the vertices ratio is 0.7 (Table 8 ) indicating egos in this profile communicate with more alters virtually than physically (Figure 12). Another feature is that this cluster scores highly on both local and global clustering and closeness suggesting that they tend to generate relationships with very few people but the few people they generate a relationship with know each other, e.g. egos in this profiles could have very high number of family and extended family members, with who they equally communicate both physically and virtually.
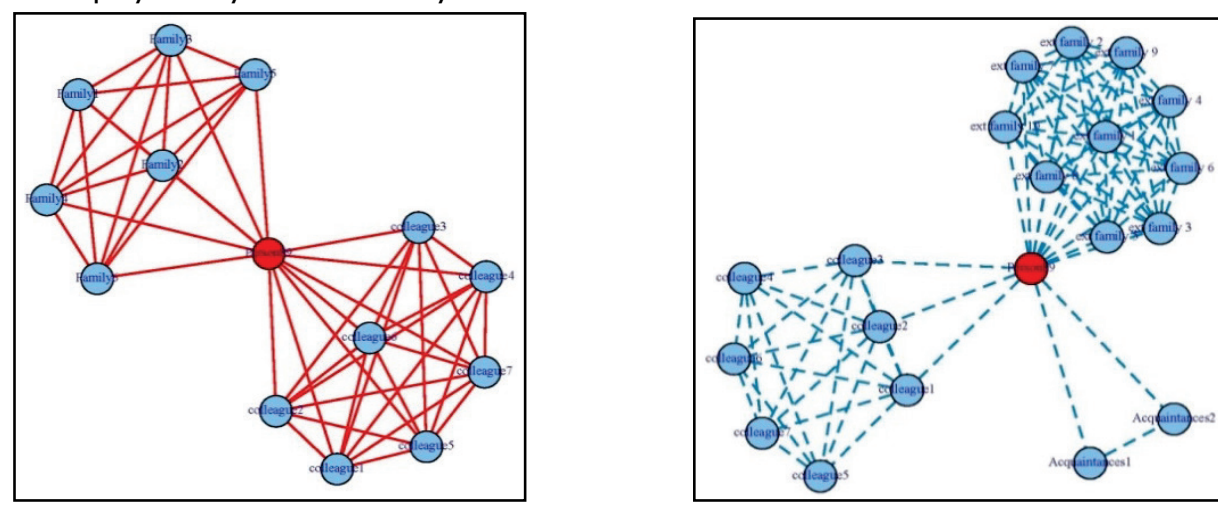

Figure 12 Physical travel (left) and E-communication (right) of a typical person in cluster 3 
Table 7 C/T balance score of a typical person in cluster 3

\begin{tabular}{|l|l|l|l|l|l|l|l|}
\hline $\begin{array}{l}\text { Charac- } \\
\text { teristics }\end{array}$ & $\begin{array}{l}\text { Densit } \\
\mathrm{y}\end{array}$ & $\begin{array}{l}\text { Transi- } \\
\text { tivity }\end{array}$ & Vertices & Diameter & $\begin{array}{l}\text { Path } \\
\text { Length }\end{array}$ & Degree & $\begin{array}{l}\text { Close- } \\
\text { ness }\end{array}$ \\
\hline $\mathrm{C} / \mathrm{T}$ ratios & 1.723 & 0.963 & 0.700 & 0.667 & 0.803 & 1.179 & 1.232 \\
\hline
\end{tabular}

\subsubsection{Cluster 4. Popular people}

Egos belonging to cluster 4 are difficult to place in a high or low C/T balance profile (Table 3). They are a unique profile of ego who do not communicate with many people physically (vertices score is 0.5 ), but the diameter (the absolute number of people connected physically) is the highest (Figure 13) and (Table 9). Also the shortest path is more physical than virtual (path length score is high). The explanation of such a $\mathrm{C} / \mathrm{T}$ balance could be that this profile of egos has a high number of acquaintances who they communicate with virtually and also physically, e.g. a shopkeeper or a politician. This might also explain the global and local clustering being nearly the same.
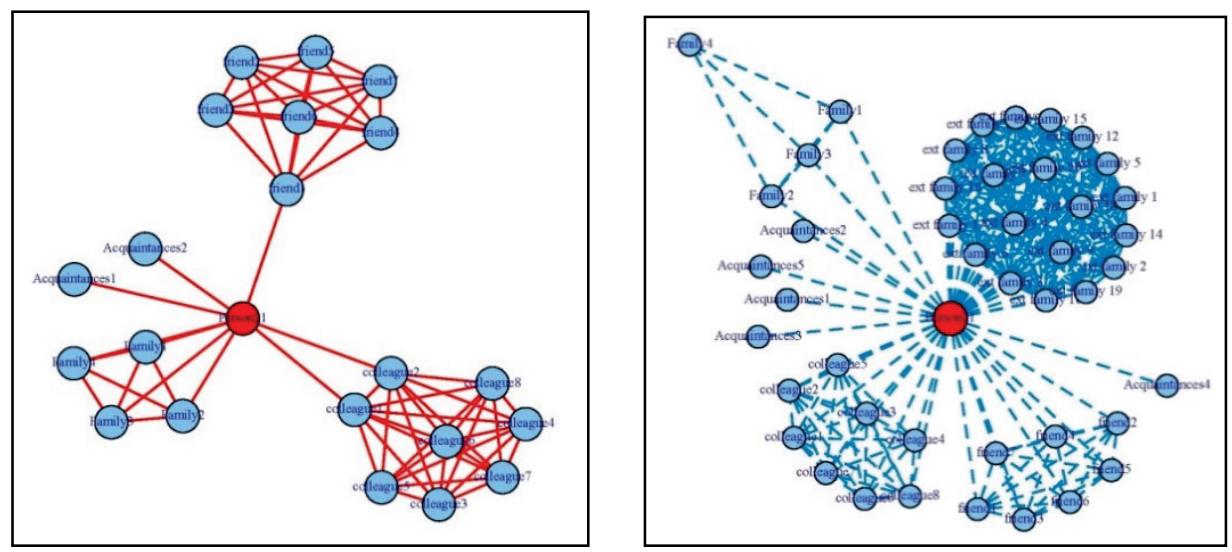

Figure 13 Physical travel (left) and E-communication (right) of a typical person in cluster 4

Table $8 \mathrm{C} / \mathrm{T}$ balance score of a typical person in cluster 4

\begin{tabular}{|l|l|l|l|l|l|l|l|}
\hline $\begin{array}{l}\text { Charac- } \\
\text { teristics }\end{array}$ & Density & $\begin{array}{l}\text { Transi- } \\
\text { tivity }\end{array}$ & Vertices & Diameter & $\begin{array}{l}\text { Path } \\
\text { Length }\end{array}$ & Degree & $\begin{array}{l}\text { Close- } \\
\text { ness }\end{array}$ \\
\hline $\mathrm{C} / \mathrm{T}$ ratios & 1.487 & 0.997 & 0.489 & 1.333 & 1.386 & 0.710 & 0.724 \\
\hline
\end{tabular}

\subsubsection{Cluster 5. Digitally inclined}

Cluster 5 represents egos that would shift to a more, ICT prone lifestyle with a little push. They tend to be more prone to e-communication than physical travel. Most of the scores are less than 1 or tending towards 1 (Table 3 ). The diameter ratio is 0.8 (Table 10) which means that the longest path between any two alters in the network is not so long unlike other clusters, which might indicate that egos of this cluster do not have very big networks. Egos of this 
cluster also communicate with more alters virtually than they do physically (vertices score is 0.9 ). Since the local and global clustering of this profile tends to 1 , it could mean that even the alters are e-communication prone like the egos (Figure 14).
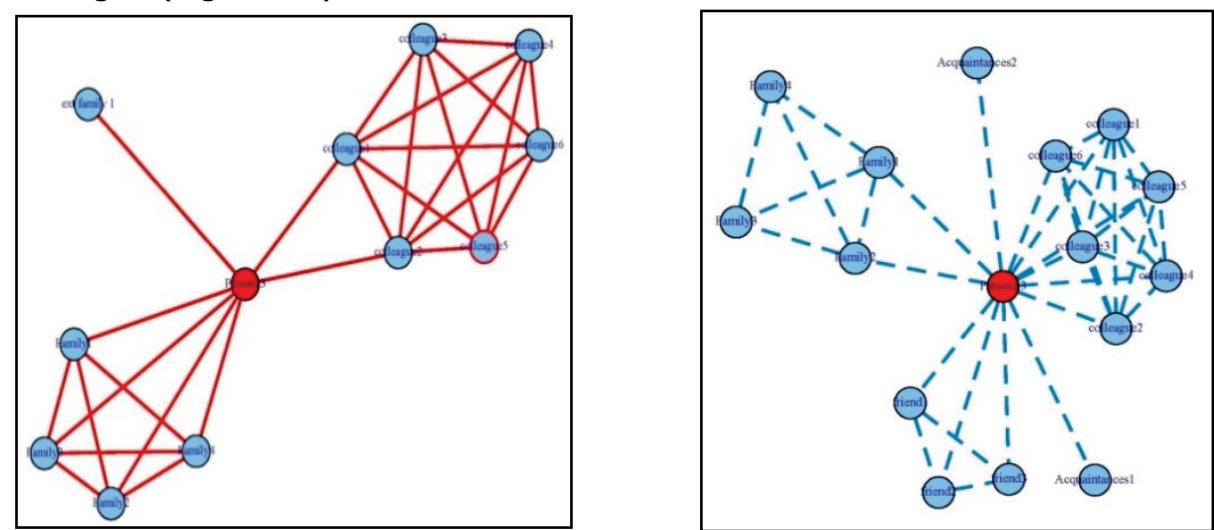

Figure 14 Physical travel (left) and E-communication (right) of a typical person in cluster 5

Table $9 \mathrm{C} / \mathrm{T}$ balance score of a typical person in cluster 5

\begin{tabular}{|l|c|c|c|c|c|c|c|}
\hline $\begin{array}{l}\text { Charac- } \\
\text { teristics }\end{array}$ & Density & $\begin{array}{l}\text { Transi- } \\
\text { tivity }\end{array}$ & Vertices & Diameter & $\begin{array}{l}\text { Path } \\
\text { Length }\end{array}$ & Degree & $\begin{array}{l}\text { Close- } \\
\text { ness }\end{array}$ \\
\hline C/T ratios & 0.955 & 0.657 & 0.500 & 0.750 & 1.115 & 0.462 & 0.887 \\
\hline
\end{tabular}

\subsubsection{Socioeconomic and demographic comparison of the clusters}

Axhausen (2008) comments that " instead of relying exclusively on the generalized costs of travel and the hedonic utility of a location as modulated by the socio-demographics of an individual and perhaps his or her values, one can add as explanatory factors both the social network geography of the person and his or her biography and network-based decision making..".

In this chapter we try to explain the $\mathrm{C} / \mathrm{T}$ decisions of an individual focusing on the social networks instead of relying on the socio-demographics. Since networks are dynamic (Sharmeen et al., 2010), they help us in understanding the behavior and decision changes. But if we look at only socio-demographic this is not possible, e.g. the event of 'getting married' could mean that the spouse's (partial) social network is now included, resulting in a change in social network of the individual and could eventually lead to a changed $\mathrm{C} / \mathrm{T}$ behavior. In such cases the socioeconomic and demographic (age, gender, income etc.) of the individual remains same, but the $\mathrm{C} / \mathrm{T}$ behavior changes. 
Table 10 Comparison of socioeconomic and demographic characteristics of Ahmedabad, the census 2001 versus the sample and clusters

\begin{tabular}{|l|c|c|c|c|c|c|c|}
\hline $\begin{array}{l}\text { Charac- } \\
\text { teristics }\end{array}$ & $\begin{array}{l}\text { Ahmedabad } \\
\text { (census } \\
2001)\end{array}$ & Sample & $\begin{array}{c}\text { Cluster } \\
1\end{array}$ & $\begin{array}{c}\text { Cluster } \\
2\end{array}$ & $\begin{array}{c}\text { Cluster } \\
3\end{array}$ & $\begin{array}{c}\text { Cluster } \\
4\end{array}$ & $\begin{array}{c}\text { Cluster } \\
5\end{array}$ \\
\hline Number & 4.2 million & 418 & 23 & 36 & 109 & 90 & 160 \\
\hline $\begin{array}{l}\text { Average Age } \\
\text { [years] }\end{array}$ & $28.5^{2}$ & 34 & 31 & 30 & 28 & 33 & 32 \\
\hline $\begin{array}{l}\text { Predominant } \\
\text { Mode } \\
\text { Income } \\
\text { group }\end{array}$ & $\begin{array}{c}\text { Middle } \\
\text { income }\end{array}$ & $\begin{array}{c}\text { Middle } \\
\text { Income }\end{array}$ & $\begin{array}{c}\text { Middle } \\
\text { Income }\end{array}$ & $\begin{array}{c}\text { Middle } \\
\text { Income }\end{array}$ & $\begin{array}{c}\text { Middle } \\
\text { Income }\end{array}$ & $\begin{array}{c}\text { Middle } \\
\text { Income }\end{array}$ & $\begin{array}{c}\text { Middle } \\
\text { Income }\end{array}$ \\
\hline $\begin{array}{l}\text { Literacy } \\
\text { level }\end{array}$ & N/A & 2 & 1 & 2 & 2 & 2 & 2 \\
\hline$\%$ males & $53 \%$ & $56 \%$ & $48 \%$ & $53 \%$ & $59 \%$ & $62 \%$ & $42 \%$ \\
\hline$\%$ females & $47 \%$ & $44 \%$ & $52 \%$ & $47 \%$ & $41 \%$ & $38 \%$ & $58 \%$ \\
\hline
\end{tabular}

In this chapter we try to capture this change in the $\mathrm{C} / \mathrm{T}$ behavior by capturing the change in the social networks and not in the socioeconomic and demographics. Several mechanisms and conceptual frameworks have been advanced to explain the possible relationship between social networks, ICT use and travel. Rogerson (1997) has found that there exists a relationship between socio-demographic, social network and physical travel. For instance people who have higher education may have larger networks. However, no such relationship was found when e-activities were introduced in travel behavior studies. Silvis et al. (2006) found no statistically significant differences on socio-demographic variables between mobility groups, suggesting that social patterns were fairly universal on a socioeconomic and demographic level. This chapter has similar findings where Table 11 shows the socioeconomic and demographic characteristics of the Ahmedabad population, the sample and the clusters. The average age for all the 5 clusters varies between $28-33$ years. The income category is a middle income group throughout the sample, reflecting the dominance of the middle class in the city. The literacy level on average varies between 1 (passed primary school) to 2 (passed middle school). A similar case is found for the male/female percentages. Hence, most of these socioeconomic and demographic data only show modest variations, while the clusters differ strongly in terms of e- communication versus travel behavior. Table 4 already showed that there exists a clear difference between the clusters with cluster

\footnotetext{
${ }^{2}$ Was calculated from the Age-Sex pyramid of Gujarat in 2001(IIPS, 2010)

${ }^{3}$ GDP $\$ 16$ billion/population of Ahmedabad. (AUDA, 2005) : annual househol income ('000) <90 Deprived, 90-200 Low income, 200-1,000 Middle income, > 1,000 High income (NCAER,2005)

${ }^{4}$ The mode of every cluster: 1 Below Primary, 2 Primary, 3 Middle, 4 Graduate, 5 Above graduate. (Census of India, 2001)
} 
1 and cluster 2 representing two extremes. But no such clear differences can be found in table 11 which shows only slight variation between clusters. Table 11 also points out a variation within each cluster. All the clusters have individuals from age groups varying from 18 years to $60+$ years. Sociodemographic studies based on age would have cluster each age as a separate cluster, but $\mathrm{C} / \mathrm{T}$ ratios point out that each cluster has individuals from different age groups. The same can be extended to income group, literacy levels and male-female percentages.

\subsection{Conclusion}

The study contributes to the understanding of people's physical travel and communication patterns in the following ways.

Firstly, to maintain a social network people communicate, be it physically or virtually. The analysis demonstrates a tendency that people of Ahmedabad are more prone to maintaining their social networks virtually. A reason for this could be the relative ease of communication virtually (no physical travel needed) and the falling costs of the mobile phone calls in the Indian markets. However, face to face communication also prevails among some people, which, could be basically because, face to face communication established a personal touch and sustains trust (Urry, 2004).

Secondly, in Ahmedabad people usually have large very well-knit networks. This might be because as a community the Guajarati's have very close kinship ties and well maintained networks. Thus maintaining a large network does not need a lot of effort both in economic terms and in terms of effort that has to be put in. Also since all human beings are economically rational (Foss and Couclelis, 2009), they tend to choose a less expensive mode of communication. Mobile phones present themselves as an inexpensive way of communication in developing countries such as India (Economist, 2009). This could also be a reason for the clear signs of a 'digital divide' (Monroe, 2002) seen from the analysis of the clusters. Cluster 1 is very physical while cluster 2 which is totally opposite from cluster 1 which is virtual.

Thirdly, people are effectively classified into different clusters based on their network sizes, mode of communication and frequency of communication rather than being classified based on age, income, gender and other socioeconomic indicators. This is a better classification than previous classifications because this takes into consideration the social networks of people (which generate travel and communication) when creating the clusters. 
Finally social network characteristics can be coupled with socioeconomic data so as to include the spatial and economical aspects of the $C / T$ balance. The study can then be used to understand the $C / T$ pattern of different segments of society over space. This knowledge can be used for transport planning of future Ahmedabad. This study fits better actual transformation of travel behaviour and since the chapter provides profiles of a person the study can also be used by planners in a novel way. The policy makers can effectively identify target profile when making IT policies. These profiles can be understood by policy makers which make diagnosing problems related to particular profile easier. This helps them make policies which are more strategic and successful.

Results in this chapter empirically confirm that people's social network have a bearing on their travel (Carrasco et al., 2008) and that they can be classified according to their $\mathrm{C} / \mathrm{T}$ balance. Also it indicates that social network studies regarding communication and travel can be conducted with a number of alters higher than 5, as was not done in earlier studies (Tillema et al., 2010). This study successfully conducts the questionnaire survey which takes into account the different social ties of a person and extracts from them their physical versus e-communication patterns. The advantage of using the full network (as opposed to the 5 alter approach) of the ego, for analysis is that then we take into consideration the weak ties also, and from the ego's point of view, weak ties are an important resource facilitating his own movement (Granovetter, 1973).

The discipline of urban transportation analysis has evolved in the last three decades to reflect the changing nature of policy needs- in general moving from a focus on infrastructure solutions to a more holistic approach. Existing research has yielded theory, data and methods to incorporate the individual's factor affecting travel. But as trip-based analysis gives way to activity-based and other approaches such as micro simulation, there is a need to shift from an individualistic perspective of travel, to more socially influenced profile behavior (Dugundji et al., 2008). Through the analysis we have profiled people according to their $\mathrm{C} / \mathrm{T}$ balance behavior. 


\section{Chapter 4}

Observing travel and e-communication behaviour: a social network approach ${ }^{5}$

${ }^{5}$ This chapter is under review by : Journal of Transport Geography 


\section{Abstract}

Research on travel behaviour has increasingly considered the role of Information and Communication Technology (ICT) (e.g. phones and internet). Recently, social networks are becoming more important in describing the trade-off between physical travel and the use of ICT means. This research is based on the assumption that people's travel and electronic communication usage is a derived demand, i.e. people try to engage in activities by traveling or using e-communication to maintain or increase their social networks. Empirical data is gathered from Ahmedabad, India, using a Social Network Analysis combined with an activity-travel-communication diary. Five social network profiles have been developed, each representing people with their own, specific, balance of physical (face-to-face) and electronic communication with social network members. The travel and ecommunication behaviour of people from each profile is investigated thoroughly on seven travel related aspects typically used for travel demand studies. We investigated whether the differences in the various travel behaviour aspects can be attributed to socioeconomics, spatial characteristics and social networks. Only the trip-length-frequency distributions show differences that cannot be explained by socioeconomics or spatial characteristics alone. This difference in travel patterns between social network profiles can be used in transport models. 


\subsection{Introduction}

This chapter studies how social network analysis can be used to better understand the relationship between travel and communication of people. It is well established that the recent information and communication technologies (ICT) are fundamentally altering the organization and travel of households, firms and other actors in cities (Mokhtarian, 2003; Schwanen et al., 2006). The basis of such interactions are new ways in which social life is apparently 'networked' (Urry, 2003). Societies today have moved from being based upon strong overlapping membership of social groups to a system of 'networks' where connections are spatially dispersed (Sheller and Urry, 2006). Spatiality as argued by Simmel (1908) is both the condition for, and the symbolic representation of social interaction. This spatiality is aided by the increasing availability, power and use of ICT by members of socially homogenous networks, and these networks do not necessarily overlap with one another (Axhausen, 2002). To be able to interact with spatially separated social network members, people have two options. Either they meet them face-to-face or they use electronic communication (e-communication), like phones, email, chat etc. (Mokhtarian and Salomon, 2001; Ortúzar and Willumsen, 2006; van Wee, 2009). E-communication relies on ICT next to face-to-face meetings; it is another way of exchanging information between people (Rietveld and Janssen, 1990; Lyons, 2002; Jauneikaité and Carreno, 2009). Face-to-face requires physical travel, while e-communication requires 'virtual' travel and enables both parties to stay at their original places (Kenyon and Lyons, 2007). Physical travel and e-communication are therefore, a means to an end, i.e. a means to communicate.

That there is a relationship between ICT and travel is evident (Kenyon, 2006; de Graaff and Rietveld, 2007; Kwan, 2007; Lyons, 2009). The term 'spatial technologies' adopted from Couclelis (1994) is coined as a collective name for transportation, communication and information technologies that modify spatial relationships (Shen, 1998). The earlier studies suggest that ICT use, as well as any associated travel impacts, is highly dependent on a variety of demographic, incidental, accessibility, and activity-related factors (Lu and Pas, 1999). One main difficulty in explaining the impacts of ICT on travel is identifying the likely activities in which individuals will choose to engage. However, if a closer look is taken into the social networks of the individuals it is possible to empirically generate data which can then be used to calculate whether travel is being substituted or complemented by ICT (Axhausen, 2008). This is because through social networks one can explain why travel is generated and how e-communication affects the trip lengths of individuals. We use evidence from our study of the city of Ahmedabad, India, to examine how social networks take into account factors that affect travel and then try to explain how social networks can be used in travel research. 
Ahmedabad is the largest city in Gujarat, India. It is the seventh largest city and seventh largest metropolitan area of India, with a metropolitan population of 4.2 million. In 2010, the Forbes magazine rated Ahmedabad as the fastest growing city in India, and third in the world. With the city's population, the telecom industry of Ahmedabad also has grown over the years. A large population, low telephony penetration levels, and a rise in consumer spending power have led to Ahmedabad being one of the fastestgrowing telecom markets in India. The number of mobile connections grew from a little over 4 hundred in 1997 to over 3 million in 2010. A survey in 2002 on IT-enabled services ranked Ahmedabad fifth among the top nine most competitive cities in the country (Adhvaryu, 2010). Compared to mobile phones, internet penetration has not been very fast. Ahmedabad has only $8 \%$ internet penetration as compared to $76 \%$ mobile penetration (TRAI, 2010).

Ahmedabad has a wide range of transport modes ranging from private cars to two wheelers (two wheeled motorized vehicles that are gasoline-powered scooters and motorcycles (ADB, 2009)) to government run public transport. The number of registered vehicles in Ahmedabad grew from 1.1 million in 1999, to 2.8 million in 2010. Among the number of registered vehicles twowheelers account for around $70 \%-72 \%$ of total vehicles registered. This is an indirect indication of derelict state of public transport (bus) services in Ahmedabad (GoG, 2010). Only 0.9 million commuters use the public transport everyday which is only $0.8 \%$ of traffic on the roads.

Ahmedabad is home to a large cosmopolitan population. Due to the high industrialization rate the city has attracted people from all over the central and western region of India. So, in Ahmedabad people from all regions of India can be found. A distinct feature of Ahmedabad is its peaceful coexistence of the old walled city and the new city. The city is like any other Indian city with distinct characteristics of its own. The Gujratis believe in strong kinship ties, slightly less than half of all real estate (30\%) (Sapovadia, 2007) in Ahmedabad is owned by "community organizations" (i.e. cooperatives), and the spatial growth of the city to a large extent contributes to the number of these organizations. All these make Ahmedabad a good choice for the study because in Ahmedabad people have strong social networks and they use e-communication and physical travel to maintain their relations.

\subsection{ICT and Travel}

The earlier empirical studies show that there exists a relationship between ICT and travel (Nie et al., 2002; Muhammad, 2007). Some suggest an increase in travel while others suggest a decrease in travel. Although most models aimed at understanding travel behaviors and ICT are able to explain 
the "generation" of trips, they still heavily rely on the individual's socioeconomic characteristics.

\subsubsection{The traditional approach}

In the past decade, most studies used socioeconomics and spatial characteristics to explain this relation (Carrasco and Miller, 2009; Aguiléra et al., 2012). Commonly used socioeconomics are age, gender, income, employment, education, e-communication availability and car ownership (Williams, 1989; Dieleman et al., 2002; de Graaff and Rietveld, 2007; Winters et al., 2010). Spatial characteristics used are for instance population density and the density of facilities like residential housing, commercial services, educational services, park, industry and offices (Kalenoja, 1999; Dieleman et al., 2002; Mokhtarian et al., 2004; Winters et al., 2010). Results of these studies, of which some might already been outdated, are as follows.

Fox (1995) found that some socioeconomic factors that have influenced travel were environmental consciousness, costs, budget restrictions and the changing socioeconomic aspects of society. Zhang et al. (2008) found that in the same age group there was a significant difference in travel behavior between males and females in Beijing. Haustein et al. (2009) observed that travel of young Germans were influenced by peer pressure, level of socializing and communication with parents. Bhat et al. (2003) show that individuals who are young, employed and/or highly educated, are more prone to using mobile phones.

Rogerson (1997) has found that there exists a relationship between sociodemographic, social network and physical travel. For instance people who have higher education may have larger networks. However, no such relationship was found when e-activities were introduced in travel behavior studies. Silvis et al. (2006) found no statistically significant differences on socio-demographic variables between mobility groups, suggesting that social patterns were fairly universal on a socioeconomic and demographic level.

Thus, the above studies present contradictory results and there is no unanimity among researchers about the effects of socio-economics and spatial characteristics on ICT and travel. Also these studies focus on only one aspect of individuals like age, gender, income etc. Studies that encompass all the aspects together are not available. It brings us to the first hypothesis of this chapter, i.e. socio-economic and spatial characteristics cannot be solely used as explanatory factors for the effects of ITC on travel. 


\subsubsection{Social network approach}

So far, no direct causal relation has been found between socioeconomic and spatial characteristics and the trade-off between e-communication and travel. The differences between the studies might be the result of a lack of explanatory variables. According to de Graaff and Rietveld (2007), people's attitude towards e-communication influences travel behaviour as well. Next to that, the relationship cannot be described solely by spatial factors and socioeconomics, but is inseparable from social interest of residents and their communication partners (i.e. social network) (Carrasco and Miller, 2006; Axhausen, 2008; Carrasco and Miller, 2009; Jauneikaité and Carreno, 2009).

According to Chapin (1974), a person's travel behaviour can be explained by the individual's propensity and opportunity to engage in social activities. The opportunity and propensity do not only emerge from socioeconomic characteristics, but from social networks as well. The opportunity (based on space and time constraints) depends partially on the spatial distribution of social network members, i.e. with whom activities are conducted (Schwanen et al., 2008). These constraints are reduced by e-communication since it facilitates distant distribution of people's practices, i.e. increases people's flexibility in conducting their everyday activities (Aguiléra et al., 2012). The propensity to travel depends on people's e-communication means, attitude towards e-communication vs. travel and the way e-communication is used by social network members (Mannering and Mokhtarian, 1995; Carrasco and Miller, 2006; Aguiléra et al., 2012).

The interaction between social network members can change a person's travel behaviour (Salomon, 1986; Hackney and Axhausen, 2006; Sunitiyoso et al., 2011). According to Mokhtarian (1990), Carrasco and Miller (2006) and Axhausen (2008), travel choices are often made as a result of joint choices with other people. Therefore, the relation between e-communication and travel is influenced by an individual's social network as well (next to the socio-economic characteristics). This is echoed by Carrasco et al. (2008), who state that researchers should take people's social relationships into account, since these interactions influence people's decision making process.

In addition, Carrasco and Miller (2009) investigated the relevance of using personal social networks as a source of explanation of social activity-travel generation behaviour. They stated that information on "with whom" social activities are performed and the ego's network composition and structure is required to understand the social activity generation. Tillema et al. (2010) used social networks to investigate the use of e-communication and face-toface communication in maintaining an individual's social network. Chapter 3 argues that individuals do not use only e-communication or only physical 
travel to communicate with their network members. They use a fine balance known as the e-communication/Travel $(C / T)$ balance. They classify individuals into 5 groups with varying degree of the $C / T$ balance. Thus, a second hypothesis of this chapter can be formulated, i.e. since individuals have different $C / T$ balance their travel is affected differently by ICT, this effect captured by difference in travel patterns can be explained by social network analysis.

\subsection{Data and methods}

To investigate the role social networks play with respect to travel and ecommunication behaviour, two questionnaires were developed and used for interviewing 350 people in Ahmedabad, India. The data collected is schematically shown in Figure 15. The Social Network Analysis (SNA) questionnaire is used to derive the five social Network profiles (as in Roy et al., 2012). The travel and e-communication behaviour is accordingly captured by an activity-travel-communication diary. Both questionnaires also gathered data regarding people's socio-economics like age and gender. Spatial characteristics, like population density and percentage slums, are extracted from ArcGIS maps derived from ANANDA (2007).

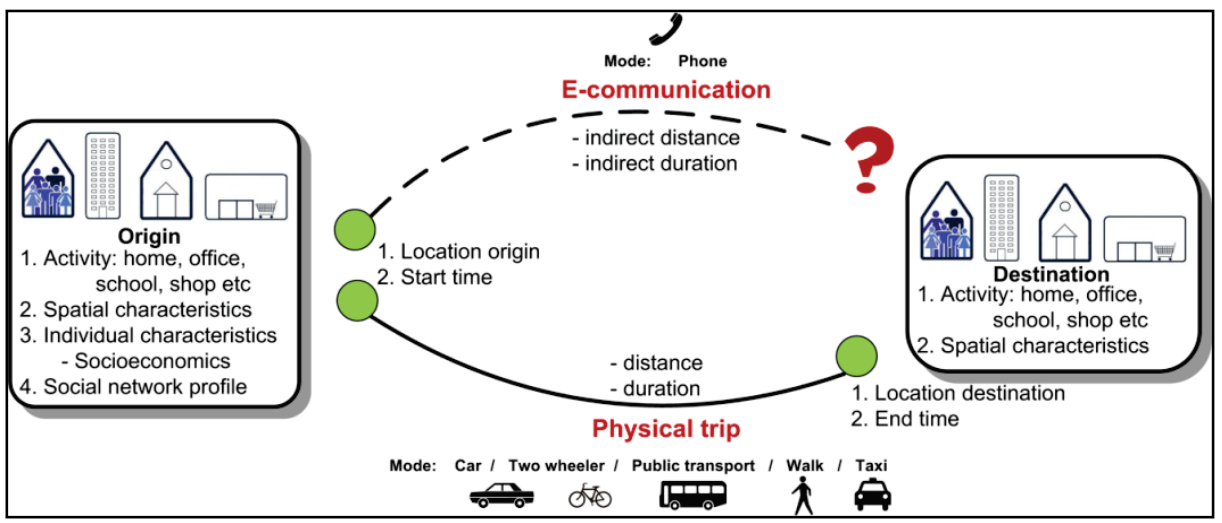

Figure 15 Overview dataset collected for chapter 4

\subsubsection{Social Network Profiles}

This study follows the social network approach of chapter 3, which states that the trade-off between travel and the use of e-communication emerges from the balance between people's social network maintained by face-to-face meetings and their social network maintained via e-communication like phones (mobile phones and landline phones), emails and chat. Using the SNA questionnaire, respondents are clustered (in a non-ordinal scale) into these five profiles: 
1. The Easy riders profile prefers physical travel over e-communication when communicating with their social network members. They have a rather small network.

2. The Balanced people profile tends to have a nearly equal number of network members for both their physical and e-communication network but slightly prefers physical traveling over e-communication.

3. The Popular people profile knows many people (high number of acquaintances) with whom they communicate both face-to-face as by ecommunication, e.g. doctors and shopkeepers.

4. The Digitally inclined profile tends to prefer e-communication over traveling to maintain their rather small networks.

5. The ' $I$ ' generation profile is opposite to the Easy riders and is therefore prone to maintain their large network by using e-communication.

\subsubsection{E-communication and travel}

People's e-communication and travel behaviour are collected by an activitytravel-communication diary. This diary maps all activities and communication on a typical workday. Some assumptions and calculations were made in order to derive the required data for analysis, which are explained in the following sections.

\subsubsection{Phone calls represent e-communication}

In this study e-communication is represented by only mobile and landline phone calls for three reasons. First of all, because of the low internet penetration, internet is expected to have a rather small added value with respect to e-communication behaviour in India. Ahmedabad has only $8 \%$ internet penetration as compared to $76 \%$ mobile penetration (TRAI, 2010). Secondly, people are probably better in remembering their daily phone calls than their emails sent since synchronous types of communication, like the telephone, are used for exchanging the most important and urgent information (Tillema et al., 2010). Finally, it is hard to derive the amount of 'virtual trips' made when people are using for instance chat or Facebook. Since the phone is primarily used for social activities (communicating) (Carrasco and Miller, 2009), it is expected that phone calls mainly substitute or complement physical face-to-face trips, e.g. no shopping trips are performed by phone. This means that in this research, e-communication is limited to communication as a purpose.

When ICT is discussed in relation to the developing world, scholars emphasize the importance of mobile telephony, because it provides connectivity, rather than mobility (Palackal et al., 2011). This chapter focuses on mobile and landline phones also because it provides us with a proxy for travel costs versus usage costs for individuals in the city of Ahmedabad. 


\subsubsection{Defining e-communication trips}

Social activities can be performed by e-communication or meeting face-toface. According to Tillema et al. (2010), the decision depends on the availability of and attitude towards the transport and communication modes and the cost of traveling. In this research, the cost of traveling for ecommunication trips is based on the 'indirect distance/duration' (Figure 15). It is assumed that people (i.e. the ego), when using e-communication, do consider the distance/duration they would travel if they would not use ecommunication, i.e. the distance/duration when meeting the alter (person the ego wants to communicate with) face-to-face. Required information was gathered by adding three questions to the diary: "Where would you travel to when replacing the e-communication trip by a physical trip?" (Q1), "How long would it take you to get there?" (Q2) and "Would you actually replace the ecommunication trip by a physical one, if you did not have access to the phone?" (Q3).

The indirect duration is obtained by Q2, while the indirect distance is calculated (see Section 4.3.2.4) by using people's origin and destination. The destination is derived from Q1. The origin is equal to the location of the caller unless the caller was traveling physically at the same time. When ecommunication was used while traveling, the destination of the physical trip is used as origin of the e-communication trip (Figure 16). We assume the caller would not change his physical trip directly when e-communication is unavailable (e.g. when not picking up the phone). Instead, he would finish his trip before replacing the e-communication trip by another physical trip. A limitation of deriving the origin from someone's current location or physical trip destination, is that we assume people make the physical trip right away. In reality, it is shown that e-communication increases people's flexibility (Yuan et al., 2012) and so, the physical trip might be made from a different location, resulting in a different e-communication distance.

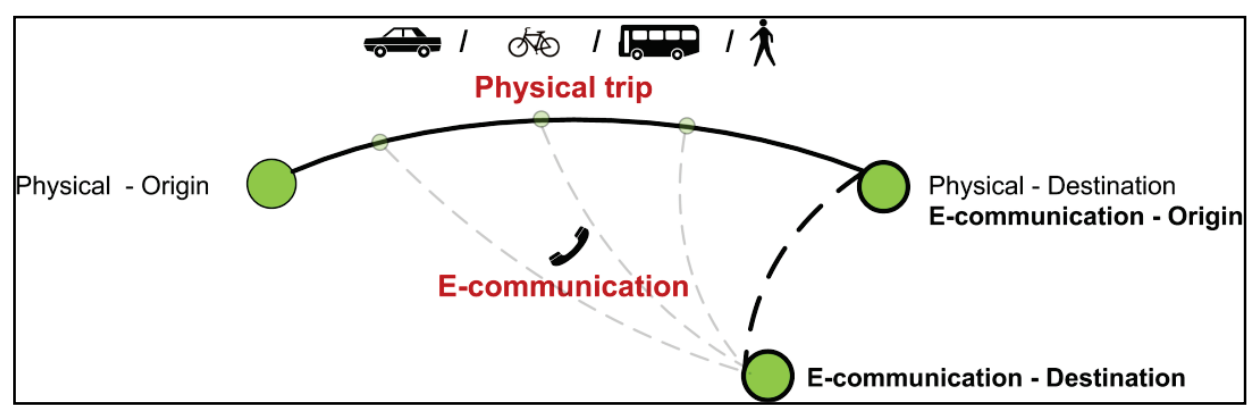

Figure 16 Origin and destination of e-communication trips during traveling 


\subsubsection{Classification e-communication trips}

For the analysis of e-communication behaviour, e-communication trips are subdivided into "potential substitutive phone calls" and "substitutive phone calls". All calls of which the respondent was able to give a physical destination (i.e. answer Q1) are classified as "potential substitutive phone calls". When respondents were unable to answer Q1, the phone call could never be a substitute of a physical trip. The final question, Q3, was used to reveal the "substitutive phone calls".

\subsubsection{Distance calculation}

The physical and e-communication trip distances are calculated via the road network between ward centroids (most detailed zone level respondents were willing to provide) following Dijkstra (1959). The intrazonal distances are calculated by taking one half of the distance to the centroid of its nearest ward (Venigalla et al., 1999). The ward centroids are based on land-useweighted centroids, i.e. the centroid of the ward is based on the land use geometry with respect to facilities that induce (produce or attract) travel (e.g. residential areas and commercial centres). This is done since the outer wards cover a larger area than what is used for facilities, which might otherwise result in excessively long distances to the outer wards (Figure 17).

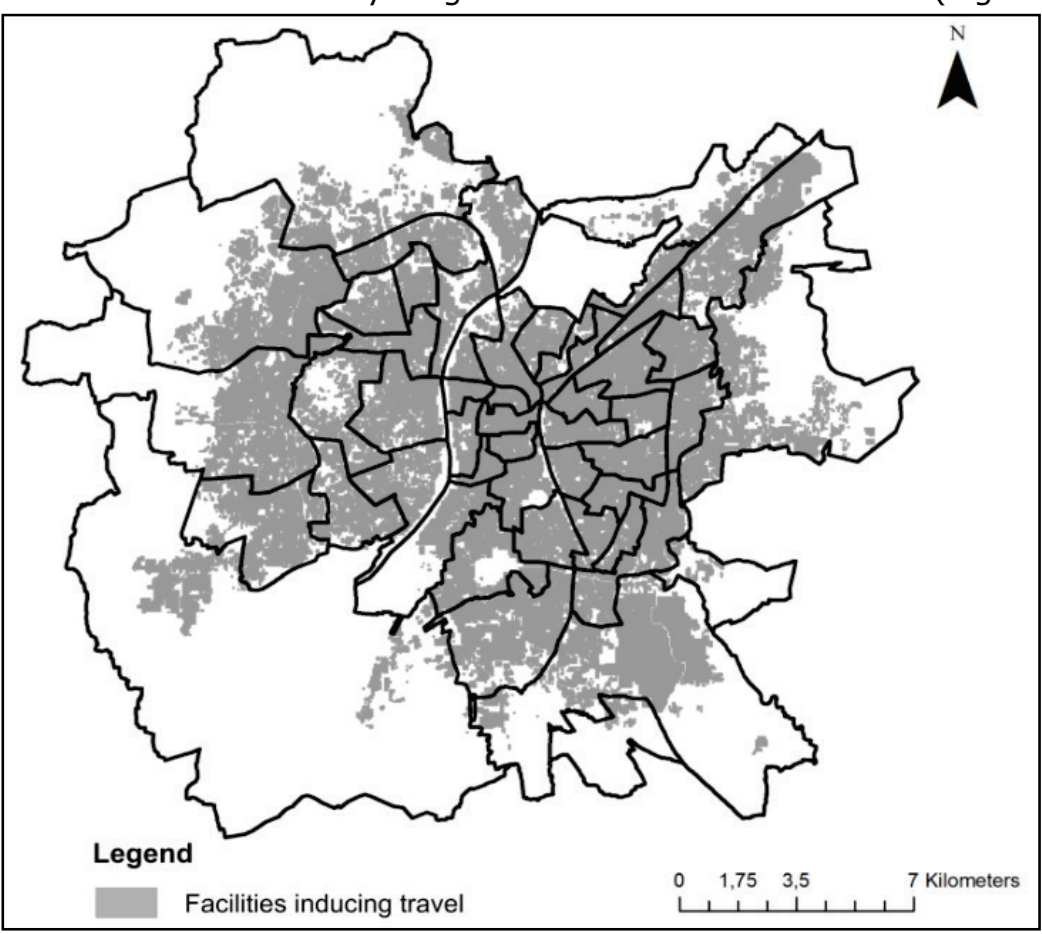

Figure 17 Ahmedabad, India: Outer wards containing relatively less land use facilities than inner wards

Source: based on ANANDA (2007) data 
Two main steps were performed in order to answer the hypothesis. The profiles' travel and e-communication behaviour (by analysing the total phone calls and substitutive phone calls) is firstly examined for significant differences. The travel behaviour is then represented by so-called Trip Length Frequency Distributions (TLFDs), plotting the distribution of trip lengths by travel distance or travel time. ANOVA tests and independent samples t-tests were conducted in the statistical software SPSS to reveal differences between profiles' travel and e-communication behaviour. Secondly, Spearman and Pearson correlations were used to further investigate the differences in travel behaviour. The correlations showed whether the differences can actually be attributed to social network profiles themselves or that stronger correlations exists with socio-economic or spatial characteristics. This way, it is examined whether social networks can be a complement to travel demand models.

\subsection{Results}

The profiles' physical travel behaviour is outlined in the subsequent sections. Differences in TLFDs of the profiles are presented and used to examine whether social networks can satisfactorily explain the difference in travel patterns.

An overview of the number of daily phone calls, its percentage potential substitutive phone calls and its percentage of actual substitutive phone calls is shown in Figure 18. The dotted lines separate the significant different profiles, based on independent one-tailed t-tests $(p<.05 \& p<0.01)$. For instance, Balanced people, Popular people and Digitally inclined do not differ significantly from each other with respect to daily phone calls while they do significantly differ from Easy riders and 'I' generation. Despite the restricting assumption to represent e-communication by phone calls only, we see that ecommunication behavior derived from trip diaries, is confirming the expected behavior of the profiles derived from SNA questionnaires.

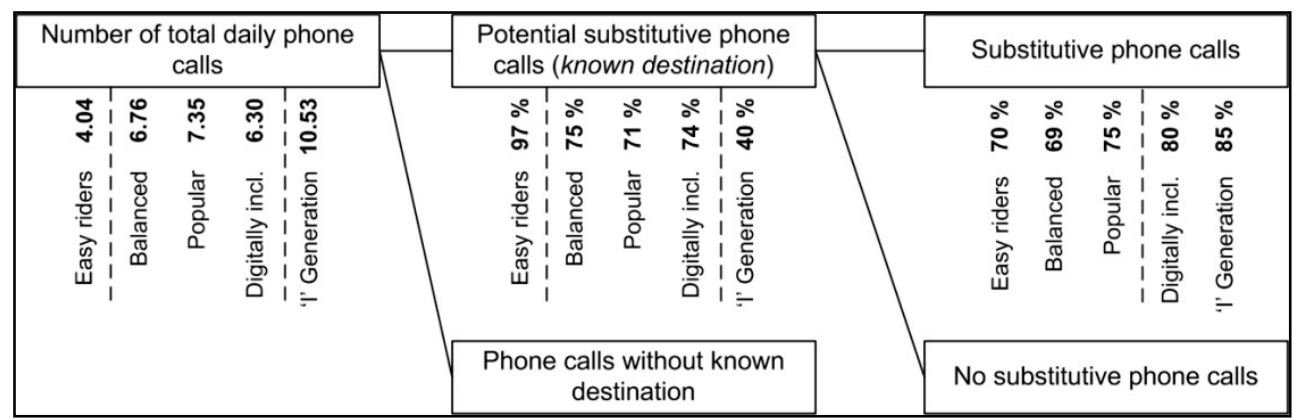

Figure 18 Number/percentage of daily, potential substitutive and substitutive phone calls. 


\subsubsection{Dissimilar travel behaviour of individuals}

\subsubsection{TLFD in general}

The TLFDs are used to examine the influence of distance on people's travel behaviour. They are often used as input for calibration of trip distribution models by comparing the observed TLFD with the modelled one (Bureau of Public Roads, 1965). This way, it is tried to determine the travel pattern between traffic zones and to identify the extent to which generalized costs (distance) are considered by people when travel decisions are made (Arasan and Wermuth, 1996; Samanta and Mazumder, 2006).

Good results can be expected if the observed trips are classified by person type in a reasonable uniform way (Wilson, 1967; U.S. Department of Transportation, 1983). It is expected to realize this by using the five SN profiles as homogeneous sets of travellers. A negative exponential function, equation (1), is used to fit the data since these usually perform well within urban areas (Rietveld and Janssen, 1990), such as Ahmedabad.

$$
f(d)=\alpha \cdot \exp (-\beta \cdot d)
$$

The percentage of trips given a certain distance bin $(d)$, is shown by $f(d)$. The $\beta$ parameter measures in some way the extent to which distance is considered when travel decisions are made, i.e. the greater the $\beta$, the stronger the decay and the less is the average distance travelled (Wilson, 1967). So, the $\beta$ indicates the influence of distance on travel and ecommunication behaviour. For physical trips, the distance is assumed to directly (negatively) influence travel, i.e. we expect to find a decay. For ecommunication trips on the other hand, it is assumed that distance will not directly influence the e-communication behaviour since the generalized costs of making a phone call are the same throughout the case city. The goodnessof-fit of the exponential function is given by $R^{2}$, which represents the percentage of variation in the outcome that can be explained by the model. So, a low $R^{2}$ indicates that the $S N$ profile's distribution doesn't fit the negative exponential function as assumed. Both the $\beta$ and $R^{2}$ are used as an indicator for the influence of distance on travel behaviour.

The TLFDs for physical and e-communication trips are shown in Figure 19, with $N$ being the sample size (No. of trips). The e-communication trips are represented by the potential substitutive phone calls, i.e. the phone calls of which people do know a physical destination. In accordance with the study by Tillema et al. (2010), e-communication trips are less influenced by distance than physical trips, i.e. the TLFD of e-communication is somewhat flattened compared to the physical trips (lower $\beta$ ). Next to that, the mean daily e- 
communication distances $(M=7.43 \mathrm{~km}$; $\mathrm{SE}=0.15)$ are larger than physical travel distances $(M=6.13 \mathrm{~km}$; $S E=0.16)$, indicating that communication with people living further away, is rather done by e-communication than by travel. This difference is significant ( $p$ (two-tailed) $<.001 ; r=0.14$ ) and is found for all profiles.
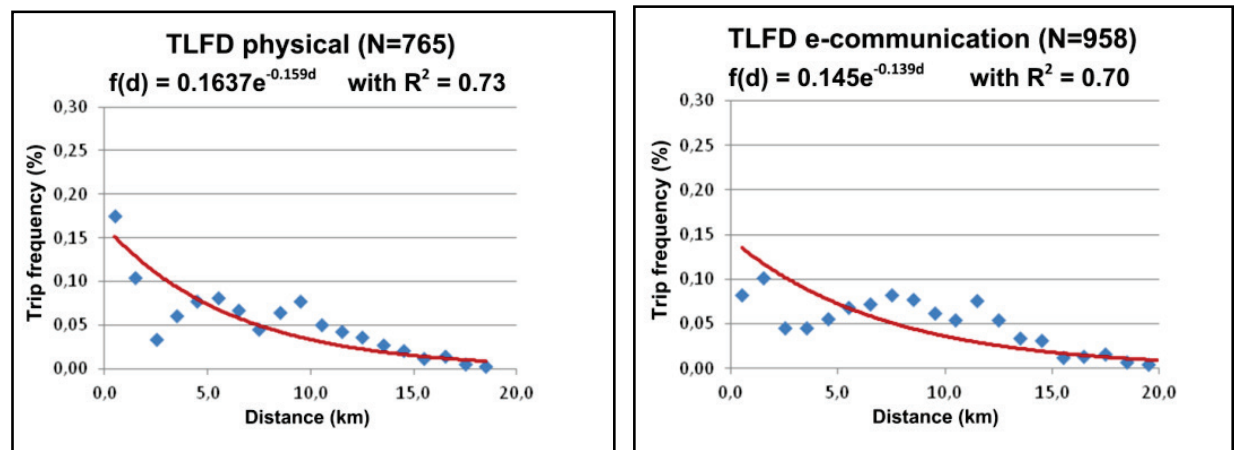

Figure 19 TLFD of physical trips (left) and potential substitutive ecommunication trips (right)

The TLFD for e-communication shows a clear decay. Despite the fact that the costs of making phone calls does not differ within Ahmedabad, i.e. distance is not correlated with telephone charges within Ahmedabad, there is a decline in the number of phone calls with respect to distance. Such a negative relationship is also shown by Rietveld and Janssen (1990) in their study about communication barriers to telephone use, indicating that the phone is primarily used to communicate with persons living in geographic proximity. According to Ling and Stald (2010), the phone contributes to the development or maintenance of social networks with friends and family close by. The reason can possibly be found in the location of the alters.

The negative relationship between trip frequency and distance for both ecommunication and travel therefore shows that people's behaviour is not only related to their willingness to travel certain distances or use ecommunication, but also to the geographic distribution of their social network members. Tillema et al. (2010) for instance found an increase in the share of e-communication contacts by an increase in geographical dispersion of the social network members. It is assumed that by including the locations of an ego's alters in the TLFD (i.e. the geographic distribution of the individual's social network members), the physical trips and phone calls per person known at a certain distance can be derived. It is hypothesized that this will reveal people's willingness to use e-communication over travel at certain distances. Further research is required to examine this. 


\subsubsection{TLFD for physical trips}

Next to the overall difference in TLFD between e-communication and physical trips, also TLFD's for physical trips among profiles differ (Figure 20).
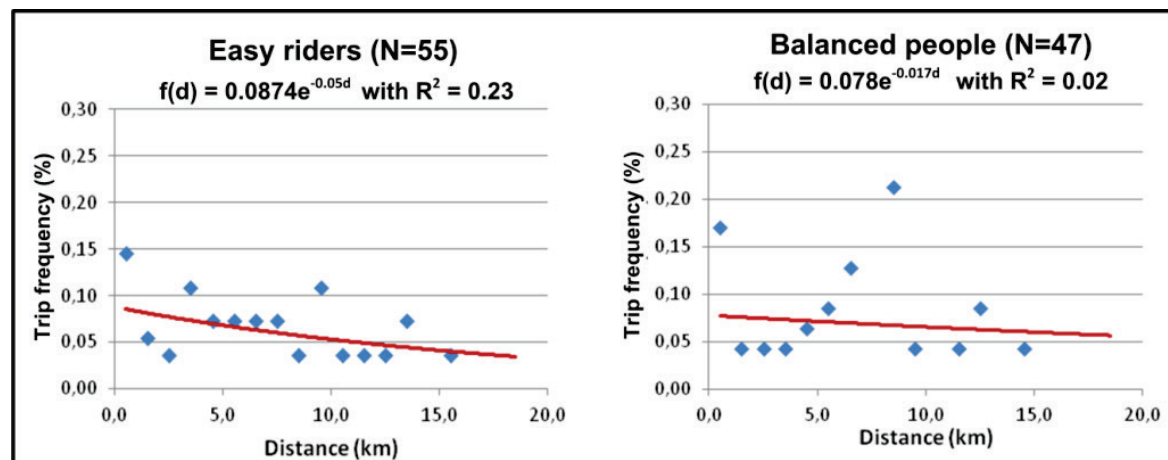

Popular people $(\mathrm{N}=253)$
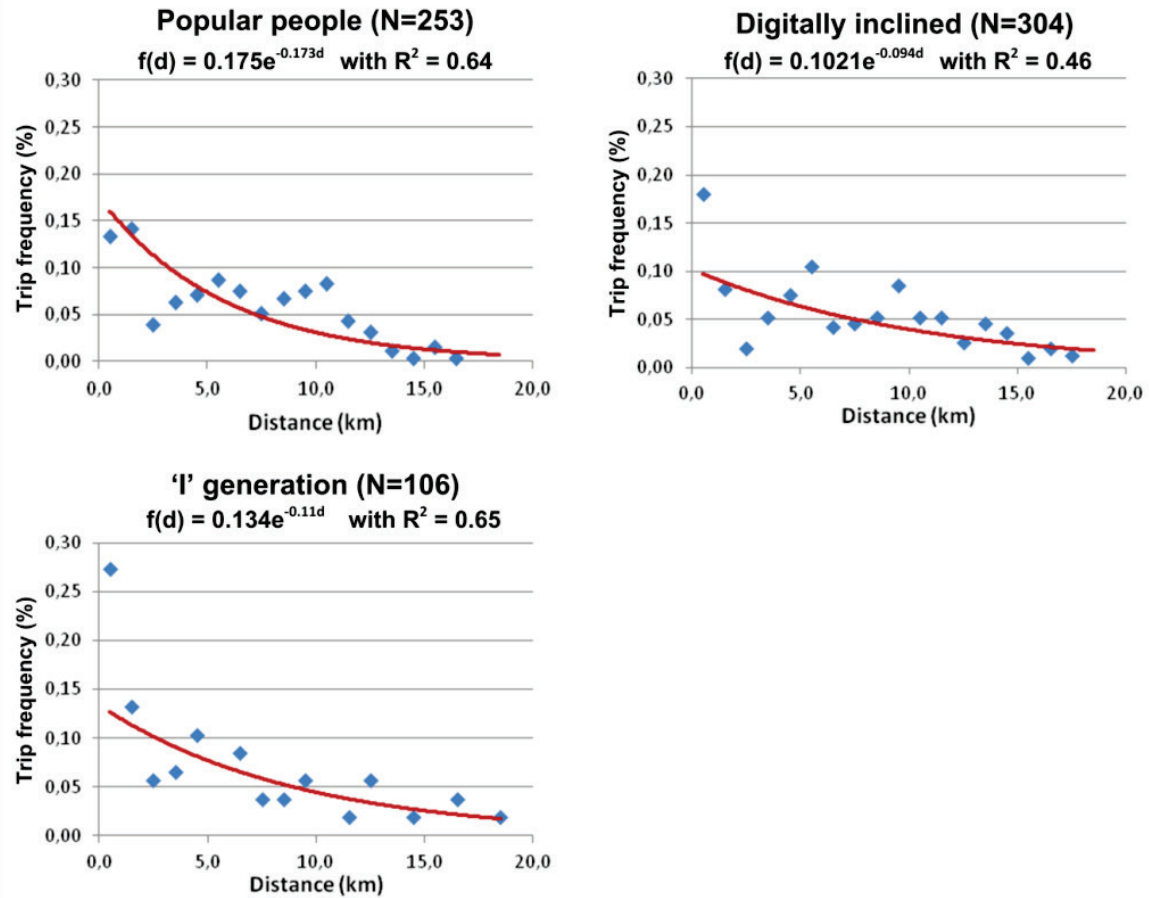

Figure 20 TLFD of physical trips by profile

It should be noted that the profiles do not divide the sample in equal parts. The sample sizes influence the $R^{2}$ as can be seen when comparing the TLFD of the Easy riders and Balanced people with the other profiles. The profiles with the lowest sample size have the lowest $R^{2}$. The sample size is however not the only aspect influencing the $R^{2}$. The ' $I$ ' generation for example, has the 
highest $R^{2}$ while its sample size is only half or one third of the sample sizes of the Popular people or Digitally inclined. If people are less influenced by distance, their TLFD might be less explained by the negative exponential trendline, i.e. the $R^{2}$ is a result as well indicating the influence of distance on trip frequency. It is assumed that despite the differences in sample size, the profiles' TLFD can still be compared broadly.

\section{Easy riders}

The TLFD of the Easy riders is not fitted well by the exponential function $\left(R^{2}\right.$ is 0.23 ). Besides, the $\beta$ is low indicating the physical trip making behaviour of the Easy riders is only marginally influenced by distance, which is expected.

\section{Balanced people}

The exponential function does not fit the TLFD of the Balanced people $\left(R^{2}\right.$ is only 0.02 ). The low $R^{2}$ and low $\beta$, indicate their physical trip making behaviour is least influenced by distance. This result was not expected.

\section{Popular people}

The TLFD of the Popular shows the steepest decline of all profiles, that is, has the highest $\beta$ (0.173). Besides, together with the ' $I^{\prime}$ generation, the TLFD is best fitted by the exponential function ( $R^{2}$ is 0.64$)$ indicating a clear influence of distance on Popular people's travel behaviour.

\section{Digitally inclined}

The travel behaviour of the Digitally inclined is well fitted by the exponential function ( $R^{2}$ is 0.46$)$ with a medium $\beta(0.094)$. So, their travel behaviour is influenced by the distance, but not as strong as for the Popular people.

\section{'I' generation}

The highest $R^{2}$ is found for the ' $\mathrm{I}^{\prime}$ generation, indicating their travel behaviour fits best, by the exponential function. With a medium $\beta$ but rather large $a$, the 'I' generation's travel behaviour is, apart from the Popular people, most influenced by distance.

From this analysis, it can be seen that the profiles most prone to physical travel, Easy riders and Balanced people, are probably least influenced by distance (low $R^{2}$ and low $\beta$ ). The travel behaviour of profiles more oriented at e-communication, Popular people, Digitally inclined and ' $\mathrm{I}$ ' generation, show to be stronger influenced by distance. It is likely that travel decisions are made differently among the profiles. People who are prone to ecommunication are resistant to travel physically since their TLFD's show a steep decay and vice versa. Apparently, the differences in travel patterns, derived from the TLFD, are captured by using social networks, derived from the trade-off between physical communication and e-communication. These 
differences in travel behaviour between the profiles' could complement to trip distribution modelling when using SN profiles as homogeneous sets of travellers. This is consistent with our earlier hypothesis.

Thus the second hypothesis is supported: since individuals have different $\mathrm{C} / \mathrm{T}$ balance their travel is affected differently by ICT, and this effect captured by difference in travel patterns can be explained by social network analysis.

Table 12 Socio-economic characteristics by profile

\begin{tabular}{|c|c|c|c|c|c|}
\hline & $\begin{array}{l}\text { Easy } \\
\text { riders }\end{array}$ & $\begin{array}{l}\text { Balanced } \\
\text { people }\end{array}$ & $\begin{array}{l}\text { Popular } \\
\text { people }\end{array}$ & $\begin{array}{l}\text { Digitally } \\
\text { inclined }\end{array}$ & $\begin{array}{l}\text { 'I’ } \\
\text { generation }\end{array}$ \\
\hline Number & 26 & 21 & 116 & 137 & 50 \\
\hline Average age (years) & 35 & 35 & 34 & 35 & 35 \\
\hline $\begin{array}{l}\text { Gender } \\
\% \text { males } \\
\% \text { females }\end{array}$ & $\begin{array}{l}62 \\
38\end{array}$ & $\begin{array}{l}71 \\
29\end{array}$ & $\begin{array}{l}68 \\
32\end{array}$ & $\begin{array}{l}68 \\
32\end{array}$ & $\begin{array}{l}60 \\
40\end{array}$ \\
\hline Literacy level $^{1}$ & Graduate & Graduate & Graduate & Graduate & $\begin{array}{c}\text { Primary } \\
\text { school }\end{array}$ \\
\hline $\begin{array}{l}\text { Employment status } \\
\% \text { self employed } \\
\% \text { employed } \\
\% \text { student } \\
\% \text { unemployed }\end{array}$ & $\begin{array}{c}23 \\
62 \\
8 \\
4 \\
\end{array}$ & $\begin{array}{l}24 \\
52 \\
14 \\
10\end{array}$ & $\begin{array}{c}16 \\
61 \\
16 \\
4 \\
\end{array}$ & $\begin{array}{c}19 \\
61 \\
13 \\
7 \\
\end{array}$ & $\begin{array}{c}6 \\
48 \\
22 \\
22 \\
\end{array}$ \\
\hline $\begin{array}{l}\text { Vehicle ownership } \\
\% \text { car } \\
\% \text { two wheeler } \\
\% \text { vehicle }\end{array}$ & $\begin{array}{c}42 \\
77 \\
100\end{array}$ & $\begin{array}{c}57 \\
71 \\
100\end{array}$ & $\begin{array}{l}26 \\
80 \\
92\end{array}$ & $\begin{array}{l}31 \\
71 \\
93\end{array}$ & $\begin{array}{c}8 \\
61 \\
70\end{array}$ \\
\hline
\end{tabular}

\subsubsection{Relation between TLFD and socio-economics}

Contrasting to the earlier mentioned travel aspects, the differences in TLFD cannot be explained by both the spatial or socio-economic characteristics used in this research since the differences in TLFD are not correlated with socio-economics. This can be shown by comparing for instance the Popular people and Digitally inclined, two almost identical profiles with respect to socio-economics (Table 12). No significant differences are found between the profiles based on these socio-economics. According to the classic travel behaviour models, both profiles would belong to the same homogeneous population group and so, a similar travel behaviour would be expected for people from both profiles (van Wee, 2009). Despite the fact that these people do show similar socio-economic characteristics, their travel behaviour does differ with respect to their TLFD. In other words, the differences in the 
profiles' TLFD's are not caused by differences in socio-economics or spatial characteristics.

Next to that, even when controlling for employment status, comparing the travel behaviour of the profiles' employed people, the profiles' TLFD's mutually differ. The Popular people still have the strongest decay (highest $\beta$ and $R^{2}$ ) while the Easy riders and Balanced people have the weakest (Table 13).

Table 11 Statistics of TLFD trend lines by profile (corrected for employment status)

\begin{tabular}{|l|c|c|c|}
\hline & $\boldsymbol{\beta}$ & $\boldsymbol{R}^{\mathbf{2}}$ & $\mathbf{N}$ \\
\hline Easy riders & 0.024 & $6.5 \%$ & 47 \\
\hline $\begin{array}{l}\text { Balanced } \\
\text { people }\end{array}$ & 0.014 & $2.0 \%$ & 35 \\
\hline Popular people & 0.161 & $62.6 \%$ & 187 \\
\hline $\begin{array}{l}\text { Digitally } \\
\text { inclined }\end{array}$ & 0.065 & $15.9 \%$ & 236 \\
\hline 'I' generation & 0.059 & $27.4 \%$ & 60 \\
\hline
\end{tabular}

Thus we find empirical support for the first hypothesis: socio-economic and spatial characteristics cannot be used as explanatory factors for the effects of ITC on travel.

\subsection{Discussion}

Our research has contributed to the rather thin empirical literature on the potential effects of ICT on travel at a social network level. Social networks induce travel or e-communication since people try to maintain or increase their social networks. Phones are used as e-communication means and therefore this research mainly focuses on performing social activities with social network members (friends, family, colleagues etc.). In view of the restricting assumption of only using phone calls to represent ecommunication, the results tend to be sufficient for this research. Significant differences are found in the e-communication behaviour (derived from the trip diary) between the profiles, which confirm the expected e-communication behaviour (based on the social network analysis).

Continuing with the argument that 'maintenance' and 'longevity' of trips can be better explained by looking into the elements that are less measurable in terms of cost and socio-economics we find that all profiles are affected by distance. Even though the cost of calling is the same all over the city, the number of calls drops as geographical distance increases. This is consistent 
with Chen and Wellman(2009) and proves distance has not died as a constraint on contact. Geographic and social distance each remain important, even in the age of net and jet.

Social network analysis can be used as a contribution factor in transport research. Differences found between profiles' physical and e-communication TLFD's, where profiles can be attributed to social networks, confirm this. Profiles, identical with respect to socio-economics and spatial characteristics, show clear differences in their TLFD. Even when controlling for employment status, the results yield the same conclusion. It empirically proves Axhausen's (2008) comment "instead of relying exclusively on the generalized costs of travel and the hedonic utility of a location as modulated by the socio-demographics of an individual and perhaps his or her values, one can add as explanatory factors both the social network geography of the person and his or her biography and network-based decision making..".

This finding shows social network profiles could complement current trip distribution modelling. Based on the differences in travel patterns, these profiles can provide homogeneous sets of travellers, that can be used in the calibration process of trip distribution modelling (Wilson, 1967; MacLean, 1976). This knowledge is relevant for transport planning of future Ahmedabad. Policy makers can effectively identify target profiles when making IT policies. These profiles can be understood and makes diagnosing problems related to particular profiles easier. It can make policies more strategic and successful.

It is well established that the recent information and communication technologies (ICTs) are fundamentally altering the organization and travel of individuals (Schwanen et al., 2006). The discipline of urban transportation analysis has evolved in the last three decades, to reflect this unprecedented personal mobility at local, national and international scales throughout the world. The movement of people is now at the core of research, exemplified by Mimi Sheller and John Urry's 'new mobilities' paradigm (Knowles, 2009). This research provides new insights into how social networks of individuals affect their travel decisions and it demonstrates in detail how social network analysis can be used as a tool to study the complex correlations between ICT and travel behaviour. 


\section{Chapter 5}

\section{Networkedness and physical travel ${ }^{6}$}

\footnotetext{
${ }^{6}$ This chapter is under review by : Mobilities
} 


\section{Abstract}

In this paper we develop the concept of networkedness. Networkedness represents the density of social networks over space. It is a spatial attribute and is defined as the average number of alters in the social networks of egos living in an area. We empirically investigate networkedness in the city of Ahmedabad, India, and analyse some of its characteristics. We have found relatively high networkedness values, indicating large social networks. Moreover, networkedness is not equally distributed over space. It is affected by the location of individuals with certain (communication) profiles, tiestrength of social networks and the e-communication/travel balance. However, socio-demographic variables do not affect networkedness. The study shows that social network analysis, in particular the clustering of individual in certain (communication) profiles together with the concept of networkedness provides new and useful information for transport planning and policy making practice. 


\subsection{Introduction}

The ever-increasing need to be spatially mobile challenges people to find new ways of developing and maintaining social ties (Viry, 2012). The recent developments in Information Communication Technologies (ICT) have enabled long distance communication without physical co-presence, rendering face-to-face meetings no longer a prerequisite in building or maintaining social contacts. During the last decade the interaction between ICT and travel has attracted much attention from scholars, and it is now well established that ICTs are fundamentally altering the organization and travel of households, firms and mainly individuals (Rheingold, 2002; Kenyon, 2006; Lyons, 2009). Although post-industrial theorist predicted a 'death of distance' leading to urban fields dominated by electronic cottages (Shen, 2000), it is increasingly recognized that ICT does not act as a mere substitute of face-toface communication. Rather it acts as a complement (Urry, 2004).

All the earlier studies suggest ICT use, as well as any associated travel impacts, is highly dependent on a variety of demographic, incidental, accessibility, and activity-related factors (Lu and Pas, 1999). Fox (1995) found that some factors that have influenced travel were environmental consciousness, costs, budget restrictions and the changing sociodemographic aspects of society. Zhang (2008) found that in the same age groups there was a significant difference in travel behavior between males and females of Beijing. Haustein et al. (2009) observed that travel of young Germans were influenced by peer pressure, level of socializing and communication with parents.

Another important factor affecting ICT use and travel is land-use and urban form. According to Cervero and Kockelman (1997) there are three dimensions of the spatial environment that influence travel: density, diversity and design. The urban form indicator which has received the most attention is urban density. Different kinds of densities have been used to measure the effects of exogenous variables affecting travel. Chatman (2008) found housing density has a fairly consistent relationship with travel, especially with activity frequency and Vehicular Miles Travelled (VMT). Su (2010) found population density and urban congestion have a negative impact on travel. Peng and Lu (2007) found the number of trips produced increased with the increase in employment density.

Thus, it is established that urban spatial density is very important in relation to travel. However, one main difficulty in explaining the impacts of ICT on travel through spatial density is identifying the likely activities in which individuals will choose to engage. For example, it is easy to roughly assess how someone who begins to e-commute due to congestion may reduce his or her commuting. But what types of travel that person still engages in, in 
his/her free times, is difficult to measure (Choo and Mokhtarian, 2007). However, if a closer look is taken into the social networks of the individual it is possible to empirically generate data that can be used to calculate which (travel) relation is being substituted or complemented by ICT (Axhausen, 2008). So it is pertinent to take into account individual's social network when studying the effects of ICT on travel.

In transportation research two lines of research into the effect of social networks on travel behaviour have emerged recently. The first line of research is concerned with the effects of social networks that are related to the desire of individuals to meet people of their social network. Tillema et al. (2010) found a negative relation between geographically dispersed networks and the number of face to face contacts, while electronic contacts remained the same irrespective of geographical location. Hipp and Perrin (2009) concluded that physical distance decreases the probability of framing social ties. In most cases, it is seen that social interaction falls with increasing distance, though the rate of decline depends on the kind of social relationship (Butts, 2002).

The second line of research focuses on the way people's social networks influence their travel decision by the exchange of information and opinion. Dugundji and Walker (2005) and Páez et al. (2008) have stressed the need to incorporate the effects of social influence in decision making. Thus, social networks and especially decisions of others in the network can have an influence on peoples decision on trip destination, route, frequency and mode. The key characteristic of social networks, i.e. 'which alters constitute the network', is very important since it can be hypothesized that the network composition constitutes a potential source of explanation for the propensity to perform travel (Carrasco and Miller, 2006).

All the studies mentioned affirm that both spatial density and social networks are equally important for travel research. But studies combining the aspect of space with social network are not available. This chapter starts to fill this gap by bringing these two important aspects together through the concept of networkedness. It is a novel way of considering space within the framework of social networks. We empirically test it in the city of Ahmedabad, India.

Networkedness is a novel attribute of space and represents the density of social networks of people living there. The practicality of the concept lies in the fact that it can be used by transport planners and policy makers to measure the demand for infrastructure. We hypothesize that networkedness has certain properties and can be used by policy makers effectively. The characteristics that might have an effect on networkedness are discussed in the following sections. 


\subsection{Theoretical framework}

\subsubsection{Geographical distance, mode of communication and networkedness}

Modern means of transport and communication facilitate maintaining contacts with family, friends, colleagues and acquaintances even at larger distances. However, studies on the association between spatial proximity and social networks have often found that spatial proximity affects the kinship ties between individuals (Verdery et al. 2012). A similar case is seen in Latané et al.'s (1995) findings on the diminishing strength of social influence with increasing spatial distance.

With the advent and rapid development of electronic forms of communication, physical presence is not always necessary for social contact. Thus, it becomes important to consider the aspect of mode of communication with respect to networkedness i.e. the distribution of an ego's social network over space. Studies have revealed that strength of social relationship or tiestrength affects the mode of communication (Mokhtarian and Meenakshisundaram 1999). The strength of ties is determined on the relation itself which affects the mode of communication, whether being a face-to-face contact or e-communication.

The relation between tie-strength and mode of communication (face-to-face or e-communication) has been studied in various contexts (Haythornthwaite, 2001; Axhausen, 2008; Carrasco et al., 2008; Dugundji et al., 2008; Tillema et al., 2010). Some argue that strong ties are more prone to electronic means of communication (Mokhtarian and Meenakshisundaram, 1999) while others are of the opinion that weak ties are maintained electronically (Mok et al., 2010). However, there is no unanimity among researchers on the mode of communication and tie-strength; they do acknowledge that ICT have an effect on social networks. We hypothesize that distance between ego and alter does not matter greatly for networkedness (sub-hypothesis H1); because egos will communicate with alters either through e-communication or face-to-face. Either ways ties are maintained, not affecting networkedness.

\subsubsection{Travel/e-communication networkedness}

balance and

Although many studies have examined the form of the relationship between spatial distances and social networks, few have mapped the spatial interaction, albeit travel or e-communication interactions arising out of such networks (Hansen et al., 2011). Roy et al. (2012) indicate that the influence 
of ICT on travel behaviour and e-communication is also related to the individual's social network, i.e. the generation of travel and e-communication always takes place among people within their network. Based on these social networks, distinctions are found between people's physical travel ( $T$ ) and ecommunication (C). For Ahmedabad, Roy et al. (2012) clustered the individual's social networks based on the ratio between individual's $\mathrm{C}$ and $\mathrm{T}$ ( $\mathrm{C} / \mathrm{T}$ balance) and obtained five distinct profiles described in Table 14.

Table 12 C/T balance profiles (Source: Roy et al. (2012))

\begin{tabular}{|l|l|l|}
\hline Profile & Name & Characteristics \\
\hline 1 & Easy Riders & $\begin{array}{l}\text { People with low e-communication and high physical } \\
\text { communication. They prefer to maintain their social } \\
\text { networks through physical travel }\end{array}$ \\
\hline 2 & Well Connected & $\begin{array}{l}\text { People who had nearly equal number of physical and } \\
\text { virtual communication. }\end{array}$ \\
\hline 4 & $\begin{array}{l}\text { People who had exceptionally high number of both } \\
\text { physical and virtual communication. They physically } \\
\text { met a lot of people and also kept in touch through } \\
\text { ICT. }\end{array}$ \\
\hline 5 & Digitally Inclined & $\begin{array}{l}\text { People who would shift to a more ICT prone } \\
\text { communication with a little push. These people are } \\
\text { more prone to e-communication than physical travel. }\end{array}$ \\
\hline 'I' Generation & $\begin{array}{l}\text { A very virtual people. This profile represented people } \\
\text { who communicated more using ICT and had very few } \\
\text { physical communications. }\end{array}$ \\
\hline
\end{tabular}

Understanding the $\mathrm{C} / \mathrm{T}$ balance of individuals (egos) in connection with networkedness is important, because as they move (change their residence) away from their neighbourhood (ward), they come in contact with other people which leads to an increase in their networks. They then might decide to maintain their old relations digitally while establishing new relations faceto-face. The relocation of egos causes a change in their $\mathrm{C} / \mathrm{T}$ balance and a change in the networkedness of wards. Thus, we hypothesize that networkedness depends on the $C / T$ profiles of the egos of that wards (subhypothesis H2). Another practical reason for reviewing networkedness in the context of $\mathrm{C} / \mathrm{T}$ balance is, that a ward with high networkedness dominated by profile 1 (easy riders) will need a different transport policy compared to a ward with high networkedness dominated by profile 5 ('I' generation).

\subsubsection{Socio-demographics and networkedness}

Several mechanisms and conceptual frameworks have been advanced to explain the possible relationship between social networks and sociodemographics. Rogerson (1997) has found that there exists a relationship between socio-demographics and social networks. For instance, people with higher education may have larger networks. Similarly, Willmott (1988) concluded that large social networks are indicative of affluence and social status. Moreover, higher income has been found to be positively correlated 
with bigger social networks (Willmott, 1988). But studies have not incorporated e-activities in this respect. Silvis et al. (2006) found no statistically significant difference on socio-demographic variables between mobility groups, suggesting that social patterns were fairly universal on a socio-economic and demographic level. Roy et al. (2012) had similar findings. We hypothesize, that socio-demographic variables do not affect networkedness (sub-hypothesis H3).

In this chapter, we consider how individuals maintain a balance between face-to-face and e-communication within their social networks, and investigate whether this balance is affected by socio-demographic characteristics of the egos. There is a vast literature about ICT and travel (Kwan et al., 2007; Axhausen, 2008; van den Berg et al., 2012) and to a lesser extent regarding the application of social network analysis in this domain (Carrasco and Miller, 2009; Hackney and Marchal, 2011). However, we have identified the following gaps in literature: firstly, studies into the relations between social networks and travel only consider part of the ego's network (Tillema et al., 2010); secondly, when tie-strength is taken into account as well as location of egos and their networks, only one kind of tie (e.g. kinship, family ties) is considered (Verdery et al., 2012); thirdly, the distribution of social networks over space and its associated characteristics have not been studied. In addition, studies on the effects of the $\mathrm{C} / \mathrm{T}$ balance, socio-demographics and location of egos on networkedness of people are not available for emerging economies like India.

In this chapter, we will address these gaps by answering the question "what are the properties of networkedness and how is networkedness being affected by distance and mode of communication $\left(H_{1}\right), C / T$ balance of egos $\left(\mathrm{H}_{2}\right)$ and socio-demographics $\left(\mathrm{H}_{3}\right)^{\prime \prime}$, on the basis of empirical data. For this purpose we have applied a simplified social network approach by focusing on communications (both virtual and physical) between a specified person (in this case the respondent) and other network members ('egocentric social network approach'). We have taken a closer look at the profiles created by (Roy et al., 2012) and relate the profile's communication patterns with alters. Then, we apply and analyse the concept of networkedness for the city of Ahmedabad in India.

\subsubsection{Case study: Ahmedabad, India}

Ahmedabad, located in the western part of India, is the sixth largest city in India. It is the largest city and the industrial capital of the state of Gujarat. The city is home to 5.6 million people distributed over 51 administrative wards (zones) of which 8 have been added in 2007. In India, and in Gujarat especially, strong kinship ties are very important (Heitzman and Worden, 
1995). Due to these strong kinship ties and the inexpensive way of communicating by phone and internet, people in India are maintaining their social network both physically as by e-communication (Roy et al., 2012). Therefore, Ahmedabad is considered an appropriate case study for this research. The phone is primarily used as a mean for e-communication (167 phones per 100 inhabitants in urban areas) (TRAI, 2012), while the internet is less prominent ( $8 \%$ internet penetration) (TRAI, 2010).

\subsection{Methodology}

\subsubsection{Networkedness}

In this chapter networkedness is a property of an area, in this particular case a ward, and it is mathematically defined as

$W_{i}=\frac{\sum_{e=1}^{N_{i}} A_{e}^{i}}{N_{i}} \quad \forall i$

where

$W_{i} \quad$ is the networkedness of ward $\mathrm{i}$,

$N_{i} \quad$ is the number of egos e living in ward i,

$A_{e}^{i} \quad$ is the number of alters (wherever they live) of ego e living in ward $\mathrm{i}$.

Networkedness represents the spatial distribution of social networks, equals the average number of alters over all egos in an area (ward) and can be interpreted as the average density of social ties in that area (ward). The practical relevance of the concept is that the higher the networkedness of a ward the more the physical and digital communication from, to and within that ward. High values of networkedness might translate to more congestion on roads, an issue to be addressed by transport planners. Thus, we believe networkedness could provide useful information for the development of transport policies.

The aim of the methodology is to derive, analyse and compare the overall networkedness of Ahmedabad. For this we collected data through a questionnaire survey. Efforts are directed to create the networkedness map of Ahmedabad and subsequently to contrast it with the socio-demographic characteristics of egos, C/T balance map, and the mode of communication with alters of varying tie strengths. The methodology of this chapter builds on the profiles created in chapter 3. To study the interaction between ecommunications and physical communication, first and foremost the individual's network attributes were divided into groups, thereby creating homogeneous subgroups, characterized by within group similarity and 
between group differences. These distributions create a distinctive social context to which individuals respond (Roy et al., 2012). As homogeneity increases, these differences are increasingly likely to acquire meaning to subgroup members, thus to influence social behaviour (Lawrence and Zyphur, 2010).

\subsubsection{Assumptions}

Usually tie strength is defined as the combination of the amount of time, the emotional intensity, the intimacy (mutual confiding), and the reciprocal services which characterize the tie. (Granovetter, 1973). However, Granovetter's work was carried out in a different cultural context than ours. In our analysis we define tie strength based on the relation e.g. family, friends, extended family, colleagues and acquaintances. The following are some assumptions made so as to focus on the concept of networkedness and not distract the focus to tie-strength.

We assume that tie strength does not only depend on time spent, emotional intensity or intimacy but on the relationship itself. i.e. family is assumed to be a strong tie (Palackal et al., 2011) while acquaintance is considered as a weak tie, because usually a person interacts more with a family member than with an acquaintance. Friends and extended family are considered as strong ties because in Ahmedabad, even 'remote' relatives and friends are considered as close family members (Henn, 2012). Colleagues are considered as strong ties because the profiles are based on the C/T balance of egos, and colleagues cause a lot of communication (both physical and electronic).

In the questionnaire we ask for the number of people and mode of communication over the last one month, because we assume all the other ties are non-existent or absent ties. If an ego does not correspond with an alter once a month the relation is absent.

\subsubsection{Data}

The collection of the data was based on an egocentric approach. We collected data through an interviewer-led survey with a questionnaire between August and October 2010 and between October and December 2011. The sampling strategy consisted of a single stage cluster sampling.

We surveyed the area of Ahmedabad Municipal Corporation (AMC) jurisdiction. AMC has 43 administrative wards and 8 outgrowths (area added to the jurisdiction of AMC after 2007). We chose the ward as survey unit because commonly in India planning policies are implemented at ward level (Smith, 2008). For the selection of respondents we considered population size of a particular ward, in particular the percentage of the total population. 
The same proportion of sampling units was selected for that ward. Individuals from that ward were selected randomly at an interval of 5 households. If the individual from one household was not available we shifted to the next household.

In total 786 questionnaires were collected. Based on an analysis of boxplots we found that 18 respondents were extreme outliers. We used k-means clustering, a standard classification technique. To make the $k$-means clustering robust, we determined the $95 \%$ quartile of the observed range of the data to identify the outliers. After removing these the total number of respondents was 768 .

For these respondents the virtual and physical social networks were derived based on their mode of communication i.e. face-to-face and electronic (emails, phone, SMS and chat). We followed the clustering methodology of Roy et al. (2012).

We collected data on how many family members, extended family members, friends, colleagues and acquaintance each respondent communicates with and the mode of communication. We mapped the spatial distribution of egos according to their ward and profile membership. Figure 22 shows proportional circles for each ward to represent their (egos) population.

\subsection{Networkedness of Ahmedabad}

The networkedness map (Figure 21) shows for each ward what the average number of alters is with whom an ego in that ward communicates (both physical and virtual). The networkedness map illustrates which parts of Ahmedabad have small or large social networks. The average number of alters range from 2 (low networkedness) to 58 (high networkedness). Wards with a higher number of alters are scattered all over the city. Networkedness does not follow any pattern, so we cannot confirm that egos near the CBD communicate with more alters than peripheral wards or vice versa. The networkedness map also shows that there are at least 20 wards where egos communicate with more than 50 alters (in both outer and inner wards).

In the following sections we will analyse relations between networkedness and characteristics like $\mathrm{C} / \mathrm{T}$ balance and profiles of egos, distance, mode of communication and socio-demographics. 


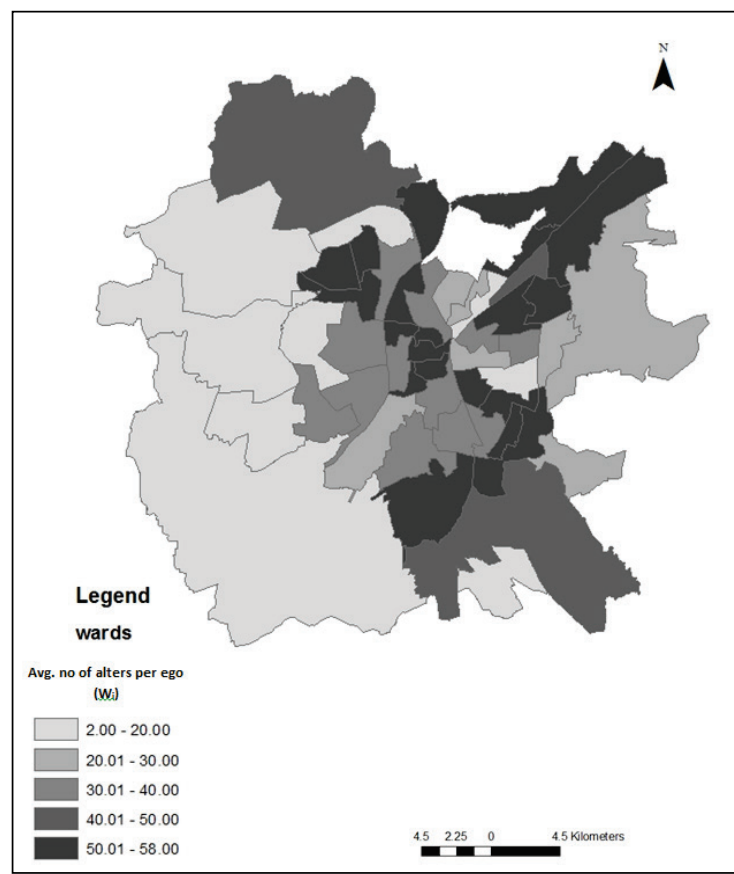

Figure 21 Networkedness map of Ahmedabad

\subsubsection{Networkedness and travel/e-communication balance}

To study the effects of communication mode and spatial distribution of social networks the $\mathrm{C} / \mathrm{T}$ balance and networkedness map is compared (Figure 22). The map presents profile percentages of each ward in pie charts, where the size of the circle is proportional to population size in the ward. It indicates how people of each ward use e-communication or physical travel to maintain their social networks. As can be seen from the map, the eastern part of Ahmedabad is more active in terms of e-communication than the western part, since the eastern part has more people with the digitally inclined profile (4 in the legend). The city centre is less e-communication prone than its surrounding areas, since it shows presence of more easy riders than its surrounding wards ( 1 in the legend). The wards just west of the river are highly e-communication prone while the outer wards (industrial wards) are more physical travel prone. The pattern seems to be, that as we move away from the city centre on the east the wards become more e-communication prone. On the west unlike the east only a few wards are more ecommunication prone. The discrepancy in the east and west could be because the east has more overall development (due to the historical CBD being in the east) while the west has concentrated areas of growth along the transport lines (Adhvaryu, 2010). We believe once the west is fully developed there is a good chance that it will show a $\mathrm{C} / \mathrm{T}$ balance like the east. 


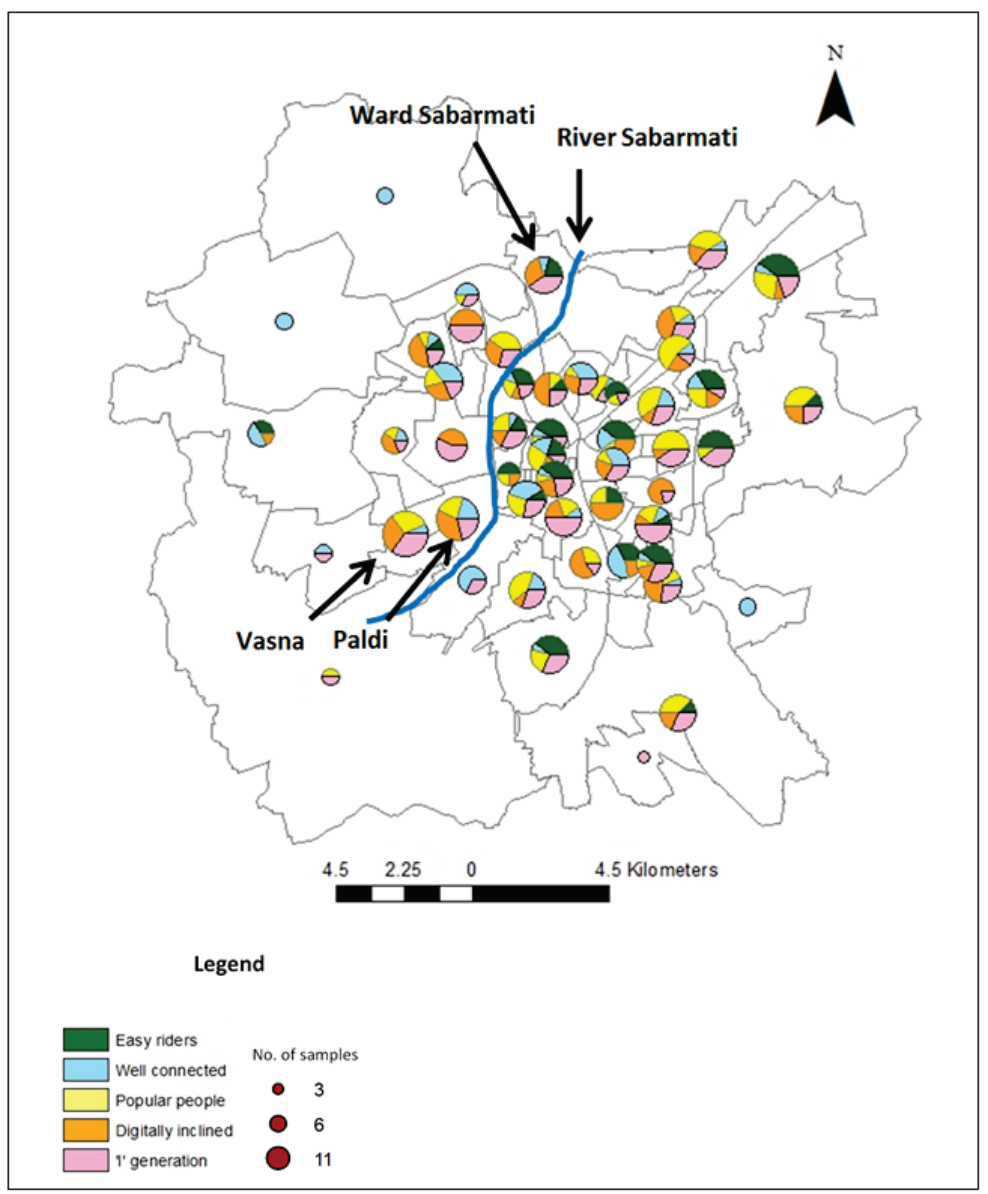

Figure $22 \mathrm{C} / \mathrm{T}$ balance map of Ahmedabad

\subsubsection{Networkedness and location of egos}

To find out whether the location of profiles has any relation with the networkedness we have selected each profile, mapped their location over Ahmedabad, and tried to understand its effect on networkedness.

Easy riders (people living in the walled city of Ahmedabad)

Easy riders (profile 1) represent egos with low e-communication and high physical communication. As can be seen from Figure 23, profile 1 is mostly located in the central parts of the city, along the Sabarmati river (Figure 23), which is also the old Ahmedabad. Also generally this profile does not live very far from the city centre. The location of this profile corresponds to high networkedness (Table 15). This indicates that egos choose to meet most of their alters face-to-face. Though they have the power of ICT they still prefer 
face-to-face communication. For transport planning it means more people on the road and higher pressure on transport infrastructure.
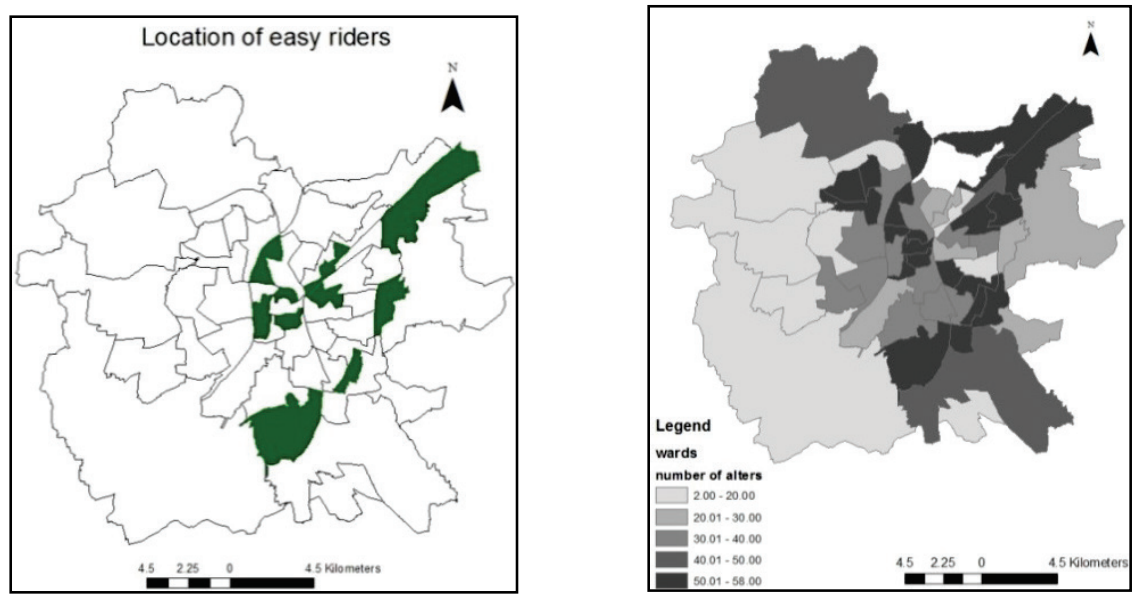

Figure 23 Comparison between location and networkedness of easy riders

Well connected (e.g. housewives, teachers)

Profile 2 representing egos with a balanced network, i.e. people who communicate equally with all their alters both face-to-face and through ecommunication is located in the north-western part of the city (Figure 24). They are located mostly away from the city centre and towards the industrial wards of Ahmedabad. However, they do not locate themselves very far away from the city centre. This group of people does not correspond to any one specific networkedness. They tend to correspond to medium to high networkedness (Table 15). It indicates a travel demand not as high as the previous profile but still considerable pressure on transport infrastructure.
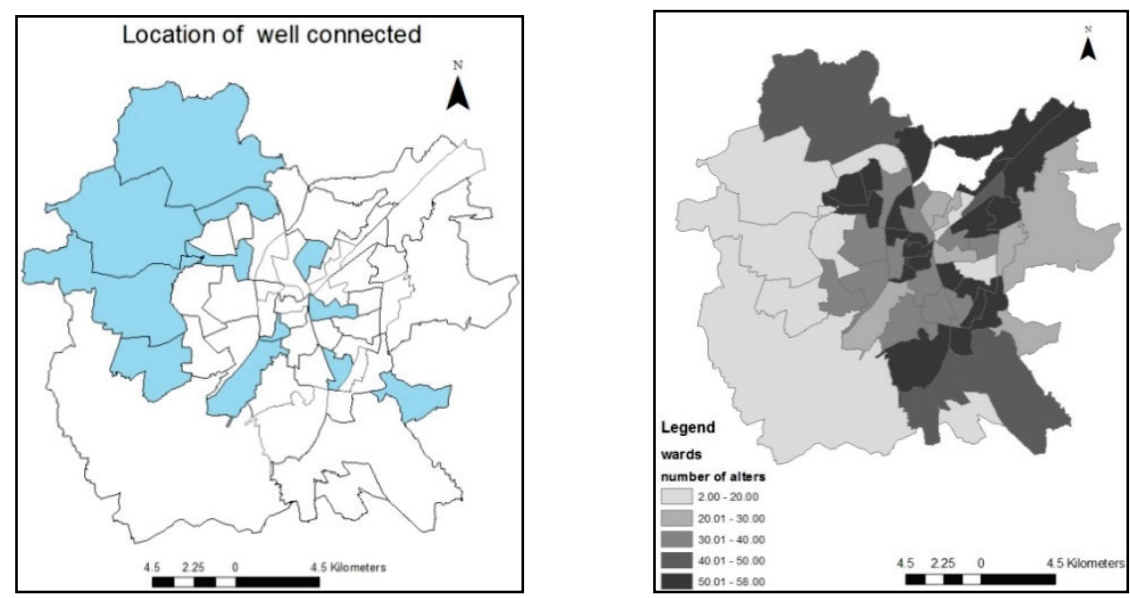

Figure 24 Comparison between location and networkedness of well-connected egos 
Popular people (e.g. shopkeepers. doctors, lawyers)

Popular people or profile 3 represent egos that are difficult to place in a high or low $\mathrm{C} / \mathrm{T}$ balance profile (Figure 25 ). These egos have a large physical network as well as a big virtual network. Their alters do not know each other. These people are typically businessmen, shopkeepers, etc. The size of the networks affects the networkedness of the wards. This profile is mostly concentrated in the eastern part of the city. They roughly correspond to high networkedness, with some wards showing medium-high networkedness (Table 15). Though it might imply extremely high volumes of traffic on the roads, this is not the case. Because a high percentage of communication of this profile is done electronically.
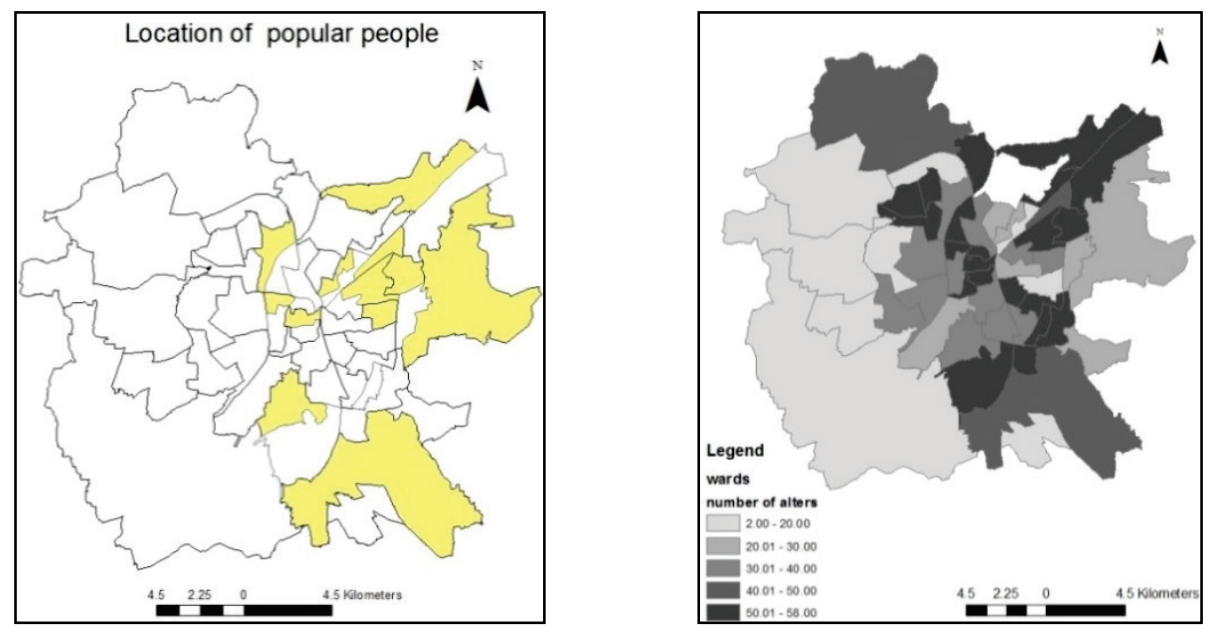

Figure 25 Location and tie strength of popular people

Digitally inclined (e.g. students)

Profile 4 consists of egos that are digitally inclined (Figure 26). They would shift to a more ICT prone lifestyle with a little push, affecting the networkedness of the ward they live in. They tend to be more prone to ecommunication than physical travel. Profile 4 is located nearly all over the city with particular concentration towards the south-east of river Sabarmati. Networkedness wise, this profile tends to have medium to low networkedness (Table 15). For this profile distance is important since they tend to be more ICT prone, indicating that for this profile the tendency to physically meet people is not strong. And it can be concluded that digitally inclined egos do not pose major risk of road congestion. 

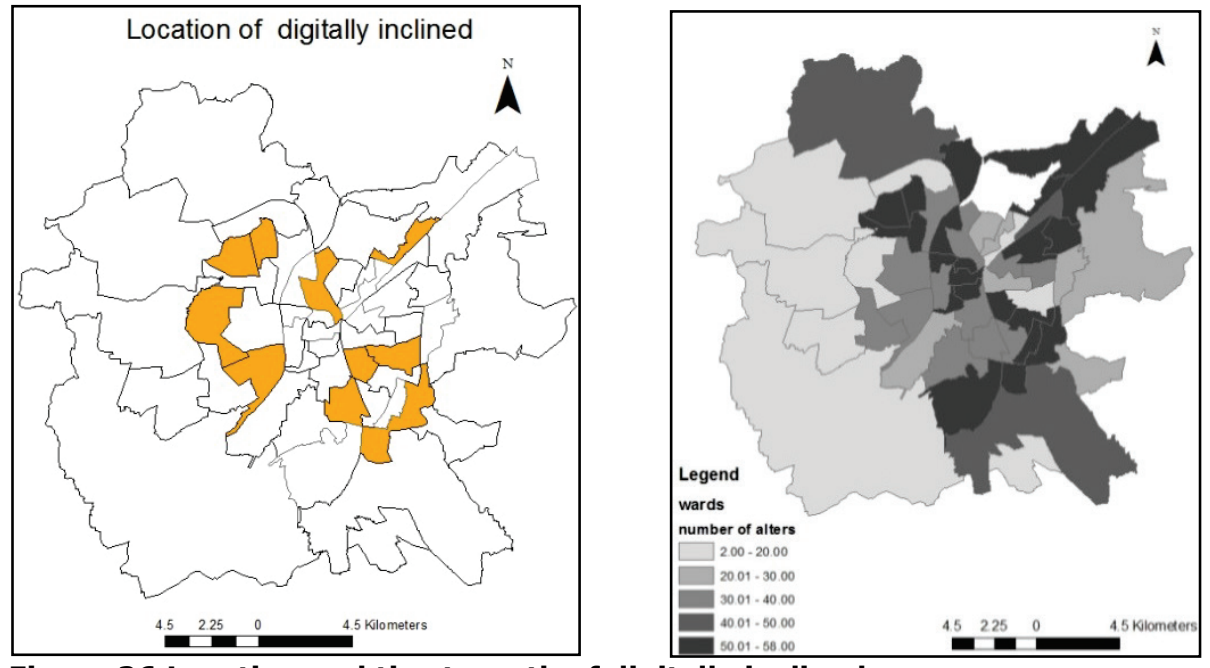

Figure 26 Location and tie strength of digitally inclined

"I" generation (e.g. people working from home, freelancers)

Profile 5 or the 'I' generation people are also spread all over the city (Figure 27). Though they are concentrated in the western part of the city, their presence is also seen in the east. They have low to medium networkedness with one exception (Table 15). We think that wards where this profile is found mostly are populated by people coming to other states of India. They communicate with their (extended) family electronically on a regular basis, thus making them ' $I$ ' generation. Since most communication of this profile is electronic it can be assumed that their intra-city physical travel is not very high, although their inter-city travel may be.
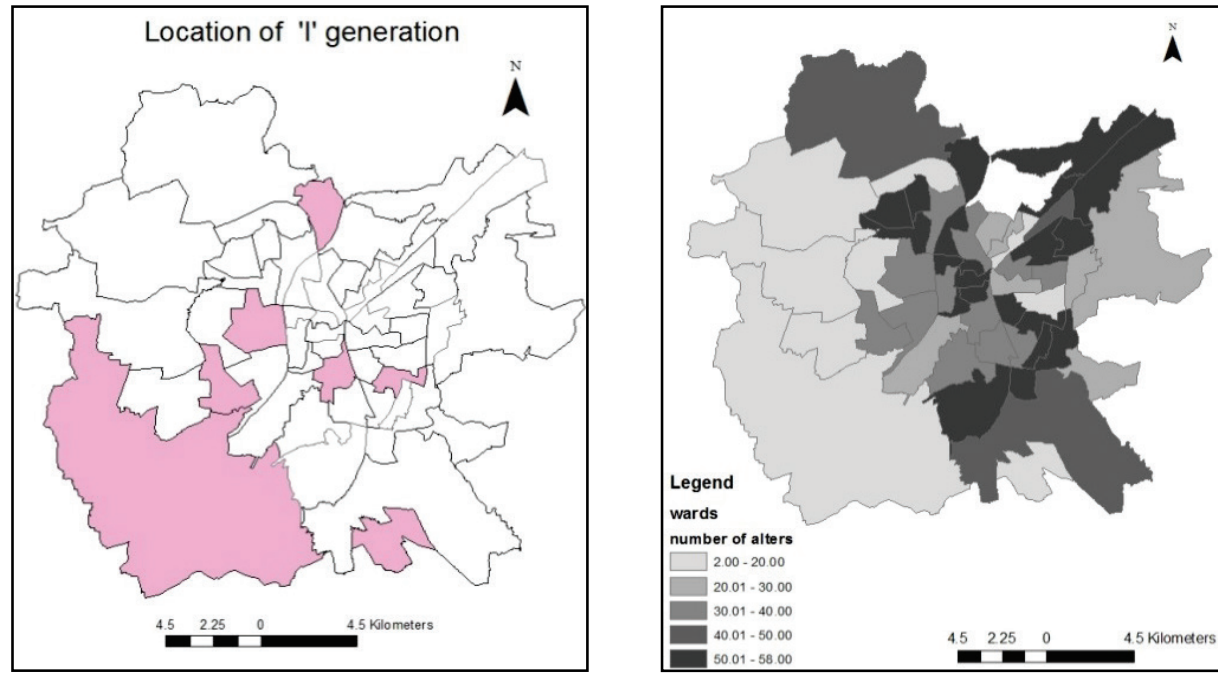

Figure 27 Location and tie strength of ' $I$ ' generation 
Table 13 Profile and Networkedness Cross tabulation

\begin{tabular}{|c|c|c|c|c|c|c|c|c|}
\hline \multirow{2}{*}{\multicolumn{3}{|c|}{ 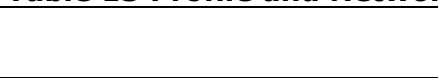 }} & \multicolumn{5}{|c|}{ Networkedness } & \multirow[t]{2}{*}{ Total } \\
\hline & & & 1.00 & 2.00 & 3.00 & 4.00 & 5.00 & \\
\hline \multirow{10}{*}{ Profile } & \multirow[t]{2}{*}{1} & Count & 0 & 1 & 2 & 1 & 6 & 10 \\
\hline & & $\begin{array}{l}\% \text { within } \\
\text { Networkedness }\end{array}$ & 0.0 & 14.3 & 15.4 & 14.3 & 42.9 & 19.6 \\
\hline & \multirow[t]{2}{*}{2} & Count & 2 & 1 & 4 & 1 & 4 & 12 \\
\hline & & $\begin{array}{l}\% \text { within } \\
\text { Networkedness }\end{array}$ & 20.0 & 14.3 & 30.8 & 14.3 & 28.6 & 23.5 \\
\hline & \multirow[t]{2}{*}{3} & Count & 1 & 2 & 2 & 5 & 2 & 12 \\
\hline & & $\begin{array}{l}\% \text { within } \\
\text { Networkedness }\end{array}$ & 14.3 & 28.6 & 15.4 & 50.0 & 14.3 & 23.5 \\
\hline & \multirow[t]{2}{*}{4} & Count & 2 & 2 & 3 & 2 & 1 & 10 \\
\hline & & $\begin{array}{l}\% \text { within } \\
\text { Networkedness }\end{array}$ & 20.0 & 28.6 & 23.1 & 28.6 & 7.1 & 19.6 \\
\hline & \multirow[t]{2}{*}{5} & Count & 1 & 1 & 2 & 2 & 1 & 7 \\
\hline & & $\begin{array}{l}\% \text { within } \\
\text { Networkedness }\end{array}$ & 10.0 & 14.3 & 15.4 & 28.6 & 7.1 & 13.7 \\
\hline \multirow{2}{*}{\multicolumn{2}{|c|}{ Total }} & Count & 10 & 7 & 13 & 7 & 14 & 51 \\
\hline & & $\begin{array}{l}\text { \% within } \\
\text { Networkedness }\end{array}$ & 100.0 & 100.0 & 100.0 & 100.0 & 100.0 & 100.0 \\
\hline
\end{tabular}

\subsubsection{Networkedness and tie-strength of profiles.}

Since we find that the $\mathrm{C} / \mathrm{T}$ balance of the egos has an effect on the networkedness, it is important to examine tie-strength of profiles. Tie strength and physical communication are directly linked to the amount of traffic on the road.

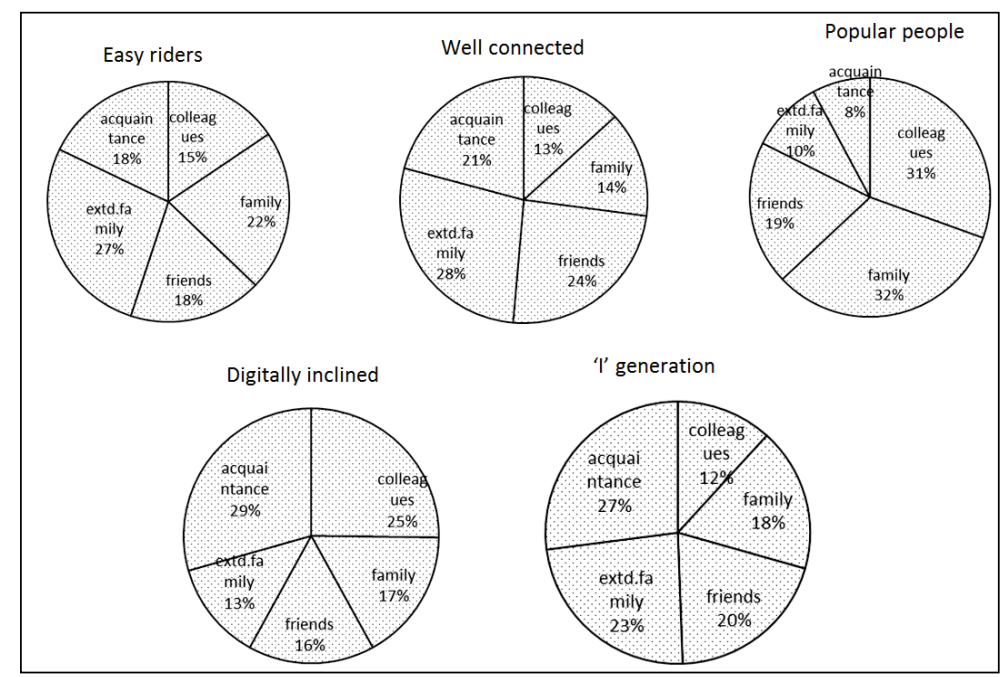

Figure 28 Social network relation with whom egos communicate physically

The easy riders have a low percentage of acquaintance (weak ties) and high percentage of (extended) family (strong ties). The high percentage of (extended) family affects the networkedness of the wards where this profile 
is found. The well connected people on the other hand have a low percentage of family (strong ties) members who they communicate with $\mathrm{e}$ communication, but a high percentage of acquaintance. This feature is very interesting because according to literature (Fish et al., 1993; Chung and Hossain, 2010) people communicate more with strong ties through ecommunication than with weak ties. The mode of communication with different ties affects the networkedness because it affects the $\mathrm{C} / \mathrm{T}$ profile of the egos. This profile 3 has a large percentage of colleagues (strong ties). They also have large percentages of family but a small percentage of extended family (strong ties), with who they communicate physically. The absence of large numbers of family members explains the medium networkedness of this profile. Profile 4 shows a very low percentage of family (strong ties) that they communicate physically. The percentage of acquaintance is highest among all the profiles. This supports the fact that distance is a deterrent for this profile, and they physically meet colleagues and acquaintances, probably because it is absolutely necessary and not out of choice. The ' $\mathrm{I}$ ' generation profile has a high percentage of acquaintance (weak ties) and a low percentage of family (strong tie). Friends and extended family (strong ties) make a major part of their network, supporting the earlier assumption that egos of this profile could be mainly people from other parts of India.

\subsubsection{Networkedness and socio-demographic characteristics}

To study whether socio-demographics has an effect on networkedness we have correlated personal attributes of egos like age, income and literacy levels with networkedness. Table 14 shows there is no significant correlation between the socio-demographic variables and networkedness. The correlation between networkedness and age is -0.023 . which means the younger the population of a ward the higher the networkedness. The correlation between networkedness and literacy level is 0.12 and income level (indicated by car ownership) is 0.09 . This is indicative that there is a very weak positive correlation between networkedness and literacy and income level. Though literacy has a comparatively stronger correlation it is still only 0.1 , which is contradicting the results of Rogerson (1997). 
Table 14 Correlation between networkedness and socio-demographic characteristics

\begin{tabular}{|l|l|l|l|l|l|}
\hline \multicolumn{2}{|l|}{ Correlations } & Networkedness & Age & $\begin{array}{l}\text { Literacy } \\
\text { level }\end{array}$ & $\begin{array}{l}\text { Car } \\
\text { ownership }\end{array}$ \\
\hline \multirow{2}{*}{ Networkedness } & $\begin{array}{l}\text { Pearson } \\
\text { Correlation }\end{array}$ & 1,000 &,- 023 &, $121^{* *}$ &, $091^{* *}$ \\
\cline { 2 - 6 } & Sig. (1-tailed) & &, 336 &, 000 &, 000 \\
\cline { 2 - 6 } & $\mathrm{N}$ & 51,000 & 51 & 51 & 51 \\
\hline
\end{tabular}

$* *$ Correlation is significant at the 0.01 level ( 1 tailed)

* Correlation is significant at the 0.05 level ( 1 tailed)

\subsection{Discussion}

We examined the characteristics of networkedness and our main findings are discussed in the following sections.

\subsubsection{Networkedness is not affected by location at city level}

At a city level location is not important when considering networkedness. This can be deduced from the fact that both the inner wards and outer wards have high networkedness (Figure 21). However, there are two explanations for this characteristic of networkedness.

Firstly, a special feature of the plan of the old city is its numerous pols. People living in the pols have high networkedness (Figure 21) and like to maintain their social networks through face-to-face communication. We argue that these people form the core of profile 1 (easy riders). This is because the profile compositions for wards of the old city show a good percentage of easy riders, which does not necessarily correlate to income level. They meet face-to-face with their strong ties and use e-communication for the weak ties (Figure 28).

Secondly, egos living in the outer wards also have high networkedness. An example of such a ward is Sabarmati, with a high percentage of 'I' generation and popular people, high networkedness, far from the walled city and near the fringe AUDA (Ahmedabad Urban Development Authority) boundary. The residents have large social networks (i.e. high networkedness of the ward). Their option is e-communication since most of their strong ties live in other parts of India (only $18 \%$ of their family they meet face-to-face). We argue that they are 'I' generation (profile 5) people. They meet only their weak ties face-to-face and communicate with the strong ties digitally (Figure 28).

The social networks of the egos which give the ward its networkedness. Once the egos decide to move out of the city or locate somewhere else in the city 
the networkedness of the ward will change completely. A change in location of the egos might lead to a change in their mode of communication, and thereby their $\mathrm{C} / \mathrm{T}$ profiles.

\subsubsection{Networkedness is ego's location and tie-strength dependent}

Networkedness is a variable dependent on the ego's location and tiestrength. It means that people do not change their tie-strengths when they change location (change their ward of residence) but the networkedness of the ward changes with a change in location of the egos. Also people maintain their networks through both physical travel and e-communication as and when. An example is the wards Paldi and Vasna that have high ecommunication prone profiles but is medium in networkedness (Figure 21 and Figure 22). The residents of these wards have strong social networks with people residing in the city centre. Given a choice some of them would like to go back to their old areas of residence but are sacred due to the riots (Chatterjee, 2009). Egos of these wards belong to the profiles digitally inclined (profile 4) and ' $\mathrm{I}$ ' generation (profile 5) mostly. They communicate with their weak ties face-to-face and with their strong ties through ecommunication. This is absolutely different from profile 1 . These wards would change their networkedness if the egos did go back to their old residence. But the egos would not change their tie-strengths even if they went back. This brings us to our first sub-hypothesis that distance between ego and alter does not matter greatly for networkedness. We accept this hypothesis.

Networkedness also depends more on the number of weak ties than strong ties. When people decide to relocate (change their residence) they do not stop communication with their strong ties. But they might choose to communicate less or not at all with their weak ties. The drop in the number of weak ties leads to a change in the total number of alters affecting the networkedness of the ward.

Also these profiles do not confirm the study of Verdery et al. (2012), that finds a relation between spatial proximity and kinship. Such patterns may be a characteristic of developing economies. But more in-depth research is needed to make any such empirical claims. The difference in the findings of the present chapter and Verdery et al. (2012) might be because of a difference in context.

\subsubsection{Networkedness is $\mathrm{C} / \mathrm{T}$ profile dependent}

As can be seen from the profiles and how they interact with their weak and strong ties, we conclude that the location of egos has an effect on their mode of communication. It means that with a change in location the $\mathrm{C} / \mathrm{T}$ balance 
changes, changing the networkedness of the wards. Profiles with higher usage of ICT have lower levels of networkedness (Table 13). They meet their weak ties face-to-face and e-communicate with their strong ties (Figure 28). According to us, the use of e-communication or physical communication to maintain ones social network is more need-based than distance-based (Hipp and Perrin, 2009). Profiles that live close to their strong ties maintain these face-to-face. But if they are forced to move away they maintain the same relations through e-communication. However, it might not be the same for weak ties. A change in $C / T$ balance has an effect on the networkedness of a ward. Like when people relocated away from the walled city (Chatterjee, 2009 ) to the west, they changed their $C / T$ profiles along with the networkedness of the ward. People might come in contact with other acquaintances thereby increasing their networks and the need for maintaining these. This again has an effect on the networkedness of the ward. The thing that can be said with any certainty is: whatever the mode of communication is, the social network is maintained (Butts, 2002), and a change in $\mathrm{C} / \mathrm{T}$ balance has an effect on networkedness. We therefore accept our second sub-hypothesis networkedness depends on the $C / T$ profiles of the egos of a ward. A change in networkedness is essential for transport planning because it might have an impact on traffic volumes on the road. With increasing availability of ICT, the notions of networkedness and $C / T$ balance of people provide relevant information for predicting traffic volumes and transport infrastructure needs.

\subsubsection{Networkedness is homogeneous in terms of socio- demographic variables}

Finally, we have investigated the relationship between socio-demographic variables and networkedness. As seen from Table 14 networkedness has only a very weak correlation with the socio-demographic attributes of egos. Thus we accept our third sub-hypothesis socio-demographic variables do not affect networkedness. Even when $\mathrm{C} / \mathrm{T}$ profiles and location is considered homogeneity is found. For instance, profile 5 (' $I$ ' generation) can be seen all over the city and does not demonstrate any particular pattern of networkedness. The reason is that for people who are prone to ecommunication, distance is not a determinant. They place themselves anywhere in the city and for them the distance tends to be the same everywhere, as far as e-communication is concerned. Profile 5 is found in outer wards, but these people also live near the city centre. It proves that location to them is not very important since they are digitally connected with their social network. Similarly, they have a balanced distribution of weak and strong ties who they meet physically. In fact they meet their weak ties more face-to-face than their strong ties. This is opposed to the idea that weak ties 
in the network are impersonal (Tilahun and Levinson, 2011) and maintained by e-communication (Fish et al., 1993).

\subsection{Conclusion}

Interests in the relationship between space and social networks have grown lately (Entwisle et al., 2007; Hipp and Perrin, 2009; Butts, 2011). In this line of thought the current study identifies networkedness, a representation of social network densities over space, in an attempt to better understand the ongoing space social network debate. The study contributes to the debate in the following ways:

Firstly, social networks in developing economies are large and they are maintained by both face-to-face and e-communication. The findings are different from an American study that suggests there has been a decrease in the size of the average American network (Hampton et al. 2010). This feature of large networks could be a characteristic of developing economies, that needs to be researched further. The chapter studied the space-social network relationship for the city of Ahmedabad and confirms that distance does not affect tie-strengths. Individuals find ways to communicate with strong ties regardless of geographical distance.

Secondly, networkedness is not equally distributed over space. It indicates how dense social networks are over space, and depending on the profiles of people and their main mode of communication it might be an indication for travel demand and traffic volumes in an area

In addition, the study offers new insights into the relation between weak ties and mode of communication and reveals that relations with weak ties are not necessarily impersonal, and can be maintained with physical travel.

Finally, this research shows that social network analysis, clustering of individuals based on $\mathrm{C} / \mathrm{T}$ balance together with the notion of networkedness provides new and useful information for transport planning and policy making practice. 


\section{Chapter 6}

\section{Phone call elasticity of city travel in Ahmedabad $^{7}$}

\footnotetext{
${ }^{7}$ This chapter is based on Roy, P., M. H. P. Zuidgeest, J. A. Martinez, G. Miscione, and M. F. A. M. van Maarseveen. Phone Call Elasticity of City Travel in Ahmedabad. Travel Behavior and Society, doi: 10.1016/j.tbs.2014.07.001, available online $15^{\text {th }}$ July 2014.
} 


\section{Abstract}

The new era of Information and Communication Technologies ICT enables people to communicate and interact with each other in different manner, changing the way they conduct their lives. This change has significant implications on their physical travels. The relationship between ICTs and travel is complex and sometimes indirect. This paper aims to better understand this complex relationship by empirically analysing the substitution versus additive effects of phone calls on physical distance travelled by individuals. This is done by analysing the phone call elasticity of physical travel. The analysis also studies the relevance of social ties in Ahmedabad, India, as a source of explanation of social activity, thus travel, undertaken by individuals. Social Network Analysis (SNA) allows capturing social determinants that affect travel in a way socio-demographics do not capture. The phone call elasticities show a variation among different people which can be connected to the type of trips that are substituted. The substituted trips are related to the social networks of individuals. Decision makers can use this tool to designing their travel and ICT policies in a novel way. 


\subsection{Introduction}

This chapter considers the role that Information and Communication Technologies (ICT) play in the physical travel of people. It is well-known that ICTs are fundamentally altering the organization and travel of households, firms and other actors in cities. The basis of these alterations is the increasing availability, power and use of mobile ICT (Aguiléra et al., 2012; Yuan et al., 2012). Although the relationship between ICTs and travel is complex and sometimes indirect, this makes it no less real and no less significant (Carrasco et al., 2008). This chapter seeks to better understand this complex relationship by empirically analysing the substitution versus additive effects of phone calls on physical distance travelled by individuals. ICT makes it easier (than physical travel) for some people to change their social activities on impulse thereby affecting their travel patterns. The effects of such changes are either an amplification or reduction of physical travel (Lenz and Nobis, 2007).

The earliest studies by transportation researchers focus largely on the effect of telecommuting on travel behaviour. They observed a significant reduction in work-related travel and a contraction of activity space as a result of telecommuting. Koenig et al. (1996) observed a significant reduction in the number of trips and vehicle-miles travelled (VMT) for telecommuters. Charlot and Duranton (2006) found that ICT improvement can mean that face-toface contact is necessary for only the most complex interactions, bringing about a relative decrease in business travel, particularly when the participants are located very far from each other.

Other studies suggest that ICT use at home may lead to an increase in nonwork trips and activities. For instance Hodge and Koski (1997) observed a considerable reduction in commute-related travel and a slight increase in non-work travel as a result of center-based telecommuting. Kwan (2002) concluded that telecommuters undertook a significantly higher number of return home, eat meal, shopping, and social/recreation trips on telecommuting days when compared to non-telecommuting days. The results of other studies (Sasaki and Nishii, 2003) also support this tendency for nonwork activities and trips to increase as a result of higher level of ICT use. Schwanen et al. (2006) observed a predominant effect of generation - which occurs when the use of one mode increases the use of another. They found that increasing use of ICT is unlikely to reduce travel significantly.

The study reported in this chapter has a case study in the city of Ahmedabad, in India. While in most studies the term ICT refers to the use of laptops, smart phones, tablets, we limit ICT use in this chapter to mobile and landline phones, because of two reasons. Firstly, the low internet penetration in India (only $8 \%$ internet penetration as compared to $76 \%$ mobile penetration (TRAI, 
2010)) and (consequently) lack of computer literacy amongst many people. Secondly, people are probably better in remembering their daily phone calls than their emails sent since synchronous types of communication, like the telephone, are used for exchanging the most important and urgent information (Tillema et al., 2010). Furthermore, since the phone is primarily used for social activities (communicating) (Carrasco and Miller, 2009), it is expected that phone calls mainly substitute or complement physical face-toface meetings, e.g. no shopping trips are performed by phone. Hence the use of the terms e-communication and e-commuters in this study.

A main difficulty in explaining the impacts of ICT on travel is in identifying the likely activities in which individuals will choose to engage. For example, it is easy to roughly assess how someone who begins to e-commute may reduce his or her physical travel. But what other types of travel that person may engage in, or perhaps even increase given the newly saved time is difficult to assess (Choo and Mokhtarian, 2007). However, if a closer look is taken into the social networks of the individuals it is possible to empirically generate data which can be used to calculate whether travel is being substituted or complemented by ICT (Axhausen, 2008). This is because through social networks we can explain why travel is generated and how, through so-called social ties, travel is maintained. Axhausen (2002) connects travel with social networks, arguing that daily life revolves around family, colleagues and friends. Societies today have moved from being based upon strong colocation membership of social groups to a system of 'networks' where connections are spatially dispersed (Axhausen, 2002). Participation in these networks then leads to adaptation of preferences and diffusion of knowledge, triggering new communication-travel bundles. A number of studies have identified the potential relationships between ICT and travel and social networks. First, the use of mobile communications affects people's use of time and increases the spatial and temporal flexibility of their daily activities and travel (Kwan, 2002). For instance, mobile phones increase flexibility not only in terms of the place where work can be performed, but also in terms of working hours and with whom one communicates. Second, people's increased geographical mobility associated with the use of mobile communications has an impact on their travel and trip making behaviour (Black, 2001). Third, depending on their binding element, social networks also evolve and change, leading to changing patterns of ICT usage (Arentze and Timmermans, 2008). Fourth, social network characteristics determine to a large extent the ratio of e-communication use and travel. This e-communication/ travel balance can actually be used to profile individuals travel behaviour (Roy et al., 2012).

The above mentioned body of literature substantially outlines the relation between ICT, travel and social networks. ICT gives greater flexibility to an individual, who may then decide either to physically travel or use ICT for any 
particular activity. This decision is thought to be affected by the social network of the individual, which might consequently increase or decrease the physical travel of the individual. However, empirical studies encompassing ICT, travel and social networks are not easily available. To better understand this multifaceted phenomenon we, in this paper, look into the substitution and complementary effects of ICT on physical travel using social networks. To achieve this we use the concept of 'elasticity' on physical travel. To incorporate the social network perspective, we place the research in the social network context of an Indian city and examine how or if at all social network ties have any effect on the elasticity.

\subsubsection{ICT, travel and Ahmedabad}

Ahmedabad is the largest city in Gujarat, India. It is the seventh largest city and seventh largest metropolitan area of India, with a population of 5.5 million (Census 2011). With the city's population, the telecom industry of Ahmedabad also has grown over the years. A large population, low telephony penetration levels, and a rise in consumer spending power have led to Ahmedabad being one of the fastest-growing telecom markets in India. The number of mobile connections grew from a little over 4 hundred in 1997 to over 3 million in 2010. However, compared to mobile phones, internet penetration has not been very fast. As mentioned earlier Ahmedabad has only $8 \%$ internet penetration as compared to $76 \%$ mobile penetration (TRAI, 2010), which justifies looking at phone use only.

Ahmedabad has a wide range of transport modes ranging from private cars to two wheelers (two wheeled motorized vehicles that are gasoline-powered scooters and motorcycles (ADB, 2009)) to government-run public transport. The number of registered vehicles in Ahmedabad grew from 1.1 million in 1999 , to 2.8 million in 2010. Among the number of registered vehicles twowheelers account to around $70 \%-72 \%$ of total vehicles registered. This is an indirect indication of the derelict state of bus services in Ahmedabad (GoG, 2010). Only 0.9 million commuters use public transport every day, which amounts to $0.8 \%$ of traffic on the roads. Like many other countries, which has seen a shift from the publicly owned public transport services to privately owned systems, (Sohail et al., 2006) Ahmedabad faces the same problems. With the decrease in the famous "Red Bus" (Ahmedabad Municipal Transport Service (AMTS)) and a population of nearly 6 million spread over 446 square $\mathrm{km}$ it is probably going to worsen the already existing high levels of traffic congestion. The more the buses lie idle, the larger the gap in public transport supply in the city, eventually leading to increasing usage of personal vehicles, hence traffic congestion (Dave, 2014). 
Present mean trip lengths in Ahmedabad are low compared to some other metropolitan cities, namely, Bengaluru, Hyderabad and Pune (Pai, 2008), mainly due to a large share of captive walking and bicycle-mode users (Munshi, 2013). However, the city is developing fast and is facing a rapid rise in motorized vehicle ownership and use.

Primarily Ahmedabad has a mixed land use. Nearly $50 \%$ of total area of Ahmedabad is built up. Water bodies and wastelands cover $12 \%$ and $17 \%$ of area respectively. Industries cover $9 \%$ of the area (AUDA, 2005). More than one third $(36 \%)$ of the total area is under residential use, followed by $15 \%$ of the area used by industries. Though in the late 1990s, a slow and steady change from residential to commercial land use has taken place along the major roads and sub-arterial roads resulting in new commercial establishments in the west, while the industrial development has continued to grow towards the east. This might be because of the influence of agglomeration effects and scales of economies along major roads (Figure 29).

Due to its high industrialization rate the city has attracted people from all over the central and western region of India. Ahmedabad is therefore home to a large cosmopolitan population from all over India. A distinct feature of Ahmedabad is its co-existence of the old walled city and the new city. The city is like any other Indian city with distinct characteristics of its own. The Guajarati's believe in strong kinship ties. Slightly less than half of all real estate $(30 \%)$ (Sapovadia, 2007) in Ahmedabad is owned by "community organizations" (i.e. cooperatives), and "the spatial growth of the city to a large extent contributes to the number of these organizations. As such Ahmedavadis are thought to have strong social networks and use both ICT and physical travel to maintain their relations, making it a good case city.

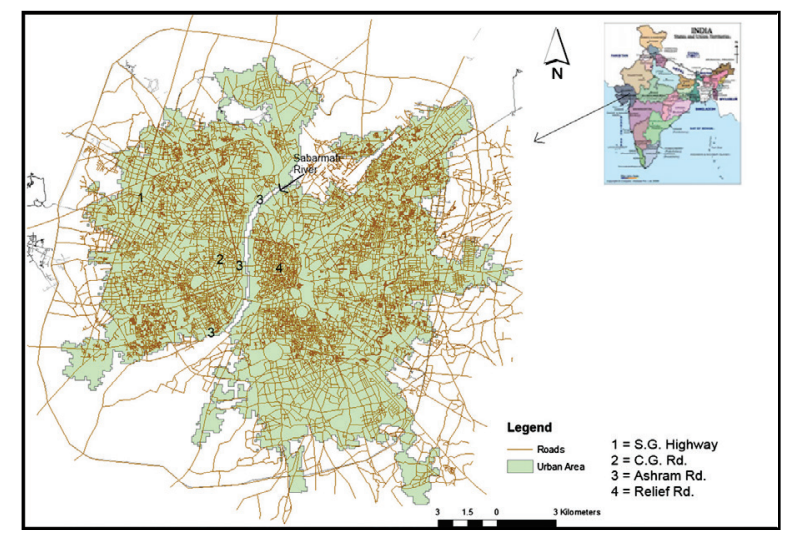

Figure 29 Land use and transport lines of Ahmedabad 


\subsection{Theoretical Framework}

The correlation between ICTs and human mobility has been a continuing theme in the field of transportation research (Yuan et al., 2012). Researchers recognized three main types of interaction: substitution, amplification, and neutrality (Mokhtarian and Meenakshisundaram, 1999). In Pendyala et al. (1991), a strong substitution effect was found between telecommuting and physical activity in people's daily lives. However, other studies provided evidence for a significant amplification effect after reviewing a considerable number of cases in empirical studies. Mokhtarian and Meenakshisundaram (1999) argued that the usage of ICT actually generated, rather than reduced extra travel. Mokhtarian (2009) concluded that not all activities have an ICT counterpart. As stated by Nobis et al. (2005), substantial differences in the use of ICTs exist, resulting from many social factors, including age, gender, culture, and socioeconomic distribution.

Zhang et al. (2008) found that in the same age groups there was a significant difference in travel behaviour between males and females in Beijing. Haustein et al. (2009) observed that travel of young Germans was influenced by peer pressure, level of socializing and communication with parents. Socio-economic distribution has been found to have an effect on travel and ICT uses e.g. car ownership might provide more opportunities for travel. Banister and Bowling (Banister and Bowling, 2004) found that people with access to a vehicle were likely to undertake more travel. However, Farber and Páez (2009) found automobile-reliant people to participate in significantly fewer activities. Thus scholars are far from arriving at a consensus about the effects of social factors on travel and ICT usage. Moreover, most research aimed at understanding travel behaviours and ICT are able to explain the "generation" of trips, they still heavily rely on the individual's socioeconomic characteristics. But these studies generally overlook the social setting of the individual, which to some extent explains the "maintenance" and "Iongevity" of such trips. Thus a better approach to understand the generation, maintenance and longevity of individual activity and travel in general, would be to look into the elements that are less measurable in terms of costs and socioeconomics, as already pointed out by Chapin (1974). In such a situation it is important to study an individual's social network characteristics to explain the effects of an individual's social setting on travel/communication decisions, and how these effects can be correctly measured to understand the trade-off between ICT and physical travel.

The maintenance of social networks is realized through social interaction (van den Berg et al., 2012). To be able to interact with spatially separated social network members, people have two options. Either they meet them face-to- 
face or they use electronic communication (e-communication), like phones, email, chat etc. (Ortúzar and Willumsen, 2006; van Wee, 2009). ICT next to face-to-face meetings is another way of exchanging information between people (Rietveld and Janssen, 1990; Lyons, 2002). Face-to-face requires physical travel, while e-communication requires 'virtual' travel and enables both parties to stay at their original places (Kenyon and Lyons, 2007). Physical travel and e-communication are therefore, with respect to communication, a means to the same end. The mode (physical or virtual) of communication however often depends on "with whom" the interaction is taking place (Tillema et al., 2010).

Social interaction is influenced by so-called alter(s) with whom individuals interact. Relational role and emotional closeness (which are usually used to measure the strength of ties (Carrasco et al., 2008)) have been found to affect people's communication with different modes (van den Berg et al., 2012). Several studies found that all communication means are used more for very close ties than for less close ties (Boase et al., 2006; Tillema et al., 2010). Rivière and Licoppe (2005) comparing text messaging in Japan and France, found that in Japan, text messages are sent to all contacts, independent of relational distance. However, telephone calls, which are relatively expensive, are mainly used to contact people who are emotionally very close. They found for example that in France text messages are mainly sent to the closest ties and not to acquaintances. In this paper we assume that tie strength does not only depend on time spent, emotional intensity or intimacy, but also on the relationship itself, i.e. family is typically assumed to be a strong tie (Palackal et al., 2011), while an acquaintance is considered as a weak tie. Friends and extended family are therefore categorized as strong ties in this research (Palackal et al., 2011). Colleagues form a special case. In some cases colleagues are considered as weak ties, while in others as strong. This distinction is based on whether the ego is self-employed or not. If the ego is self-employed then colleagues are weak ties, but if the ego is employed by an employer then colleagues are considered as strong ties. We find it necessary to make this distinction because, much of the everyday communication (both e and physical) is generated by colleagues and it would be unwise to put them all under a singular heading. E.g. a boss of a particular ego might be only a colleague but one would definitely make the physical trip to carry out the boss's instructions. While self-employed egos have no boss, they might or might not travel to carry out a colleague's instructions. Another factor that affects different mode of interaction is age. Frei and Axhausen (2009) found that with respect to the use of e-mails, young, highly educated people were forerunners and they had a high ICT mediated contact frequency. Nobis et al. (2005) confirm these findings. 
Geographical distance between people is also an important factor in explaining social interaction with different modes of communication. As social networks become more geographically spread, ICTs become more important because they provide opportunities to maintain contacts over long distances (McPherson et al., 2009). Tillema et al. (2010) found that face-to-face and electronic communication both declined with physical distance. Larsen et al. (2006) found the frequency of face-to-face contact decreased with geographical distance and frequency of e-communication increased with geographical distance. Frei and Axhausen (2009) found that face-to-face contact frequency decreased fastest with distance, while for e-communication no such effects were found. This, according to Frei and Axhausen (2009), was probably because of the low cost of communication. Thus, following Foss and Couclelis (2009) we assume that people maximize the utility of a product. In this case the product being ICT, individuals choose the mode of communication which they feel provides maximum utility with minimum cost. Cost being financial expense, time, comfort/intimacy of the contact etc. We feel that the economic concept of elasticity can be used here to statistically analyse the trade-off between physical travel and e-communication (Figure 30).

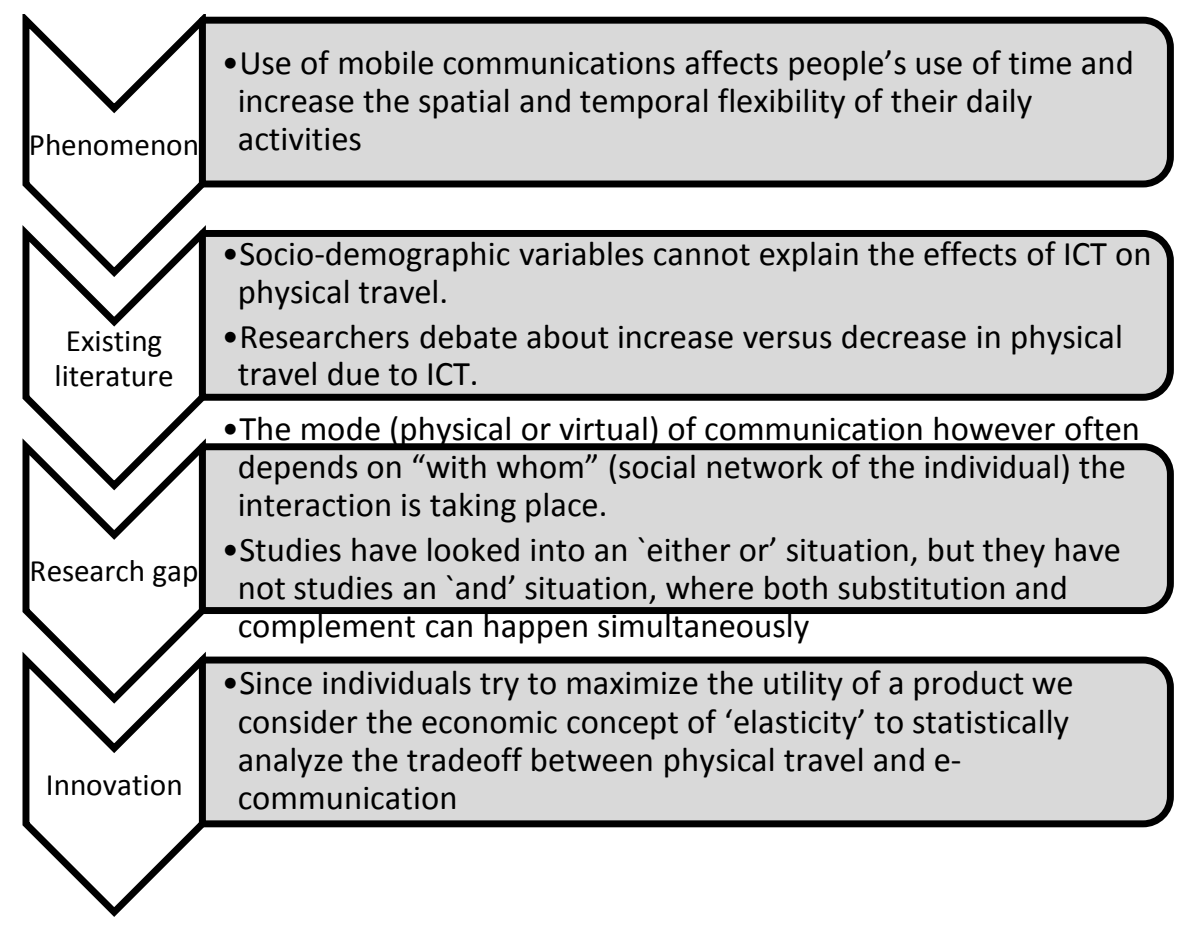

Figure 30 Theoretical Framework 


\subsection{Methodology}

The conscious decision of a person to choose or not choose e-communication depending on the social relation has its effects on the physical travel of the person. Empirical data to measure this effect can be generated by measuring the phone call elasticity of physical travel. Elasticity measures the responsiveness of travel demand to changes in factors such as travel costs and time, and can easily be derived from discrete choice models of the multinomial or nested logit form (1999). Holmgren (2007) has undertaken meta-analyses on samples of public transport elasticities to identify systematic sources of variation. Finally, studies regarding price elasticities to derive travel demand and its effects on mode choices can be found (Hensher and Bullock, 1979; Yang and Timmermans, 2013; Kwon and Lee, 2014). However, attempts to use elasticity in understanding the effects of ICT on physical travel are not available. In this research we will therefore examine phone call elasticity of travel.

In practice, elasticities are measured in several ways, according to the size of change in factors (or explanatory variables) (Odeck and Bråthen, 2008). Ordinary elasticity considers the total effect of an independent variable change whereas compensated elasticity considers only the substitution effect. In this paper we consider ordinary elasticity estimates only.

The phone call elasticity of travel by definition expresses the percentage change in distance travelled with respect to a one percent change in the number of phone calls. For example, if the number of phone calls goes up by $1 \%$, and as a result distance travelled falls by $1.5 \%$, the phone call elasticity of travel is $-1.5 \% / 1 \%=-1.5$. Thus, phone call elasticity measures responsiveness of travel to changes in phone calls. Thus, phone call elasticity measures responsiveness of travel to changes in phone calls. Phone call elasticity value greater than 1.0 absolute value is called an elastic profile in this paper, while a phone call elasticity less than 1.0 absolute is called an inelastic profile. A given percentage increase in the phone call of an elastic profile will increase the travel for the profile by a higher percentage than for an inelastic profile.

It is important to understand the profiles because the generation of travel and e-communication always takes place among people within their network. Based on these social networks, distinctions are found between people's physical travel $(T)$ and e-communication (C). The $C / T$ balance affects the elasticity of any profile, which in turn can be used to classify trip makers as is done in Roy et al. (2012), see Table 17. We use these profiles with varying degrees of $\mathrm{C} / \mathrm{T}$ balance to study if ICT has any significant effect on physical travel. 
Table 15 C/T Balance profiles (Source: Roy et al. (2012))

\begin{tabular}{|l|l|l|}
\hline Profile & Name & Characteristics \\
\hline 1 & Easy Riders & $\begin{array}{l}\text { People with low e-communication and high physical } \\
\text { communication. They prefer to maintain their social } \\
\text { networks through physical travel }\end{array}$ \\
\hline 2 & Well Connected & $\begin{array}{l}\text { People who had nearly equal number of physical and } \\
\text { virtual communication. }\end{array}$ \\
\hline 3 & $\begin{array}{l}\text { People who had exceptionally high number of both } \\
\text { physical and virtual communication. They physically } \\
\text { met a lot of people and also kept in touch through } \\
\text { ICT. }\end{array}$ \\
\hline 5 & Digitally Inclined & $\begin{array}{l}\text { People who would shift to a more ICT prone } \\
\text { communication with a little push. These people are } \\
\text { more prone to e-communication than physical travel. }\end{array}$ \\
\hline 'I' Generation & $\begin{array}{l}\text { A very virtual people. This profile represented people } \\
\text { who communicated more using ICT and had very few } \\
\text { physical communications. }\end{array}$ \\
\hline
\end{tabular}

There is literature regarding the interaction between communication and travel and social networks (Kwan, 2007; Carrasco and Miller, 2009; Nobis and Lenz, 2009) and to a somewhat lesser extent regarding the relation between tie-strength and travel/e-communication (Tillema et al., 2010). We find some gaps in the literature in this regard. Firstly, many studies which focus on the effects of ICT and travel do not statistically measure the increase or decrease of physical travel due to ICT use. Secondly, studies which focus on the length of trips which are substituted or complimented by ICT at a social network level are not easily available. Finally empirical proof about the effects of distance travelled on tie-strength for developing economies such as India are not yet available.

By investigating the phone call elasticity on physical travel of each profile, which emerges from an individual's social network in India based on empirical data, we hope to address these gaps. We will then look at the kinds of trips that are substituted and if the trips play a role in deciding the elasticity. Finally we examine how or if at all tie-strength has any effect on the substitution pattern.

\subsubsection{Data preparation for exploring elasticity of travel}

To gain greater insight into how ICT affects the physical travel of individuals we first and foremost created homogenous groups of people with similar ICT usages as described in Roy et al. (2012). These groups were created on their $\mathrm{C} / \mathrm{T}$ balance ratios which are characterized by within-group similarities and between-group differences.

A questionnaire survey was designed explicitly to collect data about the individual's telephone activity using an ego centric scheme (Kowald et al., 2010), constituted by the social structure of specific individuals (ego), and 
the interplay between their social activities and social networks, and the communication pattern with their network members. The objective of the data collection was to gather a data set that can help to study the elasticity of physical travel in the aspects of (i) substitution of physical travel by virtual communication i.e. elasticity of each profile (ii) type of trips that are most affected by phone calls (iii) effects of tie-strength on physical travel.

The data was collected through the help of 218 questionnaire survey in the city of Ahmadabad, India during July 2012. The sampling strategy consisted of a single stage cluster sampling. Within each administrative ward respondents were randomly selected via a systematic sampling approach. The survey was done in the area of Ahmadabad Municipal Corporation (AMC) jurisdiction. AMC has 43 administrative wards and 8 outgrowths. Table 16 shows the socio-economic characteristics of the sample.

Table 16 Socio-economic characteristics of respondents

\begin{tabular}{|c|c|c|}
\hline & Ahmedabad & Sample \\
\hline$\%$ Males & 52.7 & 56.3 \\
\hline$\%$ Females & 47.2 & 43.7 \\
\hline $\mathrm{Age}^{\mathrm{a}}$ & 28.5 & 32.8 \\
\hline \multirow{6}{*}{ Education } & \multirow[t]{6}{*}{$\mathrm{N} / \mathrm{A}$} & Primary School $11 \%$ \\
\hline & & Middle School \\
\hline & & High School \\
\hline & & Graduate \\
\hline & & Masters \\
\hline & & Above Masters $\quad 7 \%$ \\
\hline Employment Status & N/A & Employed \\
\hline No of Phones in $\mathrm{HH}$ & N/A & 2.8 \\
\hline \multirow[t]{3}{*}{ Income Group ${ }^{b}$} & \multirow[t]{3}{*}{ Middle Income } & Low Income \\
\hline & & Middle Income $\quad 53 \%$ \\
\hline & & High \& Very High Income $23 \%$ \\
\hline
\end{tabular}

${ }^{a}$ Was calculated from the age-sex pyramid of Gujarat in 2001 (IIPS, 2010)

${ }^{b}$ GDP $\$ 16$ billion/population of Ahmedabad. (AUDA, 2005) : annual household income ('000) < 90 Deprived, 90-200 Low income, 200-1000 Middle income, >1000 high income (NCAER, 2005)

\section{The questionnaire}

The first part of the questionnaire contained questions about socioeconomic background and lifestyle (e.g. age, gender, literacy level), ICT use in general and with regard to social contacts in particular. The second part of the questionnaire was a phone diary. The data collection instrument that was designed, consisted of paper and pencil phone diary, in which the individual respondents were asked to record all their calls for the previous day by 
consulting the call logs in their mobile phone. Compared with other data collection methods, such as interviews and observations diaries are less time consuming and more familiar and unobtrusive to respondents as diaries enable people to self-record their contacts with other people (Kowald et al., 2010). Since the phone is primarily used for social activities (communicating) (Carrasco and Miller, 2009), it is expected that phone calls mainly substitute or complement physical face-to-face trips, e.g. no shopping trips are performed by phone. Details of the calls included the nature (incoming or outgoing), time of the call, the relation of the individual to the person calling (e.g. friend, colleague family etc.), the place from where the call was initiated (Figure 32). The relationship between the respondent and the caller is used to determine if tie strength has any effect on distance travelled. The place of initiation of the call is used to analyze the kind of trip that is being substituted (small, medium or long). The trip length determination is explained later in section 4.3. The diary also included a question aimed at studying the substitution effect of ICT on physical travel. We asked if the individual was willing to travel to meet the caller if he/she did not have access to a mobile phone. This question is used to determine the substituted trips.

\subsubsection{Distance calculation}

We have calculated trip distance for both the physical and e-communication trip using the road network connecting ward centroids (the most detailed zone level respondents were willing to provide) following Dijkstra (1959). The intrazonal distances are calculated by taking one half of the distance to the centroid of its nearest ward (Venigalla et al., 1999). The ward centroids are determined using the land use geometry of the ward looking at facilities that induce (produce or attract) travel (e.g. residential areas and commercial centers). This to prevent excessively long distances to the large outer wards (Figure 31). 


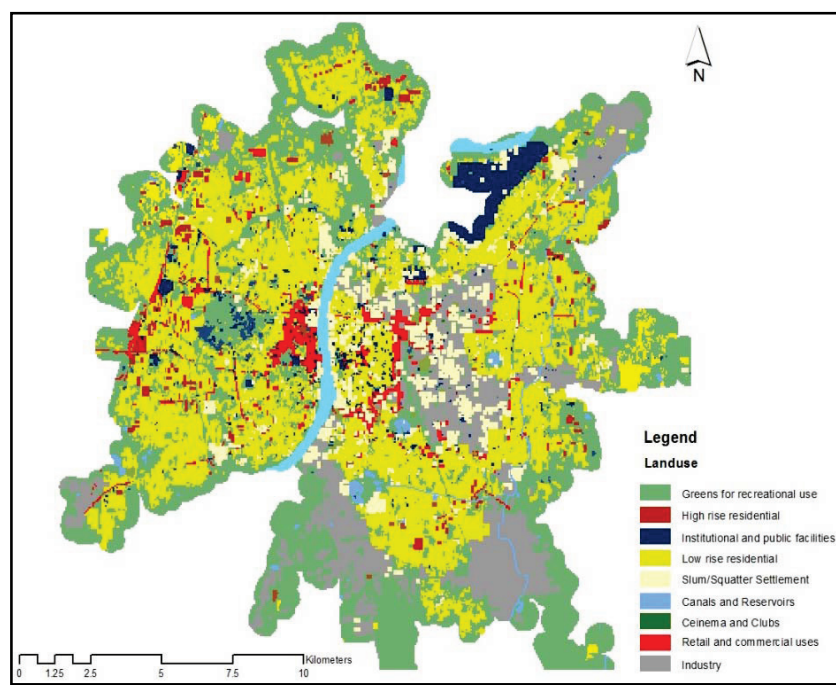

Figure 31 Land use map of Ahmedabad (Munshi 2013)

\subsubsection{Trip lengths determination}

As stated earlier, to determine which type of trips is most substituted by ICT we have categorized all the e-communication trips into three groups. For categorizing we found the difference between the longest and the shortest distance. This distance was $31 \mathrm{~km}$. then we divided this distance into three continuous classes. The three classes were $0-10 \mathrm{Km}, 10-20 \mathrm{Km}$ and $>20$ $\mathrm{Km}$. We decided on short trips, medium trips and Long trips respectively.

\subsubsection{Deriving what trips are substituted by phone calls and what trips are not substituted}

To study effects of ICT on physical travel we have to first derive the elasticity of physical travel. By definition elasticity is the change in physical travel due to the option of making a mobile phone call. We divided all the calls into "substituted trips" (calls for which the individual was willing to travel) and "not substituted trips" (calls for which the individual was not willing to travel) (Figure 32). 


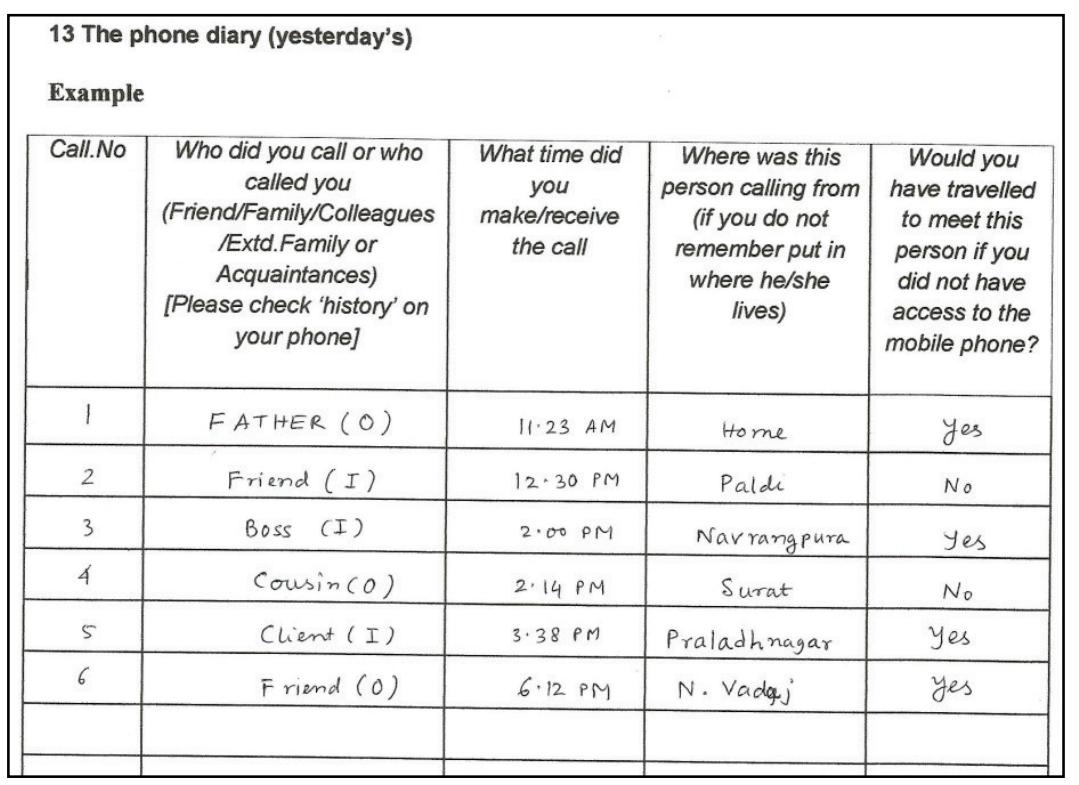

Figure 32 Example of a phone diary

We consider calls for which the individual was willing to travel as a 'substitutive call' because if the phone was not available the ego would have had to make the physical trip, thereby increasing their physical travel. But since the mobile phone is available it saves the ego a physical trip ergo physical distance substituted by the phone call. Calls for which the ego was not willing to travel are not substitutive because without the mobile phone those calls would not have taken place and neither the distance travelled. We measured the distance of each substituted trip and not substituted trip and decided if the trip was short, medium or long trip.

We measure the phone call elasticity with respect to substituted physical travel for each profile. For this we used a log linear regression model (as shown in the appendix).

\subsection{Phone call elasticity of physical travel}

Decisions to make a physical trip or communicate electronically are affected by who a person is communicating with and the geographical distance between them. In this section travel elasticity figures (Table 17) of each of the five profiles is discussed. 
Table 17 Elasticity of profiles

\begin{tabular}{|l|c|c|l|c|}
\hline Profile & $\begin{array}{l}\text { number of } \\
\text { calls }\end{array}$ & $\begin{array}{l}\text { Standardized } \\
\text { coefficient }\end{array}$ & t-value & Significance* $^{*}$ \\
\hline easy riders & 1.721 & .197 & 1.003 & .326 \\
\hline $\begin{array}{l}\text { well } \\
\text { connected }\end{array}$ & 2.412 & .254 & 1.619 & .114 \\
\hline $\begin{array}{l}\text { popular } \\
\text { people }\end{array}$ & -1.136 & -.125 & -.826 & .413 \\
\hline $\begin{array}{l}\text { digitally } \\
\text { inclined }\end{array}$ & 3.778 & .414 & 3.752 & .000 \\
\hline $\begin{array}{l}\text { 'I' } \\
\text { generation }\end{array}$ & .064 & .020 & .118 & .907 \\
\hline
\end{tabular}

* Significant at the 0.05 level

\subsubsection{Elasticity of physical travel among different profiles.}

Elasticity of physical travel among easy riders or profile 1

Profile 1, easy riders, represents individuals with low e-communication and high physical communication. Profile 1 's phone elasticity is 0.197 or $19 \%$ (Table 17). This means that the availability of mobile communication complements their physical travel, i.e. with every $1 \%$ increase in the number of phone calls this profile increases their distance travelled by $19 \%$. Actually, when we look into the trip types that are affected by phone calls for this group we find that medium length trips are affected most. The long and short trips are not affected as much, by availability of mobile communication (Table 4). This profile has the lowest number of substituted trips among all the profile (Table 18), which is consistent with the characteristics of this profile.

Elasticity of physical travel among well connected or profile 2

Profile 2, the well connected, represents individuals with a balanced ratio of e-communication and physical communication. This profile is $25 \%$ positively elastic (Table 17). This means with the availability of e-communication, people belonging to this profile complement their physical travel, i.e. with every $1 \%$ increase in the number of phone calls this profile increases their distance travelled by $25 \%$. This profile is more elastic than profile 1 . People of this profile substitute mainly their longer trips (Table 18). This could be a reason for the profile being more elastic than profile 1 . Since long trips are more time consuming they prefer to substitute them.

Elasticity of physical travel among popular people or profile 3

Profile 3 consists of individuals who have a very large social network, hence called popular people. They communicate equally both physically and virtually, but they belong to many different social groups. This profile is $12 \%$ negatively elastic (Table 17). This means with the availability of e- 
communication, people belonging to this profile substitute their physical travel. With every $1 \%$ increase in the number of phone calls this profile decreases their distance travelled by $12 \%$. People of this profile substitute trips of all length, long and medium length trips being a little more than short length trips (Table 18). Thus it is safe to conclude that individuals belonging to this profile prefer e-communication to physical travel and given a chance they would call their social network members rather than meet them face to face.

Elasticity of physical travel among digitally inclined or profile 4

Individuals belonging to profile 4 lead a more ICT prone lifestyle, hence called the digitally inclined. They are very positively elastic, with a score of $41 \%$ (Table 17). This means with the availability of e-communication, people belonging to this profile compliment their physical travel. With every $1 \%$ increase in the number of phone calls this profile increases their distance travelled by $41 \%$. This is the most elastic of all 5 profiles. There is however a similarity between profile 2 and profile 4 regarding the kind of trips substituted. Both the profiles substitute trips of all length. But profile 4 is more positively elastic than profile 2 . The difference is between the percentages of short substituted trips (Table 18). This profile has the highest percentage of short substituted trips. Thus, we can conclude that the higher shorter trips substituted the higher chances of a profile being more positively elastic.

Elasticity of physical travel among ' $I$ ' generation or profile 5

Profile 5 represents the most virtual group of people. They have very few social network contacts who they meet face to face and very large number of social network contacts with whom they communicate electronically. Profile 5 has a low positive elasticity. This profile is $2 \%$ positively elastic (Table 17 ). This means with the availability of e-communication, people belonging to this profile compliment their physical travel. With every $1 \%$ increase in the number of phone calls this profile increases their distance travelled by only $2 \%$. Though people of this profile are prone to e-communication their physical travel is not affected by phone calls. They substitute all length trips (Table 18). The explanation of such behaviour could be that since they substitute all kinds of trips, they, in general, travel less. They might not participate in an activity if not available virtually. So, since they do not travel as much the effect of e-communication is less on travel hence the profile is not as elastic as the other profiles. A second explanation for such a behaviour could be that particularly the 'I' generation profile uses the internet more, and the phone less. Since this analysis is based on phone calls it has not been able to effectively capture the effects of ICT on physical travel for this particular profile. 


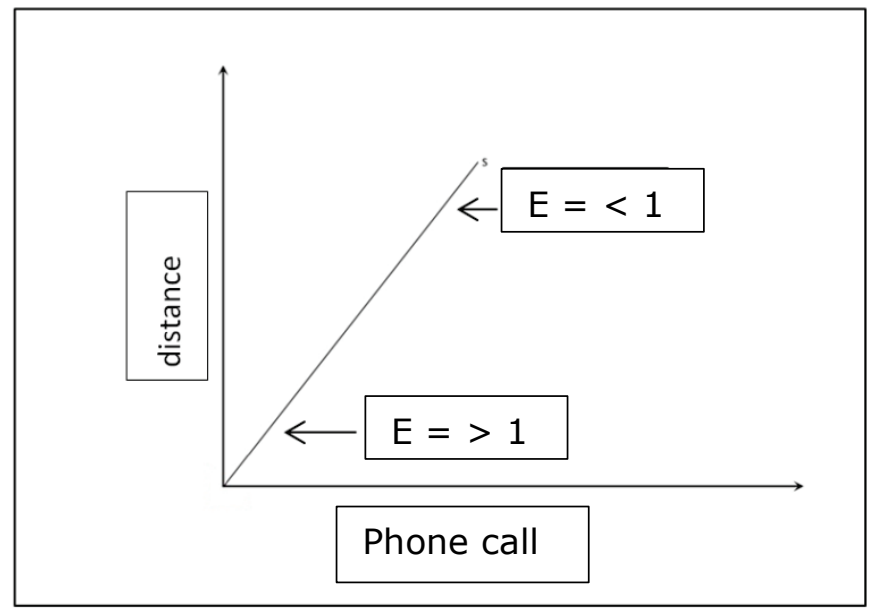

Figure 33 Possible explanations for the behaviour of profile 5

Another explanation could be that if we consider a situation where the variables are positively related, in our case the higher the number of phone calls more is the distance travelled, area of the upper part of the regression line tends to become less elastic (Figure 33). Since profile 5 tends to have a higher number of calls (provided we assume the profiles are in an ordinal scale) because it has higher usage of ICT than other profiles, its elasticity tends to be less than 1 . If this is the case then it clearly explains the behaviour of profile 5 .

Table 18 The percentage of substituted trips per profile

\begin{tabular}{|l|c|c|c|l|l|}
\hline Profile & $\begin{array}{l}\text { Short trips } \\
(0-10 \mathrm{~km}) \\
(\%)\end{array}$ & $\begin{array}{l}\text { Medium } \\
\text { trips } \\
(10-20 \mathrm{~km}) \\
(\%)\end{array}$ & $\begin{array}{l}\text { Long trips } \\
(>20 \mathrm{~km}) \\
(\%)\end{array}$ & $\begin{array}{l}\text { Positively } \\
\text { elastic }\end{array}$ & $\begin{array}{l}\text { Negatively } \\
\text { elastic }\end{array}$ \\
\hline Easy riders & 17 & 58 & 25 & $\begin{array}{l}19 \% \\
\text { elastic }\end{array}$ & \\
\hline $\begin{array}{l}\text { Well } \\
\text { connected }\end{array}$ & 39 & 32 & 29 & $\begin{array}{l}25 \% \\
\text { elastic }\end{array}$ & \\
\hline $\begin{array}{l}\text { Popular } \\
\text { people }\end{array}$ & 39 & 38 & 23 & & $\begin{array}{l}-12 \% \\
\text { elastic }\end{array}$ \\
\hline $\begin{array}{l}\text { Digitally } \\
\text { inclined }\end{array}$ & 31 & 35 & 34 & $\begin{array}{l}41 \% \\
\text { elastic }\end{array}$ & \\
\hline $\begin{array}{l}\text { 'I' } \\
\text { generation }\end{array}$ & 34 & 37 & 29 & $\begin{array}{l}2 \% \\
\text { elastic }\end{array}$ & \\
\hline
\end{tabular}

\subsubsection{Effect of distance travelled on tie-strength}

Since travel is affected not only by ICT but also the social network of individuals, we also calculated the effects that tie-strength has on the 
willingness to travel for an individual from the number of substituted trips of the person. This is undertaken to recognize how social networks affect the travel decisions of individuals. We took into consideration all the trips for which the ego was willing to undertake physical travel. We then calculated the number of strong ties and number of weak ties for which the individual was willing to make the physical trip. This calculation was done based on each profile. Analysis shows that $72 \%$ of all individuals were willing to travel any physical distance to maintain their strong ties (Figure 35 ). This number increased to $86 \%$ when people with lowest propensity of ICT usage were considered (Figure 34). For the weak ties the number of individuals willing to travel any distance was $54 \%$. From the analysis, it can be concluded that distance does not have any major effects on strong ties, but weak ties are affected by distance to a great extent. The increased emphasis is maintained by both face to face and e-communication. No such effect is found for the weak ties.

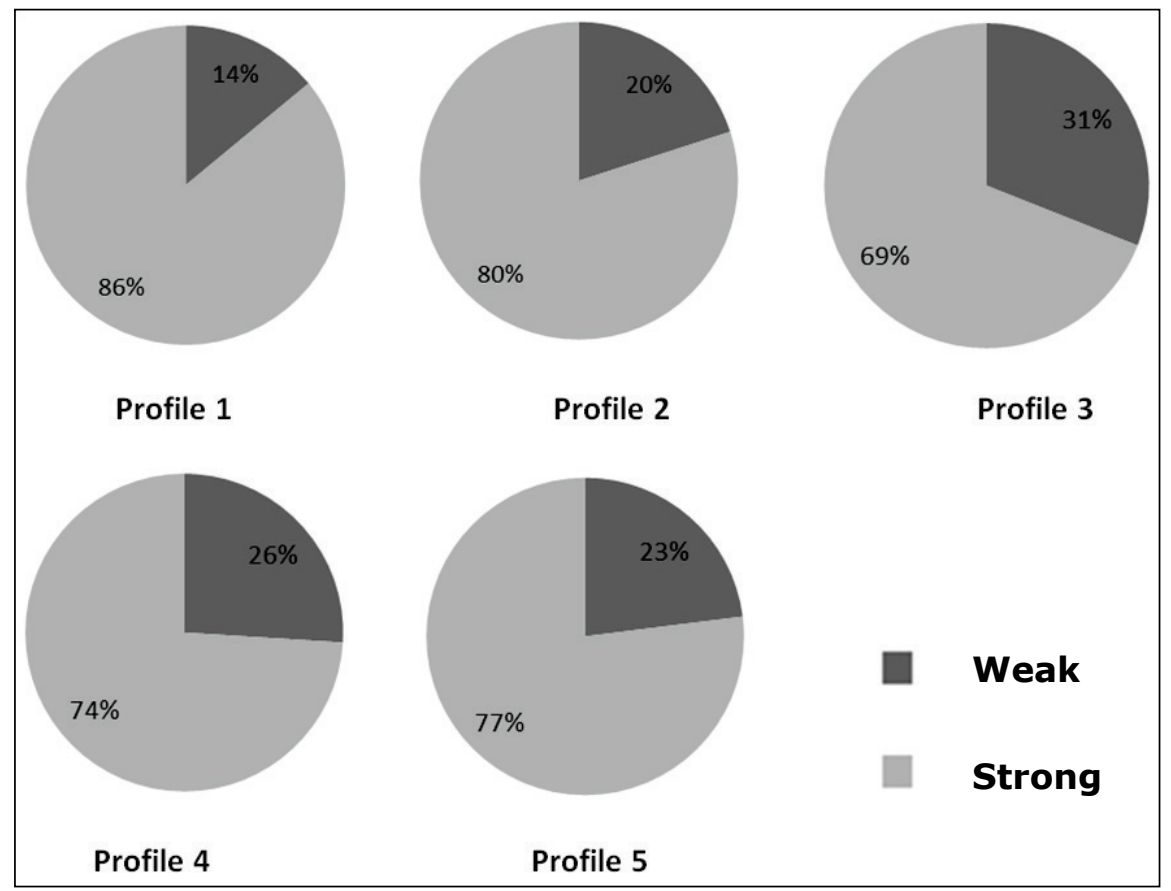

Figure 34 Willingness to travel any physical distance for strong and weak ties 


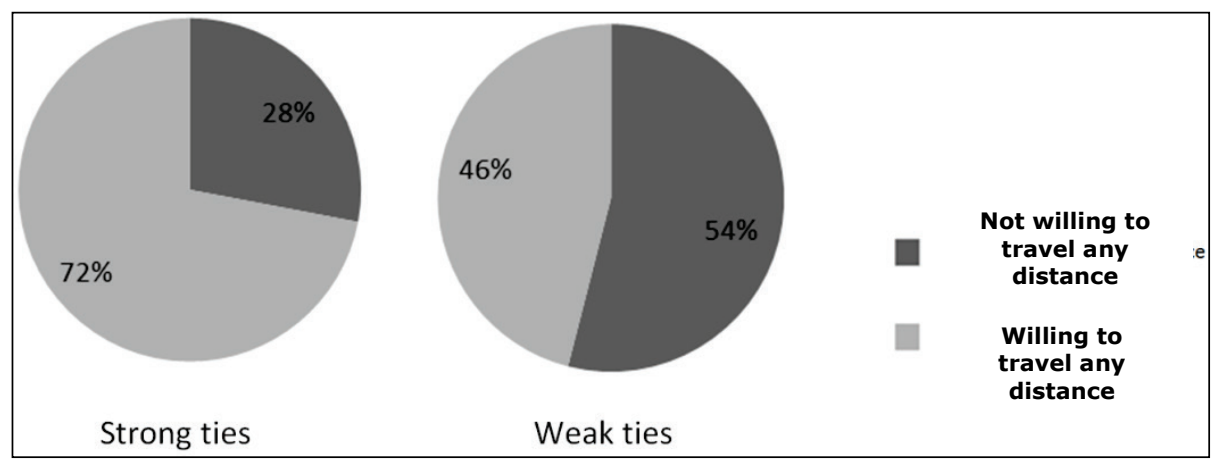

Figure 35 Relations between tie strength and travel distance

\subsubsection{Association between socioeconomic, demographic, profiles and distance substituted}

Traditional travel research shows that we cannot simply state there is one single type of relation between travel and e-communication (Kwan et al., 2007). Several mechanisms have been advanced to explain the possible relationship between ICT and travel. In the past decade most studies used socioeconomics to explain this relation (Carrasco and Miller, 2009; Aguiléra et al., 2012). Commonly used socioeconomics are age, gender, literacy, income, employment. Bhat et al. (2002) for example finds that individuals who are young, employed and/or highly educated are more prone to using mobile phones. However, no such relationship was found when e-activities were introduced in travel behavior studies. Silvis et al. (2006) found no statistically significant differences on socio-demographic variables between mobility groups, suggesting that social patterns were fairly universal on a socioeconomic and demographic level. This paper has similar findings. We performed a $\mathrm{t}$ test to check if there was indeed a significant association between the socio-economic variables and distance. We found only significant association between the profiles and the substituted distances. The socioeconomic variables were not significantly associated (Table 19).

Table 19 Association between socioeconomic, demographic, profiles and distance substituted

\begin{tabular}{|l|l|}
\hline Variable & Significance level \\
\hline Age & 0.3791 \\
\hline sex & 0.4652 \\
\hline literacy & 0.8285 \\
\hline employment & 0.0303 \\
\hline Income group & 0.4755 \\
\hline Profile & 0.0059 \\
\hline
\end{tabular}

${ }^{*}$ Significant at the 0.01 level 


\subsection{Discussion and conclusion}

The debate concerning the increase or decrease of travel due to the introduction of ICT has interested researchers for the past decade. This study looked into the substitution and complementary effects of ICT on physical travel, using social network to better understand and contributes to the debate in the following ways.

Firstly, on the aspect of using social network to better understand the effects of ICT on physical travel we find that to maintain their social network people communicate either physically or virtual. The analysis demonstrates that different people behave differently regarding this balance. That is the reason for difference in the elasticity of different profiles. Analysis also shows that individuals, who are high consumers of ICT, do not necessarily have huge impact on their physical travel. This can be seen from the example of profile 5. Contrary to popular belief that higher consumption of ICT will lead to lower physical travel, profile 5 indicates that highest use of ICT does not lead to highest impact on physical travel. We are of the opinion that the true nature of travel elasticity of people can be found in their social network structures, and not in their usage of ICT or socio-demographic characteristics as was done in earlier studies.

Secondly, this study effectively proves that the effect of ICT on physical travel is not only that of substitution or complementation. There exists an 'and' situation where both substitution and complementation can happen simultaneously. In this study we verify this balancing act which individuals undertake in maintaining their social ties. Phone call elasticity proves that the 'and' situation can be studied and empirical data can be generated for analysis to arrive at pragmatic results.

Thirdly, on the aspect of tie-strength and mode of communication, if we look at tie strength and physical distance we find, strong ties are not affected by distance as much as weak ties. The paper studies the relationship between the willingness of individuals to travel physical distances to maintain their social networks over the city of Ahmedabad and confirms that distance does not affect strong ties. Individuals find ways of communicating with their strong ties regardless of geographical distance. There is an inverse relation between distance and weak ties. Though the cost of phone call is the same all over the city. This finding is consistent with previous studies regarding tiestrength and distance (Mok et al., 2010; McGee et al., 2011; Verdery et al., 2012). Since weak ties are made up of acquaintances and colleagues, individuals are not inclined to physically travel to communicate with then when not absolutely necessary. Also, there is a similarity between elastic and non-elastic profiles regarding willingness to travel any distance to maintain 
their strong ties. All profile show an inverse relation between distance and weak ties. This phenomenon can be explained by the theory of bounded solidarity, which postulates that that mobile technology produces an increased emphasis on close family and friendship relations (Palackal et al., 2011). This empirically confirms that people's social network have a bearing on their travel decisions (Carrasco et al., 2008).

Fourthly, among profiles whose physical travel is positively affected by phone calls (positive elasticity); the kind of trips that are substituted is different. Profile 4 (most elastic of all 5 profiles) has the maximum percentage of short substituted trips. From this result we can deduce that the higher the percentage of short trip substitution, the higher the chance of any profile being elastic. An explanation for this is that people undertake more short trips than long trips. Also short trips can be more easily substituted because they are walkable trips. Given the high kinship ties among Gujratis, it is possible that people prefer walking small distances to communicate with their social network members rather than e-communicating. Thus, more number of trips are substituted by individuals of profile 4 , which affects the elasticity. More in-depth research in this area is needed.

Finally, the difference in the elasticity's of profiles can be used to understand the travel patterns of different segments of society. With the increasing growth of ICT in developing economies (Economist, 2009) it becomes pertinent for policy makers to take into account the varied effects of ICT on different segments of society. Studies on the effects of ICT on physical travel for cities in developing economies are not yet available. This study fits better actual transformation of travel behaviors and since the paper provides elasticities of profiles, the study can also be used by planners in a novel way. The policy makers can effectively identify target profile when making IT policies. These profiles can be understood by policy makers which make diagnosing problems related to particular profile easier.

Through the analysis we have tried to understand how the physical travel of different profiles are affected by phone calls and if there is an increase or decrease in their physical travel due to the availability of ICT. We have also considered how social networks of individuals affect their travel decisions. Knowledge from this paper can be used for deriving travel demand management policies for Ahmedabad and beyond.

\subsection{Limitations of the study}

This study is primarily limited by its small sample of phone diary surveys caused by resource constraints. An e-mail survey could have increased this number but would have introduced a bias to the few with internet access 
(probably concentrated in one of our profiles) given the low internet penetration in the city. Another limitation of this study is the definition of strong and weak tie and their calculation. In the study we assume that family and friends are strong ties and acquaintances are weak ties. But with no literature on how to accurately delineate tie strength it was difficult for us to assume otherwise. 


\section{Appendix}

Elasticity of any independent variable can be expressed as:

$$
\frac{d Y}{d X} * \frac{X}{Y}=E \text { (Equation i) }
$$

Where $\mathrm{E}$ is elasticity, $d$ is the $\%$ change, $\mathrm{Y}$ is the dependent variable and $\mathrm{X}$ is the independent variable

Equation i, can also be expressed as

$\frac{d \log Y}{d \log X}=E$ (Equation ii)

Equation ii can also be expressed in the log linear regression model as

$$
\log Y=B o+B 1 * \log X
$$

And this equation can be solved for,

$$
B 1=\frac{d \log Y}{d \log X}=E
$$

Thus, in a log linear regression the slope (B1) or the standardized coefficient (as shown in SPSS) is elasticity $(E)$. 
Chapter 7

Synthesis 


\subsection{Introduction}

The new ways of communicating affects individual's travel behaviour and in the long term urban travel patterns. If the introduction of mobile communication technology is nothing more than the augmentation of preexisting practices then no major shift in social structure is to be expected. If, on the other hand, mobile technologies change the nature and distribution of social connections, then their widespread diffusion may have significant consequence for the development of social structure and urban travel. One technological affordance of e-communication allows communication between distant social actors. What has changed is the potential from anywhere/anytime interactions with others who also possess such device.

Most studies about the effects of ICT on travel us socio-demographics, economic and attitudes as explanatory factors. Social factors, such as geographical distance between actors and existence of strong ties, are almost entirely lacking in explanations of ICT and travel. This oversight is remarkable, since one would intuitively expect social relations such as the kind of relations (family, friends) to play a part in affecting the individual's decision to travel or e-communicate. The few empirical studies that have investigated the relation between ICT, travel and social ties have mostly studies only a part of the individual's network and are for the developed world. They also only consider an increase versus a decrease in travel instead of the trade-off between physical travel and e-communication. Such distinctions are necessary, since different ties react to e-communication differently and it will be wrong to assume only increase or only decrease in physical travel due to ICT uses.

The aim of this research was to provide insight into how the increasing use of ICT is affecting physical travel and does the social network of individuals have an effect on the decision to travel or communicate electronically. To achieve this aim, the following research question was formulated: How can social network analysis be used to measure the effects of ICT on physical travel for a rapidly growing developing economy like Ahmedabad?

The terms e-communication and e-commuters are used here to indicate the use of these specific types of ICT for the purpose of the research and the case city, Ahmedabad.

This last chapter will summarize the key elements of this thesis in order to understand the complex multifaceted relation between urban travels, ICT and social network of individuals. Policy recommendations and directions for future research are provided in the last section. It has to be kept in mind that different datasets and methods of analysis have been used in the successive 
chapters. Chapter 3 uses data collected in 2010. Chapter 4 and 5 uses a combination of data collected in 2010 and 2011. Chapter 6 uses data collected in 2012. K-means has been used as a method of analysis in all the chapters. In addition chapter 4 also uses a density equation; chapter 5 uses the negative exponential function and chapter 6 uses the elasticity function for analysis.

\subsection{Summary and discussion of the results}

This section provides an overview of the findings by answering the objectives followed by the outcome of the main research question.

\subsubsection{Objective 1: To examine how social network analysis can be included in travel research.}

Social activities account for a large part of trips and they constitute the fastest growing segment of travel (Axhausen, 2003). Over the last decades, people's leisure time (which is dominated by social interactions with relatives and friends) as well as car ownership and usage has increased (Schlich et al., 2004), resulting in increasing travel demand for social purposes. In order to assess future transportation needs for social activities, we need to better understand the nature of people's social activities and the travel involved.

In chapter 3 we have found evidence that social ties and ICT uses are related. Social activities and associated travel can emerge from the individuals' social networks. K-means clustering is applied to the social networks of individuals to arrive at the five $C / T$ balance profiles. Overall the results indicate that to maintain a social network people communicate, be it physically or virtually. People of Ahmedabad are more prone to ecommunication than physical travel for maintaining their social networks. The relative ease of communication virtually (no physical travel needed) and the falling costs of the mobile phone call in the Indian markets facilitate this sort of behaviour. However, face-to-face communication is not absent altogether. This finding supports the notion of a hybrid form of communication in which physical travel and e-communication are combined. Which, could be basically because, face-to-face communication established a personal touch and sustains trust (Urry, 2004).

The five distinct $\mathrm{C} / \mathrm{T}$ profiles show clear signs of the 'digital divide' among the general population of Ahmedabad. Gujarati's in general have very well-knit large networks. They have close kinship ties and well maintained networks. The cost to maintain large networks is great both in economic terms and in terms of effort that has to be put in. All human beings are economically rational (Foss and Couclelis, 2009), tend to choose a less expensive mode of communication. ICT (phone calls and internet) act as the inexpensive mode 
of communication in Ahmedabad. This creates the digital divide because chiefly the language used for both the ICT modes is English. In Ahmedabad a large section of the society are not well versed with the English language creating the gulf.

Our findings further show that people are effectively classified into different clusters based on their network sizes, mode of communication and frequency of communication rather than being classified based on age, income, gender and other socioeconomic indicators. This is a better classification than previous classifications because this takes into consideration the social networks of people (which generate travel and communication) when creating the clusters. A common fact among the profiles was that, the networks were in general large (on an average 20 ties per individual).

Continuing to apply social network analysis to travel research, Chapter 4 finds evidence which proves that certain aspects of individual's travel cannot be explained by socio-economics or spatial characteristics. Social networks on the other hand can be correlated to those aspects. In the chapter people's travel pattern is investigated by plotting the distribution of trip lengths, i.e. trip-length-frequency distributions (TLFD). The TLFD's are used to examine the influence of distance on people's travel behaviour. This way, it is tried to determine the travel pattern and identify the extent to which generalized costs (distance) are considered by people when travel decisions are made. The TLFD of all the profiles show clear decays indicating that people's behaviour is not only related to their willingness to travel certain distances or use e-communication, but also to the geographic distribution of their social network members. This finding shows social network profiles could complement current trip distribution modelling. Based on the differences in travel patterns, social network profiles can provide homogeneous sets of travellers, which are used in the calibration process of trip distribution modelling.

We also find that 'maintenance' and 'longevity' of trips cannot be explained by measurable elements like density or cost. All profiles irrespective of intensity of ICT usage are affected by distance. This phenomenon cannot be explained by a simple cost benefit ratio. Even though the cost of calling is same all over the city, the number of calls drops as geographical distance increases, which proves that geographic and social distance, is still important even with falling costs. This finding is consistent with Axhausen's (2008) comment "instead of relying exclusively on the generalized costs of travel and the hedonic utility of a location as modulated by the socio-demographics of an individual and perhaps his or her values, one can add as explanatory factors both the social network geography of the person and his or her biography and network-based decision making..". 


\subsubsection{Objective 2: To examine how the inclusion of social networks in travel studies provides new ways of defining space and accessibility.}

In the past decade, most studies used socioeconomics and spatial characteristics to explain the relation between ICT and travel (Carrasco and Miller, 2009; Aguiléra et al., 2012). Commonly used socioeconomics are age, gender, income, employment, education, e-communication availability and car ownership (Williams, 1989; Dieleman et al., 2002; de Graaff and Rietveld, 2007; Winters et al., 2010). Most researchers who have investigated the factors affecting ICT and physical travel are researchers who pay scant attention to spatial distribution (Kalenoja, 1999; Dieleman et al., 2002; Mokhtarian et al., 2004; Winters et al., 2010). Very few geographers have examined social networks, ICT and physical travel from a spatial perspective.

With the advent and rapid development of electronic forms of communication, physical presence is not always necessary for social contact. Thus, it becomes important to consider the aspect of distribution of an ego's social network over space.

Chapter 5 explores the idea of geographical distance between network members and puts forward the concept of Networkedness. This is a novel way of considering space within the framework of travel studies. Networkedness is the distribution of an ego's network over space. In line with previous empirical studies, we have found that distance affects mode of communication. However, location of egos at city level does not affect Networkedness. A very important result which came out of the analysis was that distance does not affect tie strengths. Individuals find ways of communicating with their strong ties regardless of geographical distance. They might change the mode of communication with increasing distance but they do not stop communicating. In short, geography does not seem to matter for strong ties and vice versa. We also found that relations with weak ties are not necessarily impersonal. The digitally inclined profile's mode of communication indicates that they meet their weak ties face-to-face while ecommunicating with the strong ties. It is important to understand the effect of weak ties because weak ties are instrumental in the movement of egos, the new revelation of is relevant to recent works in travel research. Overall this chapter revel that social network analysis can be used as an important tool in travel research to provide new definitions of space which was missing from current literature. 


\subsubsection{Objective 3: To analyse and understand the trade- off between ICT and physical travel among social network members}

Since we do not know how people of Ahmedabad travelled before they started using ICT, the 'generation or substitution' question that has become important in the transportation literature on relationships between ICT-use and mobility (Mokhtarian, 2003). Rather than trying to come up with an absolute answer, it is better to recognize the complexity and contextdependency of these relationships. Individuals operate and make their decisions in certain social and time-space contexts. Substitution or generation of travel by ICT is shaped by such decision context, which varies for each individual. This variation could cause different outcomes for ICT and physical travel. Rendering it difficult to assess a net absolute outcome.

Chapter 6 looks into this complex relationship keeping in mind the differing contexts for each individual. The chapter answers the 'generation or substitution' question statistically by looking into the phone call elasticity of physical travel. To address the individual context, elasticity is measured for each profile. Elasticity is a concept frequently used to measure the responsiveness of demand to changes in factors determining the level of demand. This chapter finds that different $\mathrm{C} / \mathrm{T}$ balance profiles behave differently with regards to their elasticity. Contrary to popular belief, it is found that individuals, who are high consumers of ICT, do not necessarily have huge impact on their physical travel. Again individuals with very low consumption of ICT have more elastic physical travel behaviour than individuals with high consumption of ICT. This is because the true nature of travel elasticity of people can be found in their social network structures and not in their usage of ICT alone.

The phone call elasticity show a variation among different people which can be connected to the type of trips that are substituted. In the chapter we report that that the higher the percentage of short trip substitution, higher the chance of any profile being elastic. The simple explanation for this could be that individuals in general, undertake shorter trip than long trips. So if the number of short trips is more and they start substituting them then all together they substitute more trips. When substation increases, elasticity also increases. More elastic individuals mean greater effect of ICT on their physical travels.

The substituted trips are also related to the social networks of individuals. The chapter also reveals that the relevance of social ties in Ahmedabad, as a source of explanation of social activity. Individuals find ways of communicating with their strong ties regardless of geographical distance. 
There is an inverse relation between distance and weak ties. This finding is consistent with previous studies regarding tie-strength and distance. Since weak ties are made up of acquaintances and colleagues, individuals are not inclined to physically travel to communicate with them when not absolutely necessary. Finally, there is a similarity between elastic and non-elastic profiles regarding willingness to travel any distance to maintain their strong ties. All profile show an inverse relation between distance and weak ties. This empirically confirms that people's social network have a bearing on their travel decisions which can be used to study the trade-off between ICT and physical travel.

\subsection{Reflections}

This section reflects on the findings and results of the study. It includes a summary of the main contribution and recommendations of future research.

\subsubsection{Main contributions}

This study mainly extends the knowledge on the complexity of the relation between ICT and physical travel. The objectives of this research were twofold-first to understand the trade-off between e-communication and physical travel emerging from an individual's social network and second to use the indications put forward by social networks to quantify the trade-off in a metropolitan city in India.

Firstly, this study provides a rich understanding of the complex relationship between ICT and physical travel, with a particular focus on how social network of individuals play a role in the decision. As a result, this study has contributed to an in-depth insight of the consequences of rapid increase in ICT consumption and its effects on physical travel, particularly in a fast growing city like Ahmedabad. This research has strong relevance for planning of cities in India.

Secondly, the major contribution of this study is the development of the methods and social network characteristics that are of importance to travel studies. The study has bridged the knowledge gap on the development of easy to use measures (social network characteristic) to quantify and analyse the trade-off between physical travel and e-communication.

Thirdly, a major contribution is related to the creation of homogeneous ecommunication/travel balance profiles to understand the multifaceted relation between increases versus decrease of physical travel due to ICT usage. This study extends current research using social network profiles for exploring and analysing ICT usage and urban travel. The social network profiles people into different clusters based on their network sizes, mode of communication and 
frequency of communication rather than being classified based on age, income, gender and other socioeconomic indicators. This is a better classification than previous classifications because this takes into consideration the social networks of people (which generate travel and communication) when creating the clusters. The profiles provide urban planners and policy makers with a new social approach to understand the complex urban travel-ICT use phenomenon in rapidly growing cities. The profiles facilitate the investigation of why individuals make or do not make a physical trip and with who they communicate.

Fourthly, another key contribution of this thesis is related to the integration of the aspect of space and social network in a novel way through the concept of Networkedness. This study introduces Networkedness, which is an attribute of space characterized by the density of the social networks of the people who live there. The practicality of the concept lies in the fact that it can be used to measure the pressure on infrastructure by transport planners and policy makers. This study uses the existing knowledge of density and extends it to incorporate the social aspects to facilitate the understanding of the relation between social networks and urban transportation.

Fifthly, the chief contribution of the thesis is related to the development of new insights into ties and their effects on the decision to travel or use ecommunication. The new understandings (e.g. distance does not affect tie strengths, individuals find ways of communicating with their strong ties regardless of geographical distance or that developing economies are characterized by large networks) can be used by experts for planning. Also different tie composition needs different policies for accommodating the changes in travel and e-communication, these insights can act as guiding parameters for policy interventions for future planning.

Finally, contribution of this study is related to the quantification of substitution and complimentary effects of ICT on physical travel. This study provides and empirical base to urban planners to understand the main features of 'generation' and 'substitution' effects of ICT on physical travel. The different elasticity of the profiles enables planners to take an innovative and proactive approach to integrate social aspects with socio-economic aspects and to evaluate the consequences of the varied effects of ICT on different segments of society. These profiles can be understood by policy makers which make diagnosing problems related to particular profile easier. The difference in the elasticity of profiles can be used to effectively identify target profile when making IT policies. 


\subsubsection{Future research}

This research is the first of its kind that presents empirical evidence of the relation between ICT, physical travel and social networks in India, and therefore several problems were encountered in operationalizing this research. Some of these were solved during the course of the research, and some still remain to be tackled by further research. This research also opens up new vistas to be researched further on the topic in the Indian context. As a conclusion, several areas for future research are proposed.

- Comprehensive theoretical framework: A comprehensive theoretical framework that is capable of explaining hybrid forms of e-communication and physical travel taking into account individual's social and time-space contexts should be developed. Only when we begin to understand people's motivations for e-communication or physical travel can the relationship between them be accurately assessed. A theoretical framework needs to be developed, taking into account hybrid combinations of both communication modes as well as individual's decision context. Using the detailed operationalization of various social network concepts like bounded solidarity and core network approach has proven to be a fruitful approach. These should be further enhanced and streamlined to meet the demands of travel studies.

- Duplicating the study for another developing economy city: Considering the promising results of this study approach, further studies of the relationship between ICT, physical travel and social networks using the present study approach for the case of other cities of South East Asia is necessary.

- Data needs: This research is based primarily upon primary data with some secondary data. Data collection for this research was one of the most tedious and time consuming parts of the study. Since social networks is an emerging area in travel research, the data collection methods or delineation of boundaries (e.g. number of alters, definition of tie strength) are not very well set unlike when using socioeconomic or spatial variables. Given the importance of social networks in travel research, more data at the social network level should be collected and published. Efforts should be made to create a data base dealing with people's communication choice and travel preference (like the national ecommerce dataset collected by the Dutch Internet research agency). Also the available data should be made available through the internet. The census usually deals with the socio-economic-demographic data; a section on ICT usage must be added. That will solve the much needed 
temporal data scarcity. Then models which need a large amount of data can be generated for prediction purposes.

- $\quad C / T$ profiles and physical travel relations: Though C/T balance profiles are only able to explain a small portion of variation in the Trip length Frequency Distribution (TLFDs); the relation is significant and important from the IT policy point of view. Whereas this study provides the first empirical evidence on the topic in the Indian context, future research on the relation can translate into a meta-analysis with more equal number of people in all the profiles. This study does not prove the impact that the increase in the number of mobile phones and internet connections will have on future travel behaviour. A predictive model that analyses these relations can help bridge this knowledge gap. The results of this research mostly rely on the now present numbers of people in each $C / T$ profile. It should also be possible to see how the travel patterns change when the number of people increases or decrease from different profiles. The results produced in this research (e.g. Networkedness) could be inputs into a modelling framework that can help to analyse consequences like congestion on the road and air pollution.

Because this research is the first of its kind in the Indian context, it poses more questions for further research than it answers. However, the results drawn from this research are significant from the policy perspective, and the methods presented in this research should enable similar research on other cities in India leading to a meta-analysis and creation of a broader policy framework on urban travel in India. 


\section{Bibliography}

ADB (2009). Electric Two-Wheelers in India and Viet Nam: Market Analysis and Environmental Impacts. Asian Development Bank.

Adhvaryu, B. (2010). Enhancing urban planning using simplified models: SIMPLAN for Ahmedabad, India. Progress in Planning, 73(3), pp. 113207.

Aguiléra, A., C. Guillot, and A. Rallet (2012). Mobile ICTs and physical mobility: Review and research agenda. Transportation Research Part A: Policy and Practice, 46(4), pp. 664-672.

ANANDA (2007). City Map of Ahmedabad. Ahmedabad, Ananda Publications.

Aoyama, Y. (2003). Sociospatial dimensions of technology adoption : recent $\mathrm{M}$-commerce and E-commerce developments. Environment and Planning A, 35(7), pp. 1201 - 1221.

Arasan, V.T., M. Wermuth and B.S. Srinivas (1996). Modeling of stratified urban trip distribution. Journal of Transportation Engineering, 122(5), pp. 342-349.

Arentze, T. and H. Timmermans (2008). Social networks, social interactions, and activity-travel behavior: a framework for microsimulation. Environment and Planning B: Planning \& Design, 35(6), pp. 10121027.

AUDA (2005). http://www.egovamc.com/citizens/cdp/chapter2.pdf accessed 8th May 2013.

AUDA (2005). Jawaharlal Nehru National Urban Renewal Mission City Debvelopment Plan: Ahmedabad. Ahmedabad Urban Development Authority.

Axhausen, K.W. (2002). A Dynamic Understanding of Travel Demand: A Sketch. ESRC Mobile Neywork Workshop. Cambridge.

Axhausen, K.W. (2008). Social networks, mobility biographies, and travel: survey challenges. Environment and Planning B: Planning and Design, 35(6), pp. 981-996.

Banister, D. and A. Bowling (2004). Quality of life for the elderly: the transport dimension. Transport Policy, 11(2), pp. 105-115.

Bhat, C. R., A. Sivakumar and K.W. Axhausen (2003). An analysis of the impact of information and communication technologies on nonmaintenance shopping activities. Transportation Research Part B: Methodological, 37(10), pp. 857-881.

Bhatt, M. (2003). Understanding Slums: Case Studies for the Global Report on Human Settlements 2003. In: The Challenge of Slums. UN HABITAT, Earthscan, London, pp. 195 - 228.

Bhide, V. (1976). Transportation structure of a city: A case study of Ahmedabad. M.Tech thesis, Centre for Environmental Planning and Technology. 
Black, W. R. (2001). An unpopular essay on transportation. Journal of Transport Geography, 9(1), pp. 1-11.

Boase, J., J. Horrigan, B. Wellman and L. Rainie (2006). The Strength of Internet Ties. http://www.pewinternet.org/ /media/Files/Reports/2006/PIP Intern et ties.pdf.pdf, accessed 2nd October 2013.

Boase, J. and T. Kobayashi (2008). Kei-Tying teens: Using mobile phone email to bond, bridge, and break with social ties-a study of Japanese adolescents. International Journal of Human-Computer Studies, 66(12), pp. 930-943.

Bureau of Public Roads (1965). Calibrating and testing a gravity model for any sized urban area. Washington D.C., US Dept. of Commerce, Bureau of Public Roads.

Butts, C. T. (2003). Predictability of Large-scale Spatially Embedded Networks. In R. Breiger, K.M. Carley and P.Pattison (eds.), Dynamic Social Network Modeling and Analysis. Washington DC, National Academies Press.

Butts, C. T. (2011). Space and Structure: Models and Methods for LargeScale Interpersonal Networks. New York, Springer.

Carrasco, J.A. and E.J. Miller (2006). Exploring the propensity to perform social activities: a social network approach. Transportation $n_{\perp} 33(5), p p$ 463-480.

Carrasco, J.A. and E. J. Miller (2009). The social dimension in action: A multilevel, personal networks model of social activity frequency between individuals. Transportation Research Part A: Policy and Practice, 43(1), pp. 90-104.

Carrasco, J.A., B. Hogan, B. Wellman and E.J. Miller (2008). Agency in social activity interactions: the role of social networks in time and space. Tijdschrift voor economische en sociale geografie, 99(5), pp. 562583.

Carrasco, J.A., B. Hogan, B. Wellman and E.J. Miller (2008). Collecting social network data to study social activity-travel behavior: an egocentric approach. Environment and Planning B: Planning and Design, 35(6), pp 961-980.

Census (2011). Basic Data Sheet District Ahmadabad (07), Gujarat (24), Census of India.

Cervero, R. and K. Kockelman (1997). Travel demand and the 3Ds: Density, diversity, and design. Transportation Research Part D: Transport and Environment, 2(3), pp. 199-219.

Chapin, F.S. (1974). Human Activity Patterns in the City: Things People do in Time and in Space. John Wiley, New York.

Charlot, S. and G. Duranton (2006). Cities and Workplace Communication: Some Quantitative French Evidence. Urban Studies, 43(8), pp. 13651394. 
Chatman, D.G. (2008). Deconstructing development density: Quality, quantity and price effects on household non-work travel. Transportation Research Part A: Policy and Practice, 42(7), pp. 10081030.

Chatterjee, I. (2009). Violent morphologies: Landscape, border and scale in Ahmedabad conflict. Geoforum, 40(6), pp. 1003-1013.

Chen, W. and B. Wellman (2009). NET AND JET - The Internet use, travel and social networks of Chinese Canadian entrepreneurs. Information, Communication \& Society, 12(4), pp. 525-547.

Choo, S. and P.L. Mokhtarian (2007). Telecommunications and travel demand and supply: Aggregate structural equation models for the US. Transportation Research Part A: Policy and Practice, 41(1), pp. 4-18.

Chung, K.S.K. and L. Hossain (2010). Towards a social network model for understanding information and communication technology use for general practitioners in rural Australia. Computers in Human Behavior, 26(4), pp. 562-571.

Couclelis, H. (1994). Spatial technologies. Environment and Planning B: Planning and Design, 21(2), pp. 142-143.

Dave, P. (2014). The Demise of the 'Red Bus' Means Congestion in Ahmedabad. $\quad$ http://sustainablecitiescollective.com/pratikdave/214181/red-bus-ahmedabad-how-vibrant-future, accessed $7^{\text {th }}$ May 2014.

De Graaff, T. and P. Rietveld (2007). Substitution between working at home and out-of-home: The role of ICT and commuting costs. Transportation Research Part A: Policy and Practice, 41(2), pp. 142160.

DeSanctis, G. and M.S. Poole (1982). Capturing the Complexity in Advanced Technology Use: Adaptive Structuration Theory. Organization Sciences $\_$(2), pp. 121 - 147.

Dieleman, F.M., M. Dijst and G. Burghouwt (2002). Urban Form and Travel Behaviour: Micro-level Household Attributes and Residential Context. Urban Studies, 39(3), pp. 507-527.

Dijkstra, E.W. (1959). A note on two problems in connexion with graphs. Numerische Mathematik, 1(1), pp. 269-271.

Dijst, M. (2009). ICT and social networks: towards a situational perspective on the interaction between corporeal and connected presence. In R. Kitamura, T. Yoshii and T. Yamamoto (eds.), The Expanding Sphere of Travel Behaviour Research, Emerald Group, Bingley, UK, pp. 4575.

Dugundji, E., A. Páez and T. Arentze (2008). Social networks, choices, mobility, and travel. Environment and Planning B: Planning and Design, 35(6), pp. 956-960.

Dugundji, E. and J. Walker (2005). Discrete Choice with Social and Spatial Network Interdependencies: An Empirical Example Using Mixed 
Generalized Extreme Value Models with Field and Panel Effects. Transportation Research Record, 1921(1), pp. 70-78.

Economist (2009). Up, up and Huawei. The Economist : Special report on telecoms in emerging markets, September 26.

Entwisle, B., K. Faust, R.R. Rindfuss and T. Kaneda (2007). Networks and Contexts: Variation in the Structure of Social Ties. American Journal of Sociology, 112(5), pp. 1495-1533.

EuroIndia (2009). Ahmedabad City. http://www.the-euroindiacentre.org/pdf/AHMEDABAD\%20CITY-\%20Note.pdf, accessed $7^{\text {th }}$ February 2012.

Farag, S., T. Schwanen, M. Dijst and J. Faber (2007). Shopping online and/or in-store? A structural equation model of the relationships between eshopping and in-store shopping. Transportation Research Part A: Policy and Practice, 41(2), pp. 125-141.

Farber, S. and A. Páez (2009). My car, my friends, and me: a preliminary analysis of automobility and social activity participation. Journal of Transport Geography, 17(3), pp. 216-225.

Fish, R. S., R. E. Kraut, R.W. Root and R. Rice (1993). Video as a technology for informal communication. Communications of the ACM, 36(1), pp. 48-61.

Foss, S. and H. Couclelis (2009). Throwing space back in: a tale of Indian fishermen, ICT and travel behavior. Journal of Transport Geography, 17(2), pp. 134-140.

Fox, M. (1995). Transport planning and the human activity approach. Journal of Transport Geography, 3(2), pp. 105-116.

Frei, A. and K. Axhausen (2009). Modelling the frequency of contacts in a shrunken world. http://www.ivt.ethz.ch/oev/ped2012/vpl/publications/reports/ab532. pdf , accessed $2^{\text {nd }}$ April 2014.

Gillion, K.N. (1968). Ahmedabad: A study in Indian History, University of California Press.

GoG (2010). DPR for Ahmedabad Metro G. I. D. Board, Government of Gujrat, 1.

Graham, S. (1997). Telecommunications and the Future of Cities: Debunking the myths. Cities, 14(1), pp. 21-29.

Graham, S. and S. Marvin (2002). Telecommunications and the city: Electronic spaces, urban places, Routledge, London \& New York.

Granovetter, M. S. (1973). The Strength of Weak Ties. American Journal of Sociology, 78(6), pp. 1360-1380.

Hackney, J. and K.W. Axhausen (2006). An agent model of social network and travel behavior interdependence. Presented at the $11^{\text {th }}$ International Conference on Travel Behaviour Research, Kyoto 
Hampton, K.N., L.F. Sessions and E.J. Her (2010). Core networks, social isolation, and new media. Information, Communication \& Society, 14(1), pp. 130-155.

Hansen, D.L., B. Shneiderman and M.A. Smith (2011). Chapter 3 - Social Network Analysis: Measuring, Mapping, and Modeling Collections of Connections. In Analyzing Social Media Networks with NodeXL. Boston, Morgan Kaufmann, pp. 31-50.

Haustein, S., C.A. Klöckner and A. Blöbaum (2009). Car use of young adults: The role of travel socialization. Transportation Research Part F: Traffic Psychology and Behaviour, 12(2), pp. 168-178.

Haythornthwaite, C. (1996). Social network analysis: An approach and technique for the study of information exchange. Library and Information Science Research, 18(4), pp. 323-342.

Haythornthwaite, C. (2001). Tie Strength and the Impact of New Media. In: Proceedings of the 34th Hawaii International Conference on System Sciences, Maui, Hawai, IEEE.

Heitzman, J. and R. Worden. (1995). India: A Country Study. http://countrystudies.us/india/, accessed 22 November 2011.

Helminen, V. and M. Ristimäki (2007). Relationships between commuting distance, frequency and telework in Finland. Journal of Transport Geography, 15(5), pp. 331-342.

Henn, S. (2010). Transnational communities and regional cluster dynamics. The case of the Palanpuris in the Antwerp Diamond District. Die Erde, 141(1-2), pp. 127- 47.

Henn, S. (2012). Transnational entrepreneurs, global pipelines and shifting production patterns. The example of the Palanpuris in the diamond sector. Geoforum, 43(3) pp. 497-506.

Hensher, D.A. and R.G. Bullock (1979). Price elasticity of commuter mode choice: Effect of a 20 per cent rail fare reduction. Transportation Research Part A: General, 13(3), pp. 193-202.

Hipp, J.R. and A.J. Perrin (2009). The Simultaneous Effect of Social Distance and Physical Distance on the Formation of Neighborhood Ties. City \& Community, 8(1), pp. 5-25.

Hjorthol, R.J., L. Levin and A. Sirén (2010). Mobility in different generations of older persons: The development of daily travel in different cohorts in Denmark, Norway and Sweden. Journal of Transport Geography, 18(5), pp. 624-633.

Hodge, D. and H. Koski (1997). Information and communication technologies and transportation: European-US collaborative and comparative research possibilities. Journal of Transport Geography, 5(3), pp. 191197.

Holmgren, J. (2007). Meta-analysis of public transport demand. Transportation Research Part A: Policy and Practice, 41(10), pp. 1021-1035. 
IIPS (2010). District Level Household and Facility Survey (DLHS-3), International Institute for Population Sciences: Gujrat, India, http://www.rchiips.org, accessed 24 th July 2011.

India (2001). Basic Data Sheet District Ahmadabad (07), Gujarat (24), Census of India.

Jauneikaité, K. and M. Carreno (2009). Importance of virtual trips for transport infrastructure planning. The Baltic journal of road and bridge engineering, IV(2), pp. 61-68.

Julsrud, T. E., R. Hjorthol, et al. (2012). Business meetings: do new videoconferencing technologies change communication patterns? Journal of Transport Geography, 24, pp. 396-403.

Kalenoja, H. (1999). Spatial differences in the trip generation and travel behaviour - empirical observations in the Tampere region. In: Proceedings Urban Transport Systems, Lund, Tampere University of Technology, pp. 445-455.

Kenyon, S. (2006). The 'accessibility diary': Discussing a new methodological approach to understand the impact of Internet use upon personal travel and activity participation. Journal of Transport Geography, 14(2), pp. 123-134.

Kenyon, S. and G. Lyons (2007). Introducing multitasking to the study of travel and ICT: Examining its extent and assessing its potential importance. Transportation Research Part A: Policy and Practice, 41(2), pp. 161-175.

Kestnbaum, M., J.P. Robinson, A. Neustadt and A. Alvarez (2002). Information technology and social time displacement. IT\& Society, $1(1)$, pp. 21-37.

Knowles, R.D. (2009). Transport Geography. In R. Kitchin and N. Thrift (eds), International Encyclopedia of Human Geography. Elsevier, Oxford, pp. 441-451.

Koenig, B.E., D.K. Henderson and P. Mokhtarian (1996). The travel and emission impacts of telecommuting for the state of California Telecommuting Pilot Project. Transportation Research C, 4(1), pp. 13-32.

Kowald, M., A. Frei, J.K. Hackney, J. Illenberger and K.W. Axhausen (2010). Collecting data on leisure travel: The link between leisure contacts and social interactions. Procedia - Social and Behavioral Sciences, 4, pp. 38-48.

Kwan, M.P. (2002). Time, information techonologies and the geographies of everyday life. Urban Geography, 23(5), pp. 471-482.

Kwan, M.P. (2006). Transport geography in the age of mobile communications. Journal of Transport Geography, 14(5), pp.: 384385. 
Kwan, M.P., M. Dijst and T. Schwanen (2007). The interaction between ICT and human activity-travel behavior. Transportation Research Part A: Policy and Practice, 41(2), pp. 121-124.

Kwan, M.P. (2007). Mobile communications, social networks, and urban travel: Hypertext as a new metaphor for conceptualizing spatial interaction. The Professional Geographer, 59(4), pp. 434-446.

Kwon, Y. and J. Lee (2014). Asymmetric responses of highway travel demand to changes in fuel price: An explanation via fuel price uncertainty. Transportation Research Part A: Policy and Practice, 63, pp. 56-66.

Lang, J. (1994). Urban Design: The American Experience, John Wiley \& Sons.

Larsen, J., J. Urry and K. Axhausen (2006). Social networks and future mobilities. University of Lancaster and IVT, ETH Zürich, Lancaster and Zürich, 200pp.

Latané, B., J.H. Liu, A. Nowak, M. Bonevento and L. Zheng (1995). Distance Matters: Physical Space and Social Impact. Personality and Social Psychology Bulletin, 21(8), pp. 795-805.

Lawrence, B. S. and M. J. Zyphur (2011). Identifying Organizational Faultlines With Latent Class Cluster Analysis. Organizational Research Methods, 14(1), pp. 32-57.

Lenz, B. and C. Nobis (2007). The changing allocation of activities in space and time by the use of ICT-"Fragmentation" as a new concept and empirical results. Transportation Research Part A: Policy and Practice, 41(2), pp. 190-204.

Lin, G., Y. Xin, X. Niu and H. Jiang (2010). Network traffic classification based on semi-supervised clustering. The Journal of China Universities of Posts and Telecommunications, 17-Supplement 2, pp. 84-88.

Ling, R. and G. Stald (2010). Mobile Communities: Are We Talking About a Village, a Clan, or a Small Group? American Behavioral Scientist, 53(8), pp. 1133-1147.

Lu, X. and E.I. Pas (1999). Socio-demographics, activity participation and travel behavior. Transportation Research Part A: Policy and Practice, 33(1), pp. 1-18.

Lundevaller, E. H. (2009). The effect of travel cost on frequencies of shopping and recreational trips in Sweden. Journal of Transport Geography, 17(3), pp. 208-215.

Lyons, G. (2002). Internet: investigating new technology's evolving role, nature and effects on transport. Transport Policy, 9(4), pp. 335-346.

Lyons, G. (2009). The reshaping of activities and mobility through new technologies. Journal of Transport Geography, 17(2), pp. 81-82.

MacLean, A.S. (1976). Maximum likelihood and the gravity model. Transportation Research, 10(5), pp. 287-297.

MacQueen, J. B. (1967). Some Methods for classification and Analysis of Multivariate Observations. In Proceedings of $5^{\text {th }}$ Berkeley Symposium 
on Mathematical Statistics and Probability, Berkeley, University of California Press, pp. 281-297.

Mannering, J.S. and P.L. Mokhtarian (1995). Modeling the choice of telecommuting frequency in California: An exploratory analysis. Technological Forecasting and Social Change, 49(1), pp. 49-73.

Marin, A. and K.N. Hampton (2007). Simplifying the Personal Network Name Generator: Alternatives to Traditional Multiple and Single Name Generators. Field Methods, 19(2), pp. 163-193.

Marsden, P.V. (2003). Interviewer effects in measuring network size using a single name generator. Social Networks, 25(1), pp. 1-16.

Marsden, P.V. (2005). Recent developments in network measurement. In J.S. Carrington ans S. Wasserman (eds.), Models and Methods in Social Network Analysis, Cambridge, Cambridge University Press, pp. 8-30.

Marsden, P.V. and K.E. Campbell (1984). Measuring Tie Strength. Social Forces, 63(2), pp. 482-501.

McGee, J., J.A. Caverlee and Z. Cheng (2011). A geographic study of tie strength in social media. In B. Berendt et al. (eds.) Proceedings of the $20^{\text {th }}$ ACM international conference on Information and knowledge management. Glasgow, Scotland, UK, pp. 2333-2336.

McLaughlin, M. L., K. K. Osborne and C.B. Smith (1995). Standards of conduct on usenet. Thousand Oaks, CA, Sage.

McPherson, M., L. Smith-Lovin and M.E. Brashears (2009). Models and Marginals: Using Survey Evidence to Study Social Networks. American Sociological Review, 74(4), pp. 670-681.

Mebrahtu, T., M. Crossley and D. Johnson. (2000). Globalisation, educational transformation and societies in transition, Symposium Books, Oxford.

Modi, P.R. (1991). Chawl improvement and redevelopment potential: Case study, Ahmedabad. Building and Environment, 26(3), pp. 273-276.

Mok, D., B. Wellman and J. Carrasco (2010). Does Distance Matter in the Age of the Internet? Urban Studies, 47(13), pp. 2747-2783.

Mokhtarian, P. (2003). Telecommunications and Travel : the case for complementarity. Journal of Industrial Ecology, 6(2), pp. 43-57.

Mokhtarian, P. (2009). If telecommunication is such a good substitute for travel, why does congestion continue to get worse? Transportation Letters, 1(1), pp. 1-17.

Mokhtarian, P.L. (1990). A typology of relationships between telecommunications and transportation." Transportation Research Part A: General, 24(3), pp. 231-242.

Mokhtarian, P.L. and R. Meenakshisundaram (1999). Beyond telesubstitution: disaggregate longitudinal structural equations modeling of communication impacts. Transportation Research Part C: Emerging Technologies, 7(1), pp. 33-52.

Mokhtarian, P.L. and I. Salomon (2001). How derived is the demand for travel? Some conceptual and measurement considerations. 
Transportation Research Part A: Policy and Practice, 35(8), pp. 695719.

Mokhtarian, P.L. and I. Salomon (2002). Emerging travel patterns: do telecommunications make a difference? In H.S. Mahmassani (ed.), In perpetual motion: travel behavior research opportunities and application challenges, Elsevier, Oxford, pp. 143-182.

Mokhtarian, P.L., I. Salomon and S.L. Handy (2004). A Taxonomy of Leisure Activities: The Role of ICT. Research Report, Institute of Transportation Studies, University of California, Davis.

Muhammad, S. (2007). Future Urbanization Patterns: In the Netherlands, under the influence of Information and Communication Technologies, Netherlands Geographical Studies 363, Utrecht University, the Netherlands.

Munshi, T. (2013). Built Form, Travel Behaviour and Low Carbon Development in Ahmedabad, India, ITC Dissertation 226, University of Twente, the Netherlands.

NCAER (2005). The Great Indian Market: Results from the NCAER's Market Information Survey of Households. New Delhi: National Council of Applied Economic Research.

Nie, N.H., D.S. Hillygus and L. Erbring (2002). Internet Use, Interpersonal Relations and Sociability. In B. Wellman and W.B. Haythornwaite (eds.), The Internet in Everyday Life. Oxford, Blackwell Publishing, pp. 215-243.

Nobis, C. and B. Lenz (2009). Communication and mobility behaviour- a trend and panel analysis of the correlation between mobile phone use and mobility. Journal of Transport Geography, 17(2), pp. 93-103.

Nobis, C., B. Lenz, and C. Vance (2005). Communication and travel behaviour: Two facets of human activity patterns. In $\mathrm{H}$. Timmermans (Ed.) Progresses in activity based analysis. Oxford, UK, pp. 471-844.

O.N.G.C. (1956). http://www.ongcindia.com/rti 1.asp, accessed $2^{\text {nd }}$ July 2012.

Odeck, J. and S. Bråthen (2008). Travel demand elasticities and users attitudes: A case study of Norwegian toll projects. Transportation Research Part A: Policy and Practice, 42(1), pp. 77-94.

Ortúzar, J.D. and L.G. Willumsen (2006). Modelling Transport. Wiley, Chichester, UK.

Páez, A., D.M. Scott and E. Voltz (2008). A discrete-choice approach to modeling social influence on individual decision making. Environment and planning B: Planning \& design, 35(6), pp. 1055-1069.

Pai, M. (2008). India: sustainable transport indicators, Center for Sustainable Transport, EMBARQ.

Palackal, A., P.N. Mbatia, D Dzorgbo, R.B. Duque, M.A. Ynalvez and W.M. Shrum (2011). Are mobile phones changing social networks? A 
longitudinal study of core networks in Kerala. New Media \& Society, 13(3), pp. 391-410.

Paolillo, J. C. (2001). Language variation on Internet Relay Chat: A social network approach. Journal of Sociolinguistics, 5(2), pp. 180-213.

Pendyala, R.M., K.G. Goulias and R. Kitamura (1991). Impact of telecommunication on spatial and temporal patterns of household travel. Transportation $\_18$ (4), pp. 383-409.

Peng, H. and H. Lu (2007). Study on the Impacts of Urban Density on the Travel Demand Using GIS Spatial Analysis. Journal of Transportation Systems Engineering and Information Technology, 7(4), pp. 90-95.

Pustejovsky, J. E. and J. P. Spillane (2009). Question-order effects in social network name generators. Social Networks, 31(4), pp. 221-229.

Rheingold, H. (2002). Smart Mobs: The Next Social Revolution, Perseus Press, Cambridge, MA.

Rietveld, P. and L. Janssen (1990). Telephone calls and communication barriers. The Annals of Regional Science, 24(4), pp. 307-318.

Rivière, C. and C. Licoppe (2005). From Voice to Text: continuity and change in the use of mobile phones in France and Japan. In R. Harper, L. Palen and A. Taylor (eds.), The Inside Text, Springer Netherlands, pp. $103-126$.

Rogerson, P.A. (1997). Estimating the Size of Social Networks. Geographical Analysis, 29(1), pp. $50-63$

Roy, P., A. J. Martínez, et al. (2012). "Using Social Network Analysis to profile people based on their e-communication and travel balance." Journal of Transport Geography (0).

Roy, P., A. J. Martínez, G. Miscione, M.H.P. Zuidgeest, M.F.A.M. van Maarseveen (2012). Using Social Network Analysis to profile people based on their e-communication and travel balance. Journal of Transport Geography, 24, pp. 111-122.

Salomon, I. (1986). Telecommunications and travel relationships: a review. Transportation Research Part A: General, 20(3), pp. 223-238.

Samanta, B. and S.K. Mazumder (2006). The constrained gravity model with power function as a cost function. Journal of Applied Mathematics and Decision Sciences, pp. 1-13.

Sapovadia, V. (2007). A Critical Study of Urban Land Ownership by an Individual vis-à-vis Institutional (or Community) Based Ownership The Impact of type of ownership on Spatial Growth, Efficiency and Equity: A case study of Ahmedabad, India. Presented at the Fourth Urban Research Symposium, Ahmedabad.

Sasaki, K. and K. Nishii (2003). Measurement of intention to travel: Considering the effect of telecommunications on trips. Transportation Research Part C: Emerging Technologies, 18(1), pp. 36-44. 
Schwanen, T., M. Dijst and M.P. Kwan (2006). Introduction - The Internet, Changing Mobilities, and Urban Dynamice. Urban Geography, 27(7), pp. 585-589.

Schwanen, T., M.P. Kwan and F. Ren (2008). How fixed is fixed? Gendered rigidity of space-time constraints and geographies of everyday activities. Geoforum, 39(6), pp. 2109-2121.

Sharmeen, F., T. Arentze and H. Timmermans (2010). Modelling the dynamics between social networks and activity-travel behavior: Literature review and research agenda. Presented at the $12^{\text {th }}$ World Conference on Transport Research. Lisbon.

Sheller, M. and J. Urry (2006). The new mobilities paradigm. Environment and Planning A, 38(2), pp. 207-226.

Shen, Q. (1998). Spatial technologies, accessibility, and the social construction of urban space. Computers, Environment and Urban Systems, 22(5), pp. 447-464.

Shen, Q. (2000). Transportation, Telecommunications, and the Changing Geographies of Oppourtunity. In D.G. Janelle \& D.C. Hodge (eds.), Information, Place and Cyberspace Issues in accessibility, Berlin, Springer, pp. 47 - 72.

Silvis, J., D. Niemeier and R. D'Souza (2006). Social Networks and Travel Behaviour: Report from an Integrated Travel Diary. Kyoto, Presented at the $11^{\text {th }}$ International Conference on Travel Behaviour Research, Kyoto.

Simmel, G. (1908). The Stranger. In D. Levine (ed.), George Simmel on individuality and Social Forms, (1971), University of Chicago Press.

Sohail, M., D.A.C. Maunder and S. Cavill (2006). Effective regulation for sustainable public transport in developing countries. Transport Policy, 13(3), pp. 177-190.

Su, Q. (2010). Travel demand in the US urban areas: A system dynamic panel data approach. Transportation Research Part A: Policy and Practice, 44(2), pp. 110-117.

Sunitiyoso, Y., E. Avineri and K. Chatterjee (2011). The effect of social interactions on travel behaviour: An exploratory study using a laboratory experiment. Transportation Research Part A: Policy and Practice, 45(4), pp. 332-344.

Taplin, J.H.E., D.A. Hensher and B. Smith (1999). Preserving the symmetry of estimated commuter travel elasticities. Transportation Research Part B: Methodological, 33(3), pp. 215-232.

Tilahun, N. and D. Levinson (2011)."Work and home location: Possible role of social networks. Transportation Research Part A: Policy and Practice, 45(4), pp. 323-331.

Tillema, T., M. Dijst and T. Schwanen (2010). Face-to-face and electronic communications in maintaining social networks: the influence of 
geographical and relational distance and of information content. New Media \& Society, 12(6), pp. 965-983.

TRAI (2010). Annual Report 2009-10. Telecom Regulary Authority of India.

TRAI (2012). The Indian Telecom Services Performance Indicators (October December 2011). Retrieved 21 $1^{\text {st }}$ May 2012 from http://www.trai.gov.in/WriteReadData/PIRReport/Documents/Indicat or\%20Report-dec-2011.pdf.

U.S. Department of Transportation (1983). Calibrating \& testing a gravity model for any size urban area. August 1983

Urry, J. (2003). Social networks, travel and talk. British Journal of Sociology, 54(2), pp. 155-175.

Urry, J. (2004). Connections. Environment and Planning D: Society and Space, 22(1), pp. 27-37.

Van de Coevering, P. and T. Schwanen (2006). Re-evaluating the impact of urban form on travel patterns in Europe and North-America. Transport Policy, 13(3), pp. 229-239.

van den Berg, P.E.W., T.A. Arentze and H.J.P. Timmermans (2012). New ICTs and social interaction: Modelling communication frequency and communication mode choice. New Media \& Society, 14(6), pp. 9871003.

van Wee, B. (2009). Self-Selection: A Key to a Better Understanding of Location Choices, Travel Behaviour and Transport Externalities? Transport Reviews, 29(3), pp. 279-292.

Venigalla, M.M., A. Chatterjee and M.S. Bronzini (1999). A specialized equilibrium assignment algorithm for air quality modeling. Transportation Research Part D: Transport and Environment, 4(1), pp. 29-44.

Verdery, A.M., B. Entwisle, K. Faust and R.R. Rindfuss (2012). Social and spatial networks: Kinship distance and dwelling unit proximity in rural Thailand. Social Networks, 34(1), pp. 112-127.

Viry, G. (2012). Residential mobility and the spatial dispersion of personal networks: Effects on social support. Social Networks, 34(1), pp. 5972.

Wasserman, S. and K. Faust (1997). Social Network Analysis Methods and Application. Cambridge, Cambridge University Press.

Williams, P.A. (1989). The influence of residential accessibility on household trip-making. Socio-Economic Planning Sciences, 23(6), pp. 373-385.

Wilson, A.G. (1967). A statistical theory of spatial distribution models. Transportation Research, 1(3), pp. 253-269.

Winters, M., M. Brauer, E.M. Setton and K. Teschke (2010). Built Environment Influences on Healthy Transportation Choices: Bicycling versus Driving. Journal of Urban Health, 87(6), pp. 969-993.

Yagnik, A. and S. Sheth (2002). Whither Gujarat? Violence and After. Economic and Political Weekly, 37(11), pp. 1009-1011. 
Yang, D. and H. Timmermans (2013). Analysis of influence of fuel price on individual activity-travel time expenditure. Transport Policy, 30, pp. 40-55.

Yuan, Y., M. Raubal and Y. Liu (2012). Correlating mobile phone usage and travel behavior - A case study of Harbin, China. Computers, Environment and Urban Systems, 36(2), pp. 118-130.

Zhang, M., Q.X. Sun and J.C. Chen (2008). Travel Behavior Analysis of the Females in Beijing. Journal of Transportation Systems Engineering and Information Technology, 8(2), pp. 19-26. 


\section{Summary}

ICT and physical travel are strongly related. On the one hand, ready availability of ICT, a growing population with electronic acumen and lowering ICT costs cause an increase in ICT usage and decrease in physical travel. On the other hand transportation infrastructure, more communication and better information exchange is a driving force of increased physical travel. Complexity, causality and reciprocity are inherent characteristic of this relationship. Understanding this mutual relationship is vital for urban planners, transport planners and policy makers to predict accurately future physical travel patterns and urban development and to plan for appropriate policy interventions.

Traditional transport planning practices in fast growing cities cannot adequately deal with the complexities of this relationship. The inherent multifaceted interactions of the physical and social components of ICT usage with factors such as congestion and increasing fuel prices necessitate an approach that is based on social and spatial analysis. Social network analysis is not only a potentially effective mean to socially and spatially analyse and understand this complex interaction but also to create new planning methods and approaches. This research aims to analyse and understand the relationship between ICT and physical travel, using the above mentioned technique in conjunction with statistical tools, in order to support urban and transportation planning in fast growing cities. This research was conducted in Ahmedabad, a fast growing city in India. Ahmedabad has evolved rapidly in the last few decades into a high ICT using urban centre. With a large population, high telephony and internet penetration and a rise in consumer spending power Ahmedabad is a very suitable case for this research.

First, the study contributes to knowledge about the complex relationship between ICT and physical travel, with a particular focus on the role of the social network of individuals in the decision how to interact. As a result, this study generates new insights inf the consequences of a rapid increase in ICT consumption and its effects on physical travel, particularly in very dynamic city like Ahmedabad. This research has strong relevance for planning of cities in India.

Second, people are effectively classified into different clusters based on their network sizes, mode of communication and frequency of communication rather than being classified based on age, income, gender and other socioeconomic indicators. Leading principle in the clustering is the $\mathrm{C} / \mathrm{T}$ balance of individuals. It is the ratio between e-communication (C) and the physical travel $(T)$ of an individual. This classification is more suited than previous classifications because it takes into consideration the social 
networks of people (that generate travel and communication). The resulting profiles provide a rich understanding of and insight into the trade-off between physical communication and e-communication in growing cities.

Third, social network analysis is used to explain certain aspects of individual's travel which could not be explained by socio-economic or spatial characteristics. This analysis has been applied on trip making patterns of profiles which were developed earlier. It demonstrated clear decays in TLFDs indicating that people's behaviour is not only related to their willingness to travel certain distances or use e-communication, but also to the geographic distribution of their social network members. Results indicate that 'maintenance' and 'longevity' of trips cannot be explained by measurable quantities like density or cost. All profiles, irrespective of intensity of ICT usage, were affected by distance. This phenomenon cannot be explained by a simple cost benefit ratio. The findings show a strong relation between social network and travel patterns.

Fourth, the geographical distance between network members is explored and the concept of 'networkedness' is developed. Networkedness is a novel attribute of space representing the density of the social networks of individuals in an area. The practicality of the concept lies in the fact that it can be used to measure the pressure on transport infrastructure by transport planners and policy makers. Information on the number of alters and their geographical location was collected, as well as the mode of communication between ego and alter. Then the spatial distribution of egos on ward level including their profile membership was mapped. Results show that distance does not affect tie strengths. Individuals find ways of communicating with their strong ties regardless of geographical distance. They might change the mode of communication with increasing distance but they do not stop communicating.

Finally, social network analysis is used to statistically analyse the substitution versus additive effects of phone calls on physical distance travelled by individuals. The phone call elasticity of travel is used to expresses the percentage of change in distance travelled with respect to a one percent increase in the number of phone calls. The calls are divided into "substituted trips" (calls for which the individual was willing to travel) and "not substituted trips" (calls for which the individual was not willing to travel). Log-linear regression is used to derive elasticity values for each profile. For individuals, who are high consumers of ICT, e-communication does not necessarily have a huge impact on their physical travel. By contrast, travel behaviour of individuals a with very low consumption of ICT, is more elastic. The phone call elasticity depends on social network structures and not on intensity of ICT use alone. 
This thesis provides a new insights in and knowledge of the complex mutual interaction between ICT usage and physical travel. It offers new quantitative methods to analyse future changes in urban travel due to an increase in ICT usage. It allows urban and transport planners in fast growing cities to better assess the consequence of ITC use among the different population segments of society and to plan appropriate policies to cater to the varying needs of individuals in place and time accordingly. 


\section{Samenvatting}

Informatie en communicatietechnologie (ICT) en fysieke verplaatsingen zijn nauw met elkaar verbonden. Enerzijds zorgen de ruime beschikbaarheid van ICT, een groeiende gebruikersgroep met affiniteit en vaardigheden, en lagere gebruikskosten voor een toename van ICT gebruik en een afname van fysieke verplaatsingen. Anderzijds leidt transport infrastructuur, meer communicatie en betere informatie uitwisseling juist tot meer fysiek verkeer en vervoer. Complexiteit, causaliteit en wederkerigheid zijn intrinsieke kenmerken van deze relatie. Het begrijpen van deze wederzijdse relatie is van vitaal belang voor stedelijke planners, vervoersplanologen en beleidsmakers om toekomstige fysieke verkeerspatronen en stedelijke ontwikkelingen nauwkeurig te voorspellen, en geschikte beleidsinterventies te kunnen plannen.

In snel groeiende steden kan de traditionele planningspraktijk op het gebied van verkeer en vervoer onvoldoende omgaan met de complexiteit van deze relatie. De intrinsiek veelzijdige interacties tussen fysieke en sociale componenten van ICT gebruik en factoren als congestie en stijgende brandstofprijzen vereisen een benadering die geënt is op sociale en ruimtelijke analyse. Analyse van sociale netwerken is niet alleen een potentieel effectieve manier om deze complexe interactie vanuit sociaal en ruimtelijk perspectief te analyseren en te begrijpen, maar ook als voedingsbodem voor nieuwe planningsmethoden en benaderingen. Deze studie richt zich op de analyse en het begrijpen van de relatie tussen ICT en fysieke verplaatsingen, gebruikmakend van eerdergenoemde analysemethode in combinatie met statistische technieken, met als achterliggend doel een bijdrage te leveren aan stedelijke planning en vervoersplanning in snel groeiende steden. Het onderzoek is uitgevoerd in Ahmedabad, een snel groeiende stad in India. Ahmedabad is de afgelopen decennia in hoog tempo verworden tot een metropool met hoog ICT gebruik. Gelet op de omvangrijke bevolking, de hoge penetratie van (mobiele) telefoons en internet, en de sterke stijging in consumentenbestedingen is deze stad bij uitstek geschikt voor deze studie.

Allereerst leidt dit onderzoek tot meer kennis over de complexe relatie tussen ICT en verplaatsingsgedrag, en in het bijzonder over de rol die sociale netwerken van individuen spelen in de beslissing op welke wijze te interacteren. Als zodanig verdiept deze studie de inzichten in de consequenties van een snelle toename in ICT gebruik en de effecten op verplaatsingsgedrag in een zeer dynamische stad als Ahmedabad. Deze kennis wordt zeer relevant geacht voor de planning van steden in India. 
Ten tweede, in plaats van mensen te classificeren op basis van leeftijd, inkomen, geslacht en andere socio-economische kenmerken vindt in deze studie een classificatie van individuen plaats gebaseerd op de omvang van hun sociale netwerken, en de wijze en frequentie van communiceren. Voor de clustering wordt de zogenaamde $\mathrm{C} / \mathrm{T}$ balans van het individu gebruikt. Het betreft de ratio tussen het aantal interacties via e-communicatie $(C)$ enerzijds en verplaatsingen $(T)$ anderzijds. Deze classificatie wordt meer geschikt geacht omdat het in ogenschouw neemt de sociale netwerken van mensen, die feitelijk leiden tot communicatie tussen of verplaatsingen van individuen. De profielen die uit deze classificatie ontstaan verbreden onze kennis en verdiepen onze inzichten in de trade-off tussen fysieke interactie en ecommunicatie.

Ten derde is in dit onderzoek de analyse van sociale netwerken gebruikt om bepaalde aspecten van individueel verplaatsingsgedrag te verklaren, die niet verklaard kunnen worden door socio-economische of ruimtelijke kenmerken. Deze analysemethode is toegepast op verplaatsingspatronen van profielen van mensen, die in een eerder stadium zijn ontwikkeld, met als resultaat duidelijke afnames in ritlengteverdelingen (TLFDs), die een indicatie vormen voor het feit dat individueel verplaatsingsgedrag niet alleen gerelateerd is aan de bereidheid om bepaalde afstanden af te leggen of e-communicatie te gebruiken, maar ook aan de geografische distributie van de leden van het sociale netwerk. Resultaten duiden er ook op dat 'instandhouding' en 'levensduur' van verplaatsingen niet kunnen worden verklaard door meetbare grootheden als dichtheid en kosten. Alle profielen worden, ongeacht de intensiteit van ICT gebruik, beïnvloed door afstand. Dit fenomeen kan niet eenvoudig worden verklaard uit een kosten-baten verhouding. Het onderzoek toont aan dat er een sterke relatie bestaat tussen het sociale netwerk en verplaatsingspatronen.

Ten vierde wordt de geografische afstand tussen leden van het netwerk verkend en het concept 'networkedness' ontwikkeld. 'Networkedness' is een nieuw ruimtelijk attribuut dat de dichtheid van sociale netwerken van inwoners in een gebied representeert. Het praktisch belang van het concept is gelegen in het feit dat het kan worden gebruikt door vervoersplanologen en beleidsmakers om de vervoersdruk op een transportnetwerk te meten Tevens is informatie over 'alters' en hun geografische locatie verzameld, als ook de wijze van communicatie tussen 'ego' en 'alter'. Vervolgens is de ruimtelijke verdeling van 'ego's' op ward niveau inclusief hun profiel in kaart gebracht. Resultaten tonen aan dat afstand niet van invloed is op de sterkte van de relatie. Individuen vinden mogelijkheden om te communiceren met hun sterke relaties ongeacht de geografische afstand. Ze kunnen de wijze van communiceren veranderen met toenemende afstand, maar ze besluiten niet de communicatie te beëindigen. 
Tenslotte is de analyse van sociale netwerken gebruikt voor een statistische analyse van substitutie en generatie effecten van telefoonverkeer op de fysieke afstand van verplaatsingen van individuen. De gehanteerde elasticiteit van telefoonverkeer op vervoersprestatie representeert de procentuele verandering in afgelegde verplaatsingsafstand als gevolg van een één procent toename in het aantal telefoongesprekken. De gesprekken zijn onderverdeeld in "vervanging voor verplaatsingen" (gesprekken waarvoor het individu bereid was zich te verplaatsen) en "géén vervanging voor verplaatsingen" (gesprekken waarvoor geen bereidheid was om zich te verplaatsen). Vervolgens is log-lineaire regressie gebruikt om elasticiteitswaarden af te leiden voor elk profiel. Voor individuen met een hoog gebruik van ICT geldt dat e-communicatie niet noodzakelijk ook een groot effect heeft op verplaatsingsgedrag. Daarentegen is het verplaatsingsgedrag van individuen met een laag gebruik van ICT meer elastisch. De gehanteerde elasticiteit blijkt afhankelijk te zijn van de structuur van het sociale netwerk, en niet van de intensiteit van het gebruik van ICT alleen.

Deze thesis verschaft nieuwe inzichten in en kennis over de complexe wederzijdse interactie van ICT en verplaatsingsgedrag. Het biedt nieuwe kwantitatieve methoden om toekomstige veranderingen in verplaatsingsgedrag als gevolg van een toename in ICT gebruik te analyseren. Het stelt stedelijke planners en vervoersplanologen in snel groeiende steden in staat om consequenties van ICT gebruik voor verschillende groeperingen in de samenleving vast te stellen, en dienovereenkomstig passend beleid te ontwikkelen om de verschillende behoeften van individuen naar plaats en tijd te bevredigen 


\section{Author's biography}

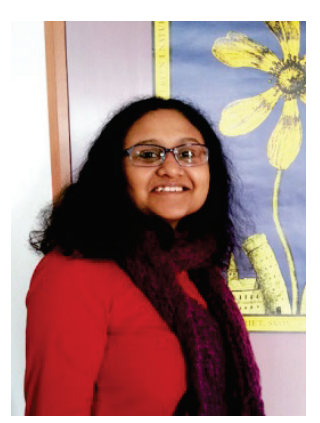

Priyasmita Roy was born in Kolkata, India on $7^{\text {th }}$ of April 1984. She received her BSc. in Geography from Loreto College, University of Calcutta in 2005. There after she continued with her higher education in Delhi School of Economics, University of Delhi where she completed her Masters in Geography in 2007. It was during her masters days that she became interested in urban geography. For her master's thesis she took a look at the co-existence of the local bazar and the shopping mall in close proximity. While working on her thesis she became interested in urban planning. Later that year she joined the Center for Environmental Planning and Technology,(CEPT) Ahmedabad to peruse her interest in planning. She graduated in 2009 with a master's degree in planning and public policy. While still at CEPT she decided to continue with academics and in the same year she was awarded the European Commission, Erasmus Mundus scholarship for her doctoral research. The research was conducted under the supervision of Prof.dr. Martin van Maarseveen at ITC, University of Twente, Netherlands. She arrived in the Netherlands in 2009 and has since successfully published her PhD thesis work with important scientific journals and participated in international conference. A geographer at heart, her main research interest is in urban transport, social network analysis and public policy.

\section{Publications}

P. Roy, A.J. Martínez, G. Miscione, M.H.P. Zuidgeest, M.F.A.M. van Maarseveen, (2012) "Using Social Network Analysis to profile people based on their e-communication and travel balance", Journal of Transport Geography, 24(0): 111-122.

P. Roy, M.H.P Zuidgeest, A.J. Martinez, G. Miscione, M.F.A.M. van Maarseveen "Phone call elasticity of city travel in Ahmedabad" (accepted) Travel Behaviour and Society; DOI: 10.1016/j.tbs.2014.07.001

P. Roy, G. Miscione, M.H.P Zuidgeest, A.J. Martínez, M.F.A.M. van Maarseveen, "Networkedness and physical travel" (under review) Mobilities

P. Roy, J.Willemsen, G. Miscione, M.H.P Zuidgeest, A.J. Martínez, E. van Berkum, M.F.A.M. van Maarseveen, "Observing travel and ecommunication behavior: A social network approach" (under review) Journal of Transport Geography

P. Roy, "Between tradition and modernity: the bazar and the mall- a discernible divide but a viable co-existence" (under review) The Journal of Social Science and Humanity Research 


\section{Conferences}

P. Roy, A.J. Martínez, G. Miscione, M.H.P. Zuidgeest, M.F.A.M. van Maarseveen, "Lifestyle based typology for Ahmedabad and group specific behavioral characteristics with regard to mobility driven Carbon Footprints", The International Workshop Megacity Project Hyderabad, 2010, Hyderabad, India.

P. Roy, G. Miscione, M.H.P Zuidgeest, A.J. Martinez, M.F.A.M. van Maarseveen, "Effects of interactions between ICT and Human activitytravel pattern on Urban Form.", MOVE International Seminar Mobile Constitutions of Society 2010, Neuchâtel, Switzerland.

P. Roy, A.J. Martínez, G. Miscione, M.H.P. Zuidgeest, M.F.A.M. van Maarseveen, "How have mobile devices changed the spatial flexibility of individuals and organizations?" Abstract Proceedings, AAG Annual Meeting, 2011, Seattle, USA

P. Roy, G. Miscione, M.H.P Zuidgeest, A.J. Martinez, "Clustering people based on their social network and socio-demographic characteristics", 8th Conference on Applications of Social Network Analysis (ASNA) 2011 Zurich, Switzerland.

P. Roy, M.H.P Zuidgeest, A.J. Martinez, G. Miscione, M.F.A.M. van Maarseveen, "Effects of distance traveled on tie-strength ", Abstract Proceedings, AAG Annual Meeting, 2013 Los Angeles, California, USA. 


\section{ITC Dissertation List}

http://www.itc.nl/research/phd/phd_graduates.aspx 